\title{
Effects of High-Temperature Irradiation on the Microstructure of Nuclear Graphite
}

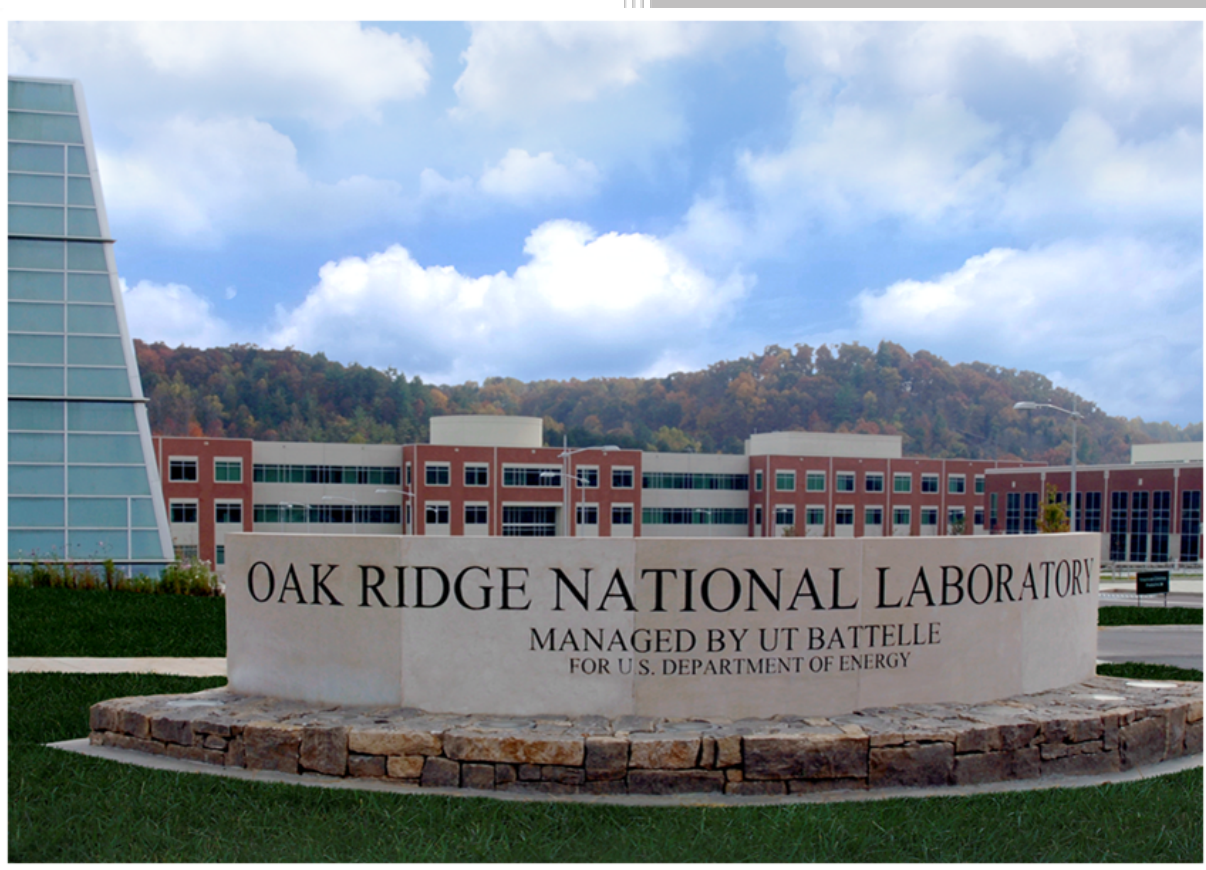

Approved for public release.

Distribution is unlimited.

Anne A. Campbell Cristian I. Contescu Ercan Cakmak Nidia C. Gallego Timothy D. Burchell

September 2019 


\section{DOCUMENT AVAILABILITY}

Reports produced after January 1, 1996, are generally available free via US Department of Energy (DOE) SciTech Connect.

Website www.osti.gov

Reports produced before January 1, 1996, may be purchased by members of the public from the following source:

National Technical Information Service

5285 Port Royal Road

Springfield, VA 22161

Telephone 703-605-6000 (1-800-553-6847)

TDD 703-487-4639

Fax 703-605-6900

E-mail info@ntis.gov

Website http://classic.ntis.gov/

Reports are available to DOE employees, DOE contractors, Energy Technology Data Exchange representatives, and International Nuclear Information System representatives from the following source:

Office of Scientific and Technical Information

PO Box 62

Oak Ridge, TN 37831

Telephone 865-576-8401

Fax 865-576-5728

E-mail reports@osti.gov

Website http://www.osti.gov/contact.html

This report was prepared as an account of work sponsored by an agency of the United States Government. Neither the United States Government nor any agency thereof, nor any of their employees, makes any warranty, express or implied, or assumes any legal liability or responsibility for the accuracy, completeness, or usefulness of any information, apparatus, product, or process disclosed, or represents that its use would not infringe privately owned rights. Reference herein to any specific commercial product, process, or service by trade name, trademark, manufacturer, or otherwise, does not necessarily constitute or imply its endorsement, recommendation, or favoring by the United States Government or any agency thereof. The views and opinions of authors expressed herein do not necessarily state or reflect those of the United States Government or any agency thereof. 
Graphite Materials Properties - ORNL

DOE Project No. AT-19OR03050405

\title{
EFFECTS OF HIGH-TEMPERATURE IRRADIATION ON THE MICROSTRUCTURE OF NUCLEAR GRAPHITE
}

\author{
Anne A. Campbell \\ Cristian I. Contescu \\ Ercan Cakmak \\ Nidia C. Gallego \\ Timothy D. Burchell
}

September 2019

Prepared by

OAK RIDGE NATIONAL LABORATORY

Oak Ridge, Tennessee 37831-6283

managed by

UT-BATTELLE, LLC

for the

US DEPARTMENT OF ENERGY

under contract DE-AC05-00OR22725 



\section{CONTENTS}

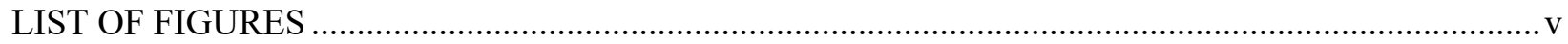

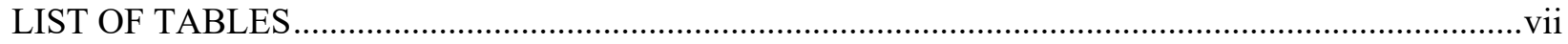

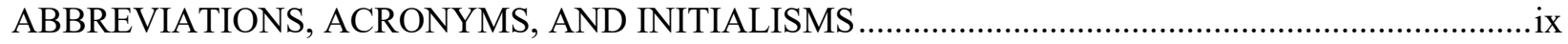

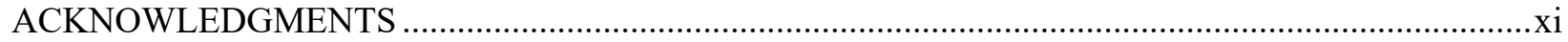

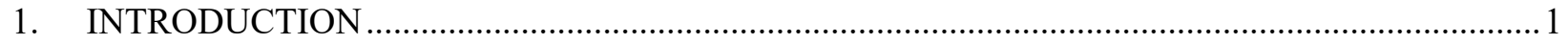

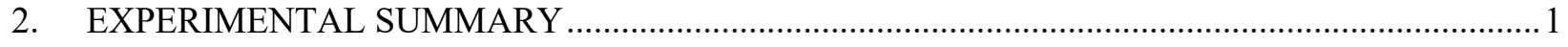

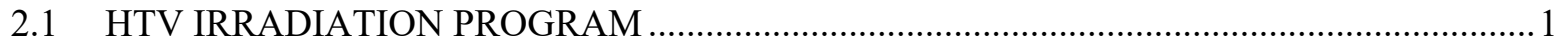

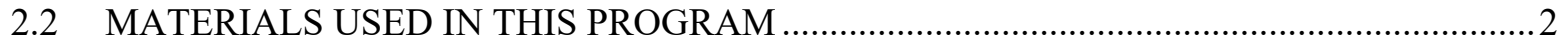

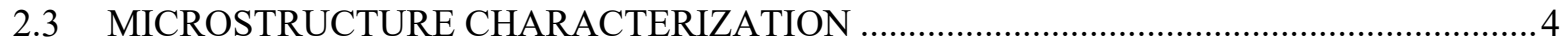

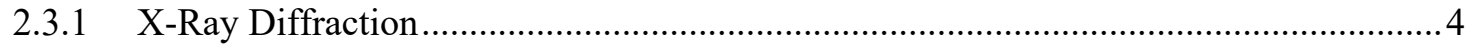

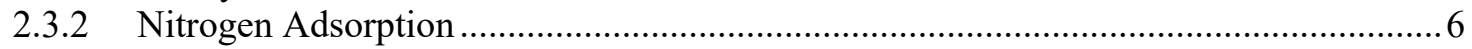

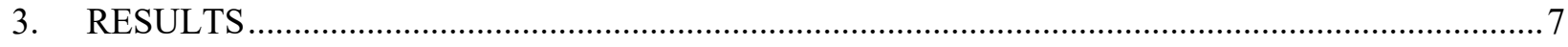

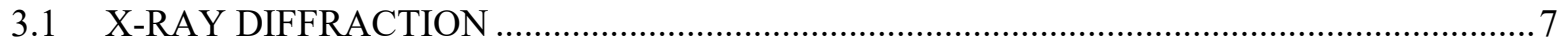

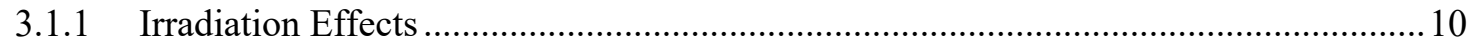

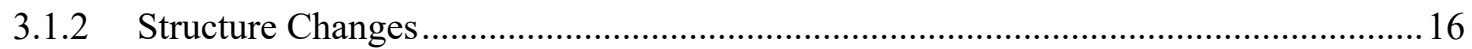

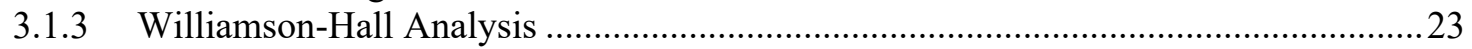

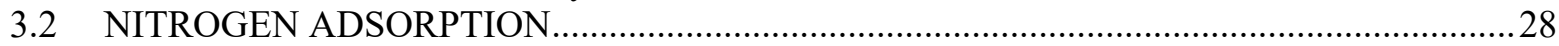

3.2.1 Microstructural Information Available from Nitrogen Adsorption Measurements .....28

3.2.2 Pore Size and Distribution of Unirradiated and Irradiated Nuclear Graphite ...............30

3.2.3 Increase of Atomic Disorder on Irradiation-Damaged Graphite Basal Planes..............33

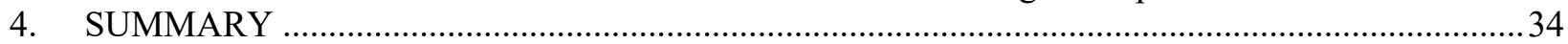

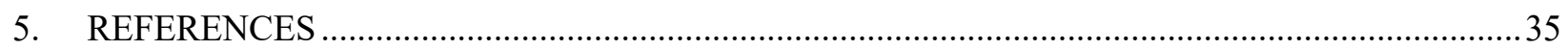

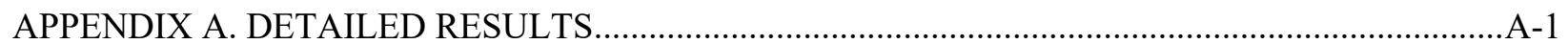





\section{LIST OF FIGURES}

Figure 1. HTV capsule design, with discrete temperature zones highlight and labeled with targeted temperature and average specimen damage .................................................................. 1

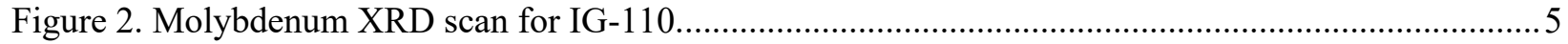

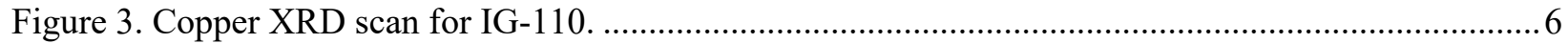

Figure 4. Hexagonal lattice structure of graphite. .............................................................................

Figure 5. Copper XRD scans of unirradiated IG-110, NBG-17, NBG-18, and PCEA.......................... 8

Figure 6. Example of localized peak fitting of unirradiated IG-110 with Jade 9..................................... 8

Figure 7. Effects of irradiation on the XRD spectra for (a) IG-110, (b) NBG-17, (c) NBG-18, and

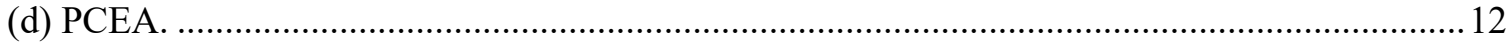

Figure 8. Change of c-direction spacing due to neutron irradiation, measured from the (a) (002),

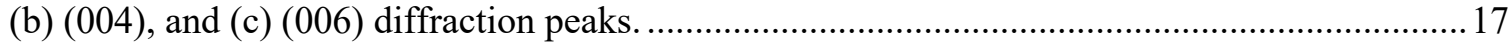

Figure 9. Change of a-direction spacing due to neutron irradiation, measured from the (a) (100),

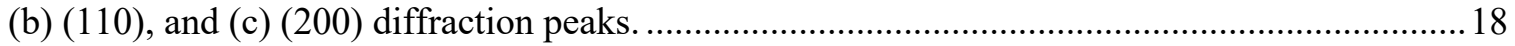

Figure 10. Net change of c-direction crystallite size due to neutron irradiation, measured from the (a) (002), (b) (004), and (c) (006) diffraction peaks................................................................ 19

Figure 11. Net change of a-direction crystallite size due to neutron irradiation, measured from the

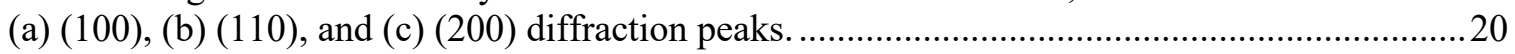

Figure 12. c-direction crystallite size due to neutron irradiation, measured from the (a) (002), (b)

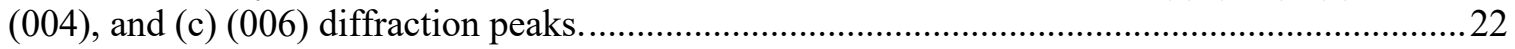

Figure 13. a-direction crystallite size due to neutron irradiation, measured from the (a) (100), (b)

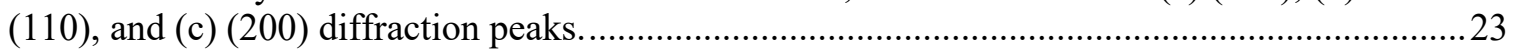

Figure 14. Williamson-Hall plots of (a) IG-110, (b) NBG-17, (c) NBG-18, and (d) PCEA.....................24

Figure 15. Williamson-Hall plots of (a) IG-110, (b) NBG-17, (c) NBG-18, and (d) PCEA with

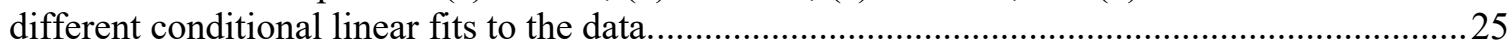

Figure 16. Williamson-Hall plots for IG-110 for the (a) (002), (004), and (006) peaks and the (b)

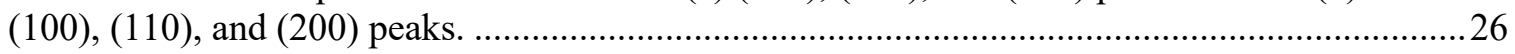

Figure 17. Williamson-Hall plots for NBG-17 for the (a) (002), (004), and (006) peaks and the (b)

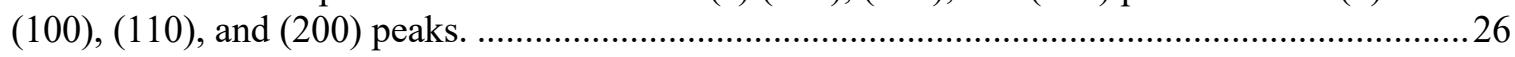

Figure 18. Williamson-Hall plots for NBG-18 for the (a) (002), (004), and (006) peaks and the (b)

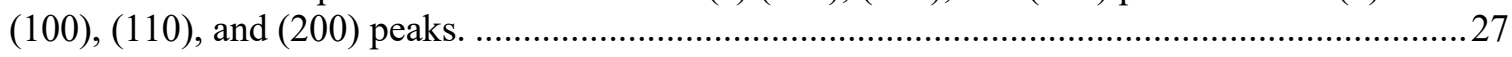

Figure 19. Williamson-Hall plots for PCEA for the (a) (002), (004), and (006) peaks and the (b) (100), (110), and (200) peaks.

Figure 20. Comparison among pore size ranges analyzed by various microstructural techniques, showing the overlap between gas adsorption results and other techniques [12].

Figure 21. Adsorption-desorption isotherms of nitrogen on graphite NBG-18 and the corresponding pore size distributions (QSDFT method).

Figure 22. Adsorption-desorption isotherms of nitrogen on graphite PCEA and the corresponding pore size distributions (QSDFT method) .................................................................................. 31

Figure 23. Adsorption-desorption isotherms of nitrogen on graphite IG-110 and the corresponding

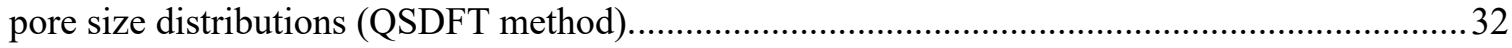

Figure 24. Adsorption-desorption isotherms of nitrogen on graphite 2114 and the corresponding

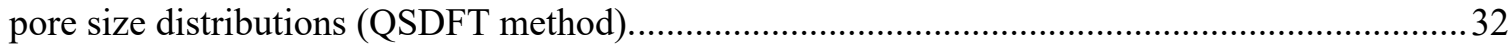

Figure 25. Initial parts of adsorption isotherms $\left(\mathrm{P} / \mathrm{P}_{0}<0.025\right)$ on unirradiated graphite and on materials irradiated at various damage levels. 



\section{LIST OF TABLES}

Table 1. Summary of graphite grades in HTV irradiation capsule.

Table 2. Summary of grades and temperature and damage combinations investigated with XRD.

Table 3. Summary of grades and temperature and damage combinations investigated with nitrogen adsorption.

Table 4. Summary of $\mathrm{Cu}$ XRD scans to capture peaks of interest.

Table 5. Summary of the peak information for unirradiated specimens of IG-110, NBG-17, NBG-

$$
18 \text {, and PCEA. }
$$

Table 6. Summary of the peak information for irradiated IG-110 specimens.

Table 7. Summary of the peak information for irradiated NBG-17 specimens

Table 8. Summary of the peak information for irradiated NBG-18 specimens

Table 9. Summary of the peak information for irradiated PCEA specimens. 



\section{ABBREVIATIONS, ACRONYMS, AND INITIALISMS}

\begin{tabular}{|c|c|}
\hline ART & Advanced Reactor Technologies \\
\hline $\mathrm{BCC}$ & body-centered cubic \\
\hline DFT & density functional theory \\
\hline DOE & Department of Energy \\
\hline dpa & displacements per atom \\
\hline FCC & face-centered cubic \\
\hline FWHM & full width at half maximum \\
\hline HFIR & High Flux Isotope Reactor \\
\hline HTV & High Temperature Vehicle \\
\hline NSUF & Nuclear Science User Facilities \\
\hline ORNL & Oak Ridge National Laboratory \\
\hline QSDFT & quenched solid state density functional theory \\
\hline RTE & Rapid Turn-around Experiment \\
\hline XRD & $\mathrm{x}$-ray diffraction \\
\hline
\end{tabular}





\section{ACKNOWLEDGMENTS}

This research was funded by the Advanced Reactor Technologies program of US Department of Energy. A portion of this research used resources at the High Flux Isotope Reactor, a DOE Office of Science User Facility operated by the Oak Ridge National Laboratory. Oak Ridge National Laboratory is managed by UT-Battelle LLC under Contract No. DE-AC05-00OR22725 for the US Department of Energy. 



\section{INTRODUCTION}

This report summarizes the nondestructive microstructure characterization undertaken at Oak Ridge National Laboratory (ORNL) to understand the effects of high-temperature neutron irradiation on the structure of nuclear graphite. Nuclear graphite specimens were irradiated in the ORNL High Flux Isotope Reactor (HFIR) in the High Temperature Vehicle (HTV) with target irradiation temperatures of $900^{\circ} \mathrm{C}$, $1200^{\circ} \mathrm{C}$, and $1500^{\circ} \mathrm{C}[1,2]$. The experiment was irradiated in the HFIR flux trap for two irradiation cycles, providing the specimens in the highest-fluence positions a total exposure of $4.5 \times 10^{21} \mathrm{n} / \mathrm{cm}^{2}[\mathrm{E}>0.1 \mathrm{MeV}]$, equivalent to radiation damage of $\sim 3.3 \mathrm{dpa}$ (displacements per atom) according to the conversion factor in Burchell [3].

The microstructural changes to the irradiated graphite specimens were investigated with x-ray diffraction (XRD) and nitrogen adsorption, both nondestructive techniques. The XRD results allowed for the quantification of the changes to the atomic spacing, and the Williamson-Hall [4] analysis was used to estimate the changes to the crystallite sizes and the lattice strain. Nitrogen adsorption measurements were used to interrogate the size and distribution of the micro- $(<2 \mathrm{~nm})$, meso- $(2-50 \mathrm{~nm})$, and macro-size $(50-$ $250 \mathrm{~nm}$ ) open porosity.

\section{EXPERIMENTAL SUMMARY}

\subsection{HTV IRRADIATION PROGRAM}

The HTV irradiation capsule for the ORNL HFIR flux trap was specially designed to irradiate graphite specimens at targeted temperatures of $900^{\circ} \mathrm{C}, 1200^{\circ} \mathrm{C}$, and $1500^{\circ} \mathrm{C}[1,2]$. A schematic of the capsule design is shown in Figure 1, in which the regions are color-coded according to the target irradiation temperature and labeled with the targeted irradiation temperature and the average specimen radiation damage (in dpa).

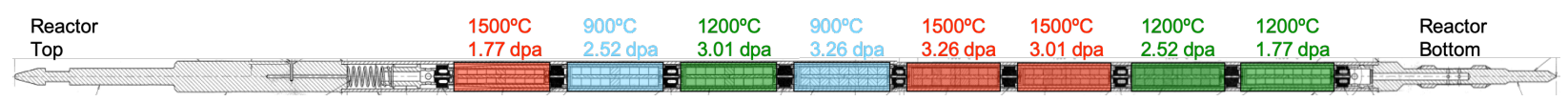

Figure 1. HTV capsule design, with discrete temperature zones highlight and labeled with targeted temperature and average specimen damage.

The post-irradiation examination of the passive silicon carbide thermal monitors showed that the average specimen temperatures were $840^{\circ} \mathrm{C}, 1189^{\circ} \mathrm{C}$, and $1412^{\circ} \mathrm{C}\left(\right.$ all $\left.\pm 25^{\circ} \mathrm{C}\right)$ [2]. The average damage levels listed in Figure 1 are the values accounting for the total irradiation time, rather than the planned time.

Samples from six nuclear graphite grades were irradiated in the HTV capsule; they are listed in Table 1 with some manufacturing details. 
Table 1. Summary of graphite grades in HTV irradiation capsule.

\begin{tabular}{c|c|c|c|c}
\hline Grade & Manufacturer & Forming process & Grain size $(\mathbf{m m})$ & Coke source \\
\hline NBG-17 & SGL Carbon & Vibrational molding & $0.8^{a}$ (medium) & Pitch \\
\hline NBG-18 & SGL Carbon & Vibrational molding & $1.6^{a}$ (large) & Pitch \\
\hline H-451 & SGL Carbon & Extrusion & $0.5^{b}$ (medium) & Petroleum \\
\hline PCEA & $\begin{array}{c}\text { GrafTech } \\
\text { International }\end{array}$ & Extrusion & $0.8^{a}$ (medium) & Petroleum \\
\hline IG-110 & Toyo Tanso & Isostatic pressing & $\begin{array}{c}0.05^{a}\left(0.020^{b}\right. \\
\text { superfine })\end{array}$ & Petroleum \\
\hline 2114 & Mersen & Isostatic pressing & $0.013^{b}$ (superfine) & Nonpetroleum \\
\hline
\end{tabular}

${ }^{a}$ maximum grain size

${ }^{b}$ average grain size

\subsection{MATERIALS USED IN THIS PROGRAM}

Specimens from graphite grades NBG-17, NBG-18, PCEA, and IG-110, with nominal irradiation temperatures of $900^{\circ} \mathrm{C}$ and $1500^{\circ} \mathrm{C}$, and the minimum and maximum total damage for each temperature were selected for investigation. A summary of the grades and temperature/damage combinations is listed in Table 2. Also included in Table 2 is the net volume change for each specimen [2], calculated from the specimen dimensions measured pre- and post-irradiation with digital micrometers. The NBG-17, PCEA, and IG-110 specimens were selected to provide a comparison with the XRD measurements performed on these same grades irradiated in the Advanced Graphite Creep-1 (AGC-1) creep capsule [5]. NBG-18 was added since it is the graphite with the largest grain size.

The original plan for the nitrogen adsorption work was to measure the same specimens that were measured via XRD for comparison, but the interior cell dimensions prevented the measurement of the specimens irradiated at $900^{\circ} \mathrm{C}$ and of the highest-dose specimen irradiated at $1500^{\circ} \mathrm{C}$. Instead, the plan was modified to perform nitrogen adsorption measurements on some of the $1200^{\circ} \mathrm{C}$ and $1500^{\circ} \mathrm{C}$ specimens and use the results from a Nuclear Science User Facilities (NSUF) Rapid Turn-around Experiment (RTE) led by James Spicer (Johns Hopkins University) and Cristian Contescu to understand changes in the porosity. The NSUF RTE experiment has already measured specimens of PCEA irradiated at $900^{\circ} \mathrm{C}$, which had neutron damage of 6.6 and 10.2 dpa (nominally at and past turn-around, respectively) [6], and samples of PCEA, NBG-18, and 2114 from the HTV capsule at $1500^{\circ} \mathrm{C}$ and neutron damage of 1.5 and 3 dpa. Specimens of IG-110 and NBG-17 were included for the comparison with the results from $\mathrm{XRD}$, and $1200^{\circ} \mathrm{C}$ specimens of each grade were included to better quantify the temperature effects. The specimens measured via nitrogen adsorption are listed in Table 3. Also included in Table 3 is the net volume change for each specimen, calculated from the specimen dimensions measured pre- and post-irradiation with digital micrometers. 
Table 2. Summary of grades and temperature and damage combinations investigated with XRD.

\begin{tabular}{|c|c|c|c|}
\hline $\begin{array}{c}\text { Graphite } \\
\text { grade }\end{array}$ & $\begin{array}{c}\text { Design } \\
\text { temperature } \\
\left({ }^{\circ} \mathrm{C}\right) \\
\end{array}$ & $\begin{array}{c}\text { Damage } \\
\text { (dpa) }\end{array}$ & $\begin{array}{c}\text { Volume } \\
\text { change }(\%)\end{array}$ \\
\hline \multirow{4}{*}{ IG-110 } & \multirow{2}{*}{$\begin{array}{l}900 \\
900\end{array}$} & 2.30 & -1.2 \\
\hline & & 3.27 & -2.0 \\
\hline & \multirow{2}{*}{$\begin{array}{l}1500 \\
1500\end{array}$} & 1.55 & -3.4 \\
\hline & & 3.29 & -7.2 \\
\hline \multirow{4}{*}{ NBG-17 } & \multirow{2}{*}{$\begin{array}{l}900 \\
900\end{array}$} & 2.47 & -0.7 \\
\hline & & 3.29 & -1.3 \\
\hline & \multirow{2}{*}{$\begin{array}{l}1500 \\
1500\end{array}$} & 1.99 & -4.0 \\
\hline & & 3.27 & -5.7 \\
\hline \multirow{4}{*}{ NBG-18 } & \multirow{2}{*}{$\begin{array}{l}900 \\
900\end{array}$} & 2.52 & -0.7 \\
\hline & & 3.26 & -1.4 \\
\hline & \multirow{2}{*}{$\begin{array}{l}1500 \\
1500\end{array}$} & 1.63 & -3.6 \\
\hline & & 3.29 & -6.1 \\
\hline \multirow{4}{*}{ PCEA } & \multirow{2}{*}{$\begin{array}{l}900 \\
900\end{array}$} & 2.41 & -1.4 \\
\hline & & 3.29 & -2.8 \\
\hline & \multirow{2}{*}{$\begin{array}{l}1500 \\
1500\end{array}$} & 1.47 & -3.2 \\
\hline & & 3.28 & -9.2 \\
\hline
\end{tabular}

Table 3. Summary of grades and temperature and damage combinations investigated with nitrogen adsorption.

\begin{tabular}{|c|c|c|c|c|}
\hline $\begin{array}{c}\text { Graphite } \\
\text { grade }\end{array}$ & $\begin{array}{c}\text { Design } \\
\text { temperature } \\
\left({ }^{\circ} \mathrm{C}\right) \\
\end{array}$ & $\begin{array}{c}\text { Damage } \\
\text { (dpa) }\end{array}$ & $\begin{array}{c}\text { Volume change } \\
(\%)\end{array}$ & Note \\
\hline \multirow{3}{*}{ IG-110 } & 1200 & 1.78 & $-1.0[2]$ & \\
\hline & \multirow{2}{*}{1500} & 1.55 & $-3.4[2]$ & \\
\hline & & 3.13 & $-6.9[2]$ & \\
\hline \multirow{3}{*}{ NBG-17 } & 1200 & 1.92 & $-1.4[2]$ & \\
\hline & \multirow{2}{*}{1500} & 1.99 & $-4.0[2]$ & \\
\hline & & 2.99 & $-6.0[2]$ & \\
\hline \multirow{3}{*}{ NBG-18 } & 1200 & 1.85 & $-1.6[2]$ & \\
\hline & \multirow{2}{*}{1500} & 1.63 & $-3.6[2]$ & NSUF RTE \\
\hline & & 3.10 & $-6.4[2]$ & NSUF RTE \\
\hline \multirow{5}{*}{ PCEA } & \multirow{2}{*}{900} & 6.61 & $-5.7[6]$ & NSUF RTE \\
\hline & & 10.16 & $-4.3[6]$ & NSUF RTE \\
\hline & 1200 & 1.98 & -1.9 [2] & \\
\hline & \multirow{2}{*}{1500} & 1.47 & $-3.2[2]$ & NSUF RTE \\
\hline & & 3.02 & $-8.7[2]$ & NSUF RTE \\
\hline \multirow{3}{*}{2114} & 1200 & 2.06 & $-1.1[2]$ & \\
\hline & \multirow{2}{*}{1500} & 1.77 & $-3.5[2]$ & NSUF RTE \\
\hline & & 3.05 & $-4.4[2]$ & NSUF RTE \\
\hline
\end{tabular}


The PCEA specimens were used to provide an understanding of the effects of irradiation temperature and total volume change on the pore evolution. The $900^{\circ} \mathrm{C}$ specimen at $6.61 \mathrm{dpa}$ was at, or near, the turnaround fluence (net $-5 \%$ volume change at this fluence), while the $10.16 \mathrm{dpa}$ specimen had started to swell but the volume change was still negative ( $-4.5 \%$ volume change). The $1500^{\circ} \mathrm{C}$ PCEA specimen at 1.49 dpa had a volume change of $-3 \%$, while the specimen at 3.06 dpa had a volumetric change of $-9 \%$. The 3.06 dpa specimen was most likely at turn-around, so its results were compared with those for the $900^{\circ} \mathrm{C}$ specimen at $6.61 \mathrm{dpa}$. The $1200^{\circ} \mathrm{C}$ PCEA specimen provided a comparison with the low-dose $1500^{\circ} \mathrm{C}$ specimen, to understand whether there was a temperature effect on the pore structure change at these doses.

\subsection{MICROSTRUCTURE CHARACTERIZATION}

As mentioned previously, two nondestructive evaluation techniques were used in this work to evaluate the microstructure changes in the irradiated graphite specimens. XRD was used to measure and determine the changes to lattice spacing, crystallite size, and lattice strain. Nitrogen adsorption was used to investigate the changes to the micro- and meso-size porosity. This section discusses the equipment and data analysis techniques used in this work.

\subsubsection{X-Ray Diffraction}

XRD measurements were collected on two Panalytic X'Pert PRO diffractometers, one molybdenum (Mo) $\mathrm{x}$-ray anode and one copper $(\mathrm{Cu}) \mathrm{x}$-ray anode. The Mo X-rays have wavelengths of $0.709319 \AA$ and $0.713609 \AA$, for $\mathrm{K}_{\alpha 1}$ and $\mathrm{K}_{\alpha 2}$ respectively, while the $\mathrm{Cu}$ x-rays have wavelengths of $1.540598 \AA$ and $1.544426 \AA$, for $K_{\alpha 1}$ and $K_{\alpha 2}$ respectively.

A pattern was collected from a single-crystal silicon standard, which is used to correct the graphite pattern analysis for instrument broadening. Peak identification, broadening correction, fitting, deconvolution, and Scherrer analysis were performed with the Jade version 9 from Materials Data Inc. The peaks were fit with a Pearson-VII peak shape, while accounting for the $\mathrm{K}_{\alpha 1}$ and $\mathrm{K}_{\alpha 2}$ peaks and a linear background. The analysis results from Jade output only the values from the $\mathrm{K}_{\alpha 1} \mathrm{X}$-rays even though the recorded spectra included contributions from both $\mathrm{K}_{\alpha 1}$ and $\mathrm{K}_{\alpha 2}$.

The first analysis performed on the data was the Scherrer analysis. This analysis was performed so that comparisons of these results with historical results can be performed in the future. The Scherrer analysis uses the Scherrer equation,

$$
\text { Equation 1: } \quad \boldsymbol{L}=\frac{\boldsymbol{K} \lambda}{\boldsymbol{\beta} \cos \boldsymbol{\theta}},
$$

to preliminarily determine the crystallite size, where $L$ is the crystallite size, $K$ is the shape factor ( 0.9 used for calculation in this work), $\lambda$ is the wavelength of the $\mathrm{x}$-ray, $\beta$ is the full width at half maximum (FWHM) of the peak corrected for instrument broadening, and $\theta$ is the Bragg angle.

In most systems, the broadening of the XRD peaks is due to a combination of crystallite size broadening and lattice strain. The Williamson-Hall [4] analysis is a method to quantify the contributions of XRD broadening due to both components. Crystallite size broadening is defined by rearranging Equation 1), and strain broadening is given by

$$
\text { Equation 2: } \quad \boldsymbol{\beta}(2 \theta)=\mathbf{4 \varepsilon} \frac{\sin \theta}{\cos \theta},
$$

where $\varepsilon$ is the lattice strain. Combining Equation 1 and Equation 2 results in 


$$
\text { Equation 3: } \quad \beta(2 \theta)=\frac{K \lambda}{L \cos \theta}+4 \varepsilon \frac{\sin \theta}{\cos \theta} \text {. }
$$

Multiplying Equation 3) by $\cos (\theta)$ results in an equation that can be fit with linear regression:

$$
\text { Equation 4: } \quad \beta \cos \theta=\underbrace{\left(\frac{K \lambda}{L}\right)}_{y-\text { intercept }}+\underbrace{4 \varepsilon}_{\text {slope }} \sin \theta .
$$

The Williamson-Hall plot is created by plotting the $\beta \cos (\theta)$ versus $\sin (\theta)$.

In isotropic crystal structures (i.e., cubic, BCC, FCC) Williamson-Hall analysis can be used for all diffraction peaks simultaneously; but in anisotropic materials, the analysis is performed only for Bragg peaks with contributions from the $<\mathrm{c}>$ or $<\mathrm{a}>$ directions. Therefore, obtaining multiple peaks with only $<\mathrm{a}>$ or $<\mathrm{c}>$ contributions was necessary. For this reason, the possibility of using a Mo anode was investigated, since the $\mathrm{Mo} \mathrm{K}_{\alpha}$ wavelength is half that of the $\mathrm{Cu} \mathrm{K} \alpha$ wavelength, so more reflections of the (002), (100), and (110) peaks could be captured. Two XRD spectra with Mo x-rays for IG-110 are shown in Figure 2, with one running from $5^{\circ}$ to $45^{\circ}$ and the second from $45^{\circ}$ to $145^{\circ}$. The higher angle scan was run with a slower scan rate to increase the intensity of the higher-order peaks.

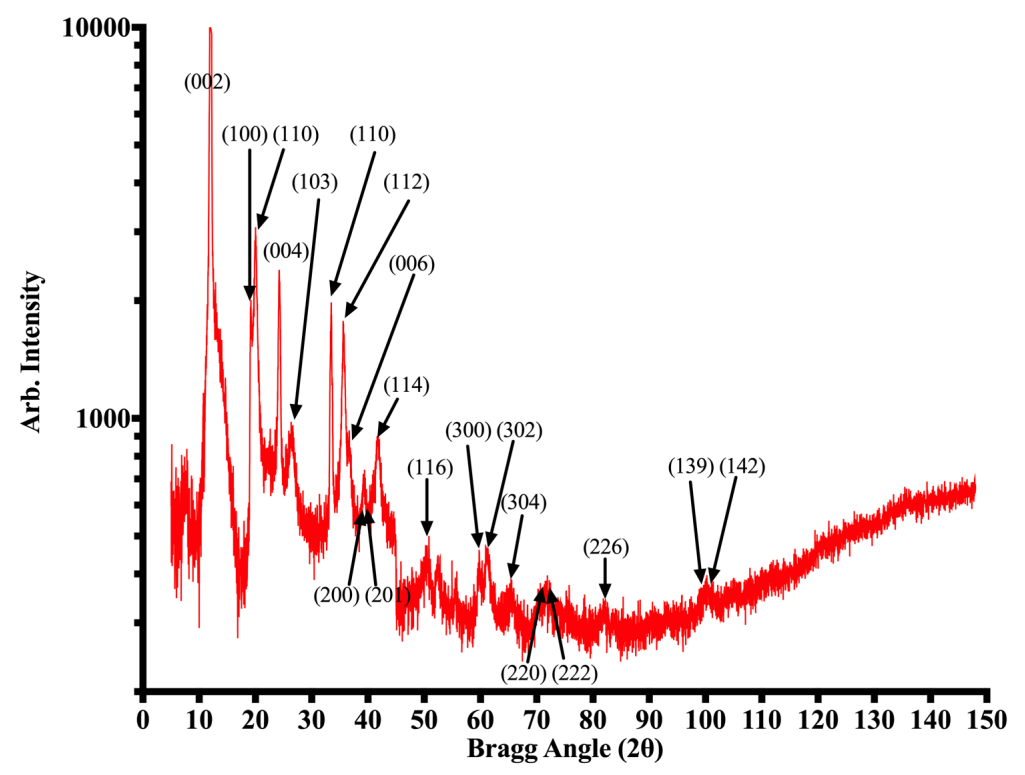

Figure 2. Molybdenum XRD scan for IG-110. The jump in data at $45^{\circ}$ is due to running two scans, with the scan above $45^{\circ}$ being run at a lower scan rate to gain higher counts.

The problem noticed with the Mo x-rays was that the peak spacing was reduced as a result of the smaller $\mathrm{x}$-ray wavelength, which made deconvolution of peaks with similar Bragg angles difficult, such as (200) and (201) located at $2 \theta$ values of $38.96^{\circ}$ and $39.46^{\circ}$, respectively. It was determined that the Mo x-ray scans would not provide the benefits originally assumed. Therefore, it was decided to proceed with $\mathrm{Cu} \mathrm{x}$ ray scans; an example scan for IG-110 is shown in Figure 3. The spacing between peaks was greater than in the Mo scan, as should occur, which made deconvolution easier. 


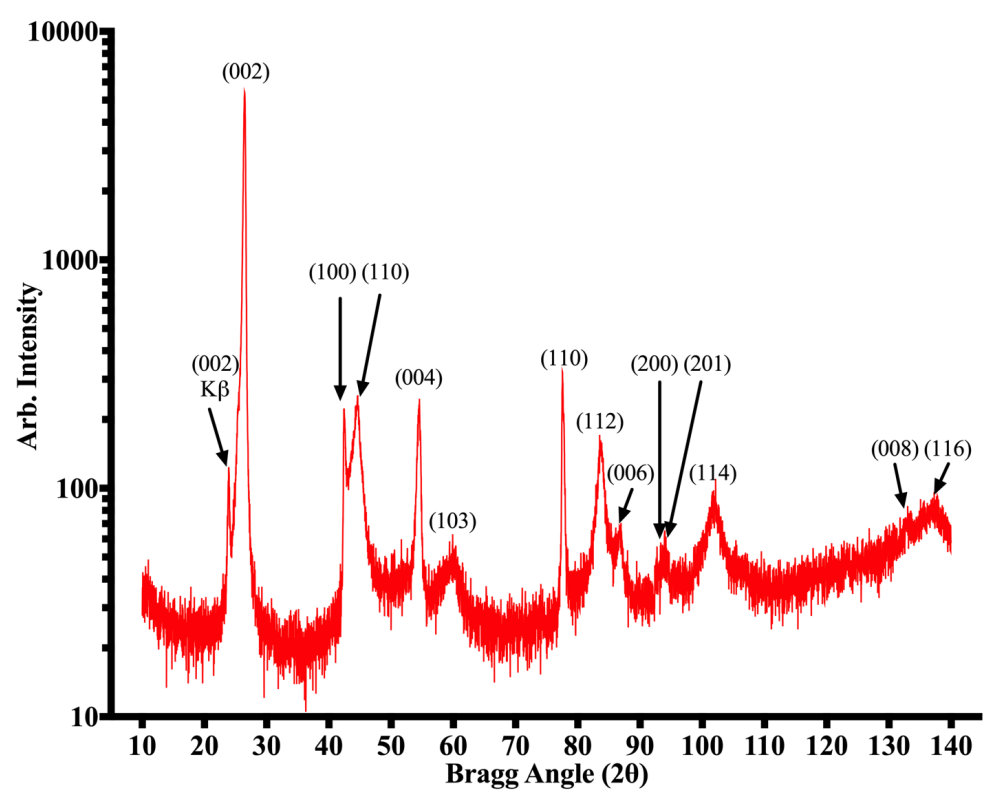

Figure 3. Copper XRD scan for IG-110.

The $\mathrm{Cu}$ scan captures four reflections for the $<\mathrm{c}>$ direction: (002), (004), (006,) and (008) and $3<\mathrm{a}>$ directions: (100), (110), and (200). At higher angles, the background increased, so capturing a sufficient peak intensity for analysis required a longer counting time; but running a full-spectrum scan with this slow rate was time-prohibitive. Instead, it was decided to perform localized scans with a slow scanning rate to allow for increased time, thereby allowing for higher counting statistics at each angle to ease peak deconvolution. The (008) peak was not captured with these localized scans because of the low intensity. The information for the Cu scanning conditions is listed in Table 4. An additional scan is listed in Table 4 for a single-crystal silicon standard, which was used to determine the instrument broadening.

Table 4. Summary of Cu XRD scans to capture peaks of interest.

\begin{tabular}{|c|c|c|c|c|}
\hline $\begin{array}{l}\text { Angle range } \\
(2 \theta)\end{array}$ & $\begin{array}{c}\text { Step size } \\
\left({ }^{\circ} 2 \theta\right)\end{array}$ & Scan time & $\begin{array}{c}\text { Peaks of } \\
\text { interest (hkl) }\end{array}$ & $\begin{array}{c}\text { Peak of interest } \\
\text { location }(2 \theta)\end{array}$ \\
\hline $21-100$ & 0.017 & $2 \mathrm{~h}$ & & \\
\hline $21-30$ & 0.017 & $30 \mathrm{~min}$ & $(002)$ & 26.6 \\
\hline $40-49$ & 0.017 & $30 \mathrm{~min}$ & $(100)$ & 42.5 \\
\hline $52-56$ & 0.017 & $30 \mathrm{~min}$ & $(004)$ & 54.8 \\
\hline $75.5-79.5$ & 0.017 & $30 \mathrm{~min}$ & $(110)$ & 77.7 \\
\hline $80-90$ & 0.017 & $3 \mathrm{~h}$ & $(006)$ & 87.3 \\
\hline $90-98$ & 0.017 & $5 \mathrm{~h}$ & $(200)$ & 92.8 \\
\hline $10-148$ & 0.017 & $2 \mathrm{~h}$ & Si standard & \\
\hline
\end{tabular}

\subsubsection{Nitrogen Adsorption}

Equilibrium adsorption/desorption isotherms of nitrogen at $77 \mathrm{~K}$ were measured on an Autosorb-1C (Quantachrome) instrument equipped with three pressure sensors. The specimens were outgassed before measurements at $300^{\circ} \mathrm{C}$ until a base pressure of $2 \mathrm{~Pa}$ was achieved and could be maintained at that temperature. A total of 117 data points were collected; of these, 57 points were in the micropore range 
starting from $5 \mathrm{~Pa}$ and distributed equidistant on the logarithmic scale, 40 more adsorption points reached up to $10^{5} \mathrm{~Pa}$, and 20 desorption points reached back to $10^{3} \mathrm{~Pa}$. The tolerance for pressure deviations was set to 0 and the equilibrium time at each pressure was 4 minutes. The micropore maxidose option was used during the micropore measurement.

The challenge of these measurements was the low amount of sample (about $0.5 \mathrm{~g}$ or less) and the low surface area of the nuclear graphite (in the range of $1-2.5 \mathrm{~m}^{2} / \mathrm{g}$ ). Because of these conditions, the specimens present in the cell had only a small absorbing area, about $1 \mathrm{~m}^{2}$ or less, which is at the lowest range of the instrument capabilities. Quantachrome recommends adjusting the sample weight in analysis so that the surface area in the cell is in the range of $1-20 \mathrm{~m}^{2}\left(5 \mathrm{~m}^{2}\right.$ recommended) [7]. To compensate for these challenging conditions, and to minimize errors caused by initial dead volume calibration, we used cells with the smallest volume available and always added filler rods inside the cell. Some measurements had to be repeated two and even three times to confirm that unexpected features observed at low pressures $\left(10^{2}-10^{3} \mathrm{~Pa}\right)$ were not caused by random errors or equipment malfunction.

\section{RESULTS}

\subsection{X-RAY DIFFRACTION}

Graphite has an anisotropic hexagonal crystal structure. The carbon atoms are arranged in the aromatic carbon rings on the basal planes, and the basal planes are stacked in an A-B-A-B order (Figure 4). The planes are offset so that, on each plane, half of the carbon atoms have atoms directly above and below them on neighboring planes (see the colorized atoms on the left side of Figure 4). The unit cell of this crystal structure is highlighted on the right side of the image, with 12 shared corner atoms (green), 2 shared face atoms (yellow) and 1 internal atom (purple) for a total of 4 atoms in each cell. The theoretical lattice parameters in the structure are $\mathrm{a}=2.4614 \AA$ and $\mathrm{c}=6.707 \AA[8]$.

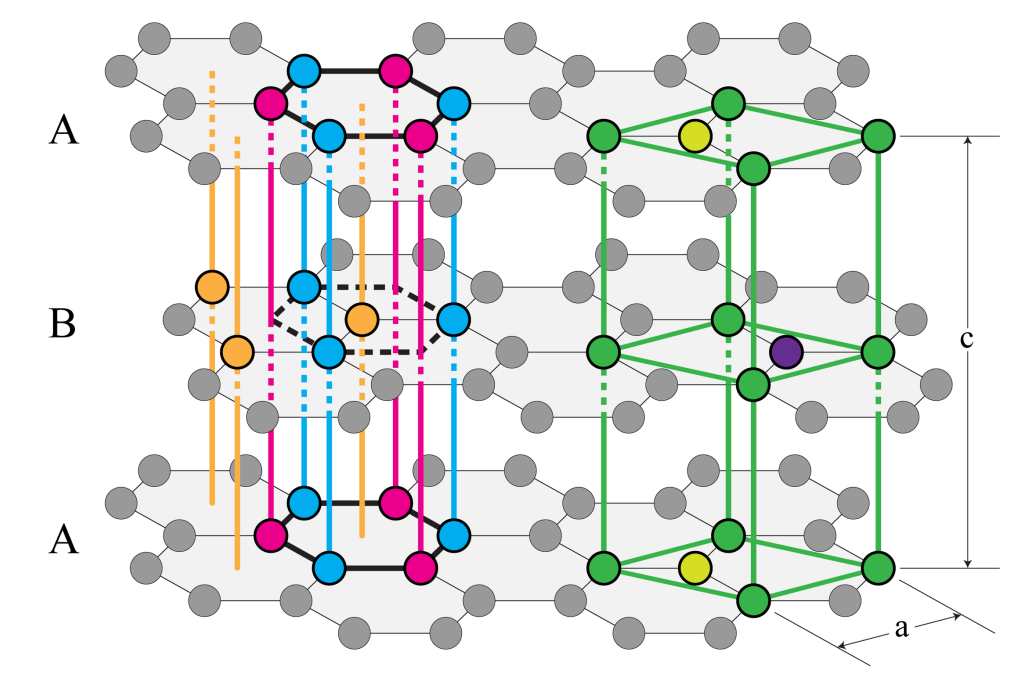

Figure 4. Hexagonal lattice structure of graphite.

The copper XRD scan conditions are listed in Table 4. The full-range scans from $21^{\circ}$ to $100^{\circ}$ for the unirradiated samples of IG-110, NBG-17, NBG-18, and PCEA are shown in Figure 5. There were only minor differences between the grades for the unirradiated condition, including slight differences in peak location and scattering intensity. One peak observed in these scans that was not from the $\mathrm{K}_{\alpha}$ scattering is located at $\sim 23.5^{\circ}$; it is the $(002)$ peak due to the $\mathrm{K}_{\beta 1} \mathrm{X}$-ray. 


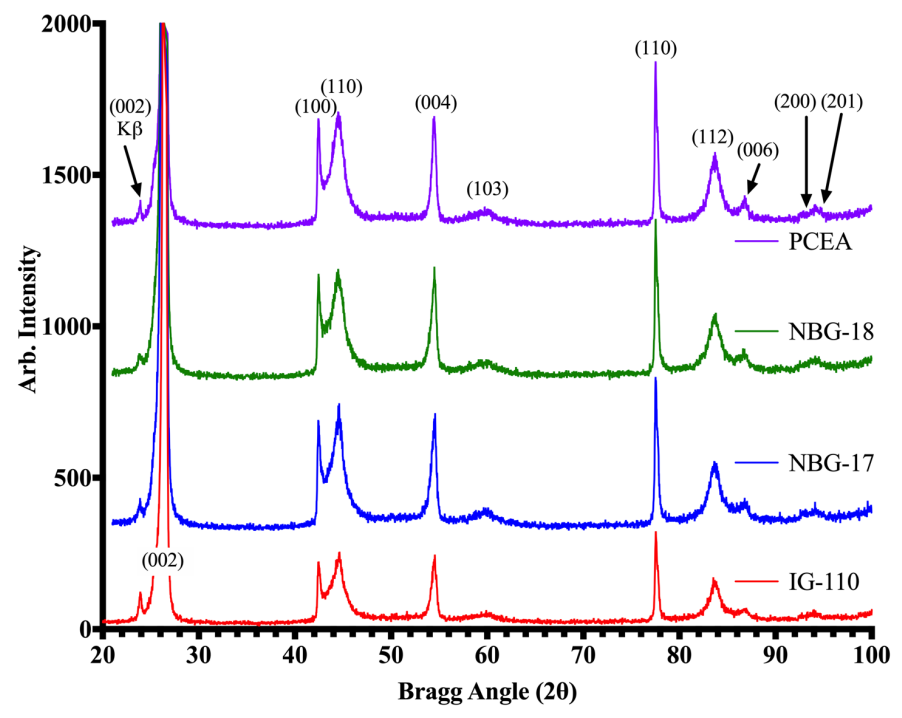

Figure 5. Copper XRD scans of unirradiated IG-110, NBG-17, NBG-18, and PCEA.

The lattice parameters and Scherrer analysis for crystallite size were determined from the localized scans with version 9 of Jade software, a dedicated scattering analysis software. The first step in the analysis required fitting of the single-crystal silicon standard to determine the instrument broadening. After this first analysis was completed, Jade then automatically used this for all analysis. Next, each localized scan was fit with the built-in peak fitting function. The XRD system is not monochromatic so any peak fitting must account for the fact that the captured peaks include contribution from both the $\mathrm{K}_{\alpha 1}$ and $\mathrm{K}_{\alpha 2} \mathrm{X}$-rays and the intensity ratio of these two x-rays. An example of the localized peak fitting with Jade 9 for unirradiated IG-110 is shown in Figure 6. The peaks from both the $\mathrm{K}_{\alpha 1}$ and $\mathrm{K}_{\alpha 2} \mathrm{x}$-rays are shown. The benefit of using Jade is that after the spectra are fit, the software outputs the peak information only for the $\mathrm{K}_{\alpha 1} \mathrm{X}$-ray, thereby simplifying any further analysis and data reduction.
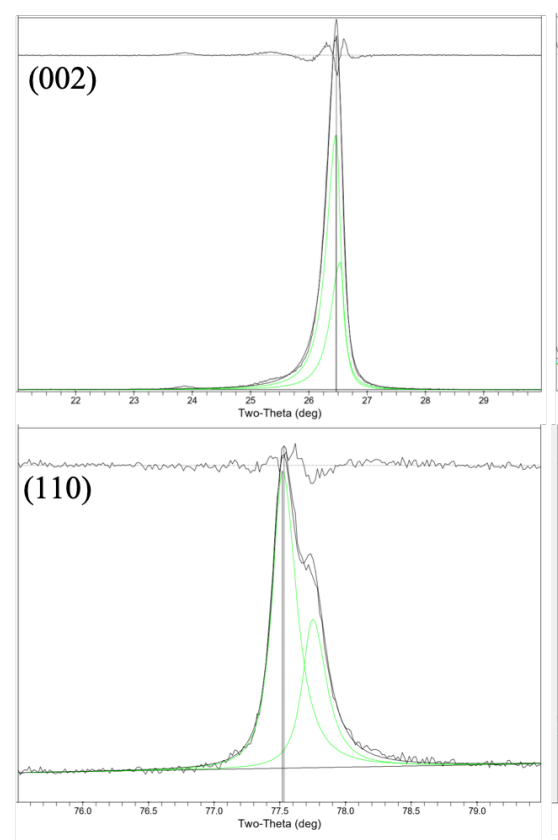
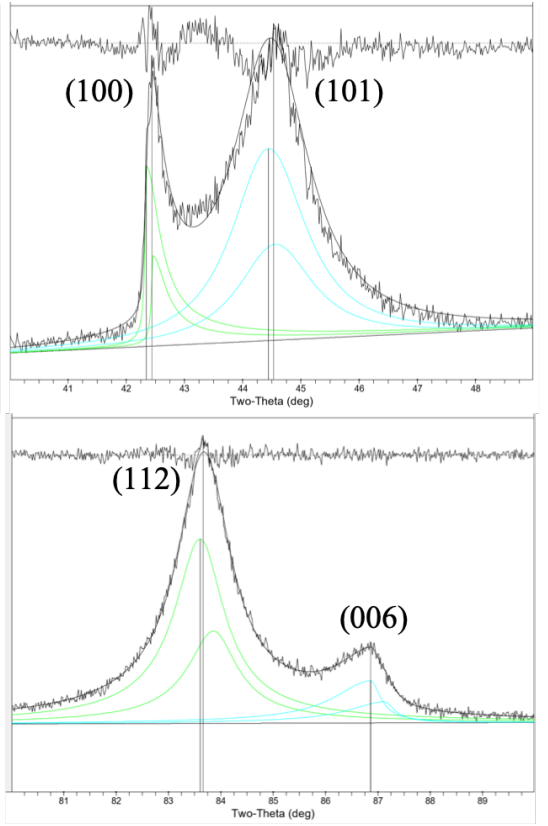

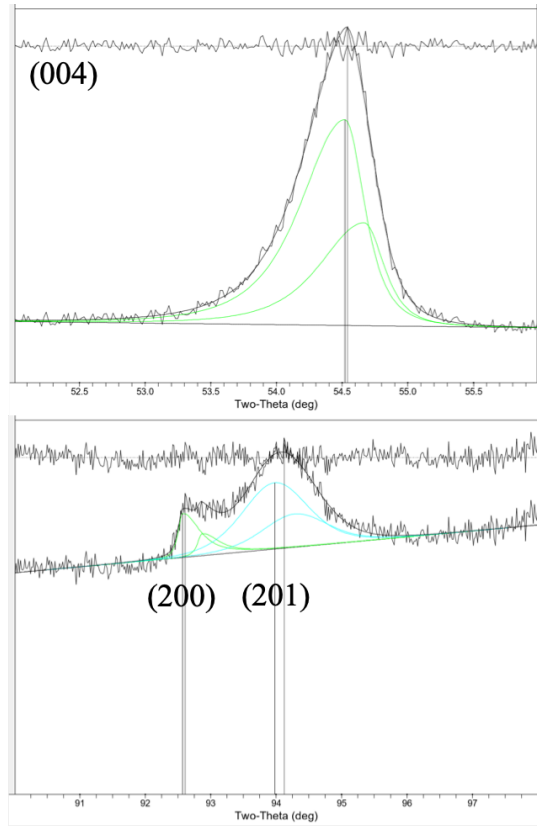

Figure 6. Example of localized peak fitting of unirradiated IG-110 with Jade 9. 
A summary of the peak information for the unirradiated specimens is given in Table 5. The peak location, d-spacing, peak breadth, and crystallite size were determined by Jade 9, while the lattice parameter and atomic spacing were calculated from d-spacing. The d-spacing $(d)$ was related to the peak location via

$$
\text { Equation 5: } \quad d=\frac{n \lambda}{2 \sin \theta},
$$

where $n$ is an integer, $\lambda$ is the wavelength of the $\mathrm{x}$-rays, and $\theta$ is the Bragg angle. From the $\mathrm{d}$-spacing, the lattice parameter for a hexagonal crystal structure was calculated via

$$
\text { Equation 6: } \quad \frac{1}{d^{2}}=\frac{4}{3 a^{2}}\left(h^{2}+h k+k^{2}\right)+\frac{1}{c^{2}} l^{2},
$$

where $a$ is the a-direction lattice parameter, $c$ is the c-direction lattice parameter, and $h k l$ are the Miller indices. The spacing between basal planes was equal to $1 / 2$ the lattice parameter $c$, while the atomic spacing in the basal planes $\left(a_{0}\right)$ was calculated from the atomic spacing $a$ by

$$
\text { Equation 7: } \quad a_{0}=\frac{a}{2 \sin (60)} .
$$


Table 5. Summary of the peak information for unirradiated specimens of IG-110, NBG-17, NBG-18, and PCEA. Fitting was performed on the localized scans rather than the full-range scan.

\begin{tabular}{|c|c|c|c|c|c|c|c|}
\hline Grade & (hkl) & $\begin{array}{c}\text { Peak } \\
\text { location }(2 \theta)\end{array}$ & $\begin{array}{c}\text { Peak } \\
\text { breadth } \\
(2 \theta) \\
\end{array}$ & $\begin{array}{c}\text { Crystallite } \\
\text { size } L_{a} \text { or } L_{c} \\
(\AA)\end{array}$ & $\begin{array}{c}\text { d-spacing } \\
(\AA)\end{array}$ & $\begin{array}{c}\text { Lattice } \\
\text { parameter } \\
(\AA)\end{array}$ & $\begin{array}{c}\text { Atomic } \\
\text { spacing } \\
(\AA) \\
\end{array}$ \\
\hline \multirow{6}{*}{ IG-110 } & $(002)$ & 26.470 & 0.2885 & 398 & 3.3646 & 6.7292 & 3.3646 \\
\hline & $(004)$ & 54.522 & 0.5730 & 177 & 1.6817 & 6.7268 & 3.3634 \\
\hline & (006) & 86.860 & 1.1224 & 103 & 1.1205 & 6.7230 & 3.3615 \\
\hline & $(100)$ & 42.346 & 0.3424 & 324 & 2.1327 & 2.4626 & 1.4218 \\
\hline & $(110)$ & 77.520 & 0.2151 & 933 & 1.2304 & 2.4608 & 1.4207 \\
\hline & (200) & 92.571 & 0.3876 & 387 & 1.0657 & 2.4611 & 1.4209 \\
\hline \multirow{6}{*}{ NBG-17 } & (002) & 26.469 & 0.3094 & 358 & 3.3647 & 6.7294 & 3.3647 \\
\hline & (004) & 54.540 & 0.5703 & 178 & 1.6812 & 6.7248 & 3.3624 \\
\hline & (006) & 86.864 & 1.2157 & 95 & 1.1204 & 6.7224 & 3.3612 \\
\hline & (100) & 42.336 & 0.3996 & 263 & 2.1332 & 2.4632 & 1.4221 \\
\hline & (110) & 77.510 & 0.2194 & 890 & 1.2305 & 2.4610 & 1.4209 \\
\hline & $(200)$ & 92.570 & 0.4331 & 332 & 1.0657 & 2.4611 & 1.4209 \\
\hline \multirow{6}{*}{ NBG-18 } & $(002)$ & 26.465 & 0.3044 & 366 & 3.3651 & 6.7302 & 3.3651 \\
\hline & (004) & 54.518 & 0.5669 & 179 & 1.6818 & 6.7272 & 3.3636 \\
\hline & $(006)$ & 86.792 & 1.1315 & 102 & 1.1212 & 6.7272 & 3.3636 \\
\hline & $(100)$ & 42.352 & 0.3697 & 291 & 2.1324 & 2.4623 & 1.4216 \\
\hline & (110) & 77.512 & 0.2167 & 917 & 1.2305 & 2.4610 & 1.4209 \\
\hline & (200) & 92.567 & 0.4957 & 278 & 1.0658 & 2.4614 & 1.4211 \\
\hline \multirow{6}{*}{ PCEA } & (002) & 26.455 & 0.2436 & 527 & 3.3664 & 6.7328 & 3.3664 \\
\hline & $(004)$ & 54.484 & 0.4505 & 237 & 1.6828 & 6.7312 & 3.3656 \\
\hline & $(006)$ & 86.747 & 0.8472 & 140 & 1.1217 & 6.7302 & 3.3651 \\
\hline & (100) & 42.353 & 0.2939 & 406 & 2.1323 & 2.4622 & 1.4215 \\
\hline & (110) & 77.510 & 0.2064 & $>1000$ & 1.2305 & 2.4610 & 1.4209 \\
\hline & (200) & 92.581 & 0.4893 & 283 & 1.0656 & 2.4609 & 1.4208 \\
\hline
\end{tabular}

\subsubsection{Irradiation Effects}

The effects of irradiation on the full XRD spectra for the four graphite grades are shown in Figure 7. In general, irradiation reduced the intensity of all the peaks, shifted the peak locations (changed lattice spacing), and caused peak broadening (reduced crystallite sizes). The summary of the peak location, peak breadth, crystallite size, crystallite size change, lattice parameter, and lattice parameter change are summarized for each material in Table 6-Table 9. The detailed Jade results for the fitted parameters, including error, are listed in APPENDIX A. For most of the peaks, the fit error was minimal, but error propagation was performed through the various calculations. The propagation followed the following rule, for a function $(z)$ defined by

$$
\text { Equation 8: } \quad \boldsymbol{z}=\boldsymbol{f}(\boldsymbol{x}, \boldsymbol{y}, \ldots) ;
$$

the error of $\mathrm{z}\left(\sigma_{z}\right)$ was calculated from the square partial derivatives of $z$ with respect to the constituent variables and their error $\left(\sigma_{x}, \sigma_{y}\right)$ : 


$$
\text { Equation 9: } \quad \sigma_{z}^{2}=\left(\frac{\partial z}{\partial x}\right)^{2} \sigma_{x}^{2}+\left(\frac{\partial z}{\partial y}\right)^{2} \sigma_{y}^{2}+\cdots
$$

This propagation was used for calculating the error in the changes of the crystal parameters from the XRD results. For the calculation of net change,

$$
\text { Equation 10: } \quad \boldsymbol{z}=\frac{y-x}{\boldsymbol{x}},
$$

the error of the net change was equal to:

$$
\text { Equation 11: } \quad \sigma_{z}^{2}=\left(\frac{-y}{x^{2}}\right)^{2} \sigma_{x}^{2}+\left(\frac{1}{x}\right)^{2} \sigma_{y}^{2}
$$

For the Williamson-Hall calculations, the $\mathrm{x}$-axis error was equal to

$$
\text { Equation 12: } \quad \boldsymbol{\sigma}_{x}^{2}=(\cos \theta)^{2} \boldsymbol{\sigma}_{\boldsymbol{\theta}}^{2}
$$

and the y-axis error was equal to

$$
\text { Equation 13: } \quad \sigma_{y}^{2}=(\cos \theta)^{2} \sigma_{\beta}^{2}+(-\beta \sin \theta)^{2} \sigma_{\theta}^{2} .
$$

In many of the calculations, the statistical error is sufficiently small that the error bars are not visible outside the data points. Error propagation has been performed for all the data comparisons in this section, but are not visible for much of the data. 

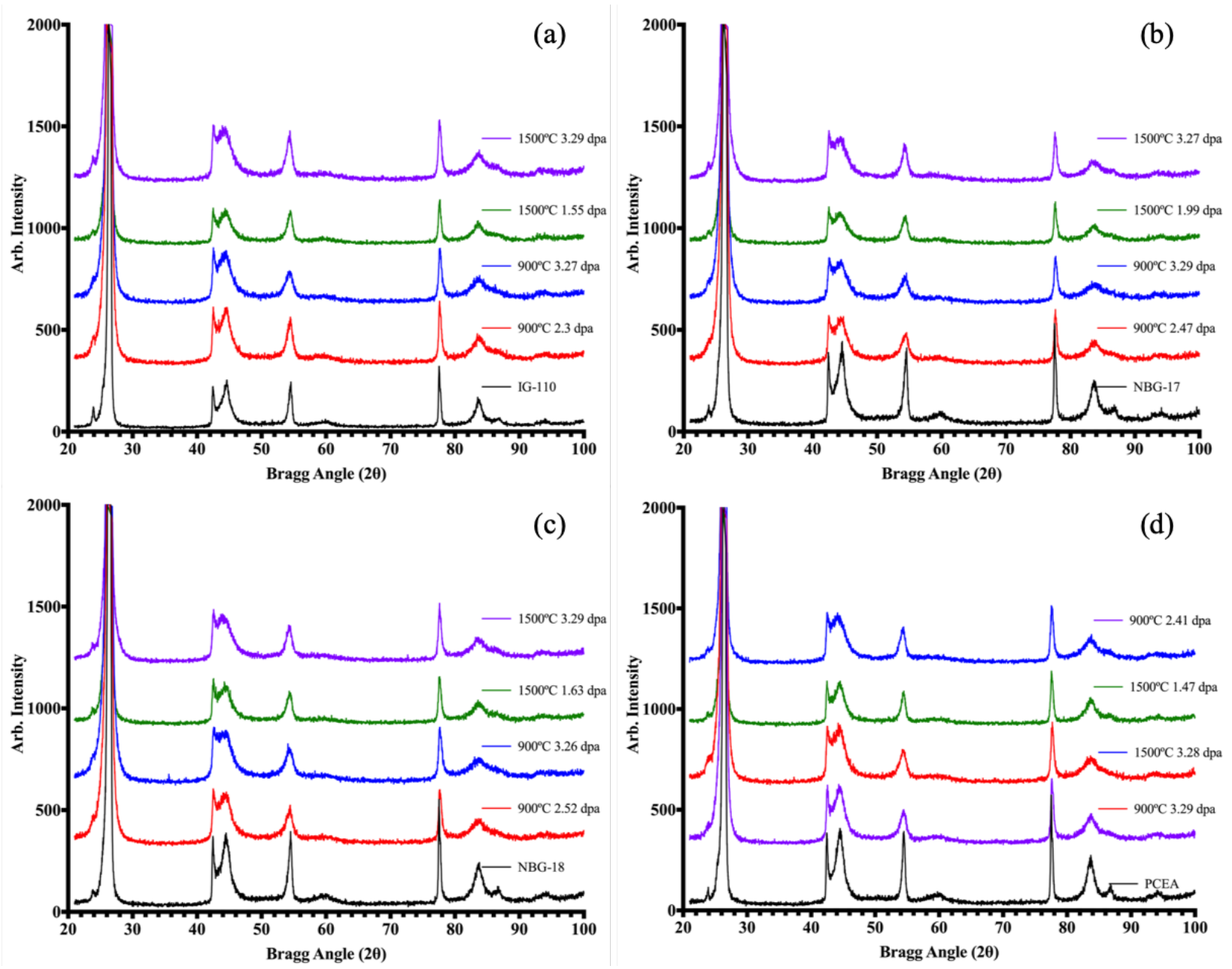

Figure 7. Effects of irradiation on the XRD spectra for (a) IG-110, (b) NBG-17, (c) NBG-18, and (d) PCEA. 
Table 6. Summary of the peak information for irradiated IG-110 specimens. Fitting was performed on the localized scans rather than the full-range scan.

\begin{tabular}{|c|c|c|c|c|c|c|c|c|}
\hline $\begin{array}{l}\text { Temp. } \\
\left({ }^{\circ} \mathrm{C}\right)\end{array}$ & $\begin{array}{l}\text { Dose } \\
\text { (dpa) }\end{array}$ & (hkl) & $2 \theta$ & $\begin{array}{c}\text { FWHM } \\
(2 \theta)\end{array}$ & $\begin{array}{c}\text { Crystallite } \\
\text { size } L_{c} \text { or } L_{a} \\
(\AA)\end{array}$ & $\begin{array}{l}\text { Lc or } L_{a} \\
\text { change }\end{array}$ & $\begin{array}{c}\text { Lattice } \\
\text { parameter } \\
(\AA)\end{array}$ & $\begin{array}{l}\text { Lattice } \\
\text { change }\end{array}$ \\
\hline \multirow{6}{*}{900} & \multirow{6}{*}{2.30} & $(002)$ & 26.455 & 0.5825 & 158 & $-60.30 \%$ & 6.7328 & $0.053 \%$ \\
\hline & & (004) & 54.441 & 1.0771 & 87 & $-50.85 \%$ & 6.7360 & $0.137 \%$ \\
\hline & & $(006)$ & 86.621 & 2.9472 & 38 & $-63.11 \%$ & 6.7380 & $0.223 \%$ \\
\hline & & $(100)$ & 42.400 & 0.5650 & 171 & $-47.22 \%$ & 2.4596 & $-0.122 \%$ \\
\hline & & (110) & 77.574 & 0.3436 & 399 & $-57.23 \%$ & 2.4594 & $-0.057 \%$ \\
\hline & & $(200)$ & 92.656 & 0.7192 & 178 & $-54.01 \%$ & 2.4595 & $-0.066 \%$ \\
\hline \multirow{6}{*}{900} & \multirow{6}{*}{3.27} & $(002)$ & 26.421 & 0.7015 & 128 & $-67.84 \%$ & 6.7412 & $0.178 \%$ \\
\hline & & (004) & 54.357 & 1.2806 & 73 & $-58.76 \%$ & 6.7456 & $0.279 \%$ \\
\hline & & $(006)$ & 86.164 & 3.4355 & 32 & $-68.93 \%$ & 6.7662 & $0.643 \%$ \\
\hline & & $(100)$ & 42.426 & 0.6961 & 135 & $-58.33 \%$ & 2.4582 & $-0.178 \%$ \\
\hline & & (110) & 77.599 & 0.4176 & 304 & $-67.42 \%$ & 2.4586 & $-0.089 \%$ \\
\hline & & $(200)$ & 92.762 & 1.3625 & 88 & $-77.26 \%$ & 2.4572 & $-0.160 \%$ \\
\hline \multirow{6}{*}{1500} & \multirow{6}{*}{1.55} & $(002)$ & 26.438 & 0.4618 & 209 & $-47.49 \%$ & 6.7370 & $0.116 \%$ \\
\hline & & (004) & 54.445 & 0.9079 & 105 & $-40.68 \%$ & 6.7356 & $0.131 \%$ \\
\hline & & (006) & 86.634 & 2.1553 & 52 & $-49.51 \%$ & 6.7368 & $0.205 \%$ \\
\hline & & $(100)$ & 42.373 & 0.6124 & 156 & $-51.85 \%$ & 2.4611 & $-0.061 \%$ \\
\hline & & $(110)$ & 77.545 & 0.3607 & 371 & $-60.24 \%$ & 2.4602 & $-0.024 \%$ \\
\hline & & $(200)$ & 92.634 & 1.3322 & 90 & $-76.74 \%$ & 2.4600 & $-0.047 \%$ \\
\hline \multirow{6}{*}{1500} & \multirow{6}{*}{3.29} & $(002)$ & 26.393 & 0.5010 & 189 & $-52.51 \%$ & 6.7482 & $0.282 \%$ \\
\hline & & (004) & 54.335 & 1.0204 & 93 & $-47.46 \%$ & 6.7484 & $0.321 \%$ \\
\hline & & $(006)$ & 86.451 & 2.3394 & 48 & $-53.40 \%$ & 6.7482 & $0.375 \%$ \\
\hline & & $(100)$ & 42.402 & 0.6530 & 145 & $-55.25 \%$ & 2.4595 & $-0.127 \%$ \\
\hline & & (110) & 77.531 & 0.4295 & 293 & $-68.60 \%$ & 2.4604 & $-0.016 \%$ \\
\hline & & (200) & 92.557 & 1.6897 & 70 & $-81.91 \%$ & 2.4614 & $0.009 \%$ \\
\hline
\end{tabular}


Table 7. Summary of the peak information for irradiated NBG-17 specimens. Fitting was performed on the localized scans rather than the full-range scan.

\begin{tabular}{|c|c|c|c|c|c|c|c|c|}
\hline $\begin{array}{c}\text { Temp. } \\
\left({ }^{\circ} \mathrm{C}\right)\end{array}$ & $\begin{array}{l}\text { Dose } \\
\text { (dpa) }\end{array}$ & (hkl) & $2 \theta$ & $\begin{array}{c}\text { FWHM } \\
(2 \theta)\end{array}$ & $\begin{array}{c}\text { Crystallite } \\
\text { size } L_{c} \text { or } L_{a} \\
(\AA)\end{array}$ & $\begin{array}{l}\text { Lc or } L_{a} \\
\text { change }\end{array}$ & $\begin{array}{c}\text { Lattice } \\
\text { parameter } \\
(\AA)\end{array}$ & $\begin{array}{l}\text { Lattice } \\
\text { change }\end{array}$ \\
\hline \multirow{6}{*}{900} & \multirow{6}{*}{2.30} & (002) & 26.439 & 0.7155 & 125 & $-65.08 \%$ & 6.7368 & $0.110 \%$ \\
\hline & & (004) & 54.412 & 1.2331 & 76 & $-57.30 \%$ & 6.7392 & $0.214 \%$ \\
\hline & & $(006)$ & 86.396 & 2.1374 & 52 & $-45.26 \%$ & 6.7518 & $0.437 \%$ \\
\hline & & $(100)$ & 42.403 & 0.6675 & 141 & $-46.39 \%$ & 2.4594 & $-0.155 \%$ \\
\hline & & (110) & 77.573 & 0.3741 & 353 & $-60.34 \%$ & 2.4594 & $-0.065 \%$ \\
\hline & & (200) & 92.738 & 1.7485 & 68 & $-79.52 \%$ & 2.4577 & $-0.141 \%$ \\
\hline \multirow{6}{*}{900} & \multirow{6}{*}{3.27} & (002) & 26.409 & 0.7669 & 115 & $-67.88 \%$ & 6.7442 & $0.220 \%$ \\
\hline & & (004) & 54.330 & 1.2903 & 72 & $-59.55 \%$ & 6.7488 & $0.357 \%$ \\
\hline & & $(006)$ & 86.270 & 3.1186 & 35 & $-63.16 \%$ & 6.7596 & $0.553 \%$ \\
\hline & & $(100)$ & 42.426 & 0.8313 & 110 & $-58.17 \%$ & 2.4581 & $-0.206 \%$ \\
\hline & & $(110)$ & 77.585 & 0.4481 & 277 & $-68.88 \%$ & 2.4590 & $-0.081 \%$ \\
\hline & & $(200)$ & 92.732 & 1.7561 & 68 & $-79.52 \%$ & 2.4579 & $-0.131 \%$ \\
\hline \multirow{6}{*}{1500} & \multirow{6}{*}{1.55} & $(002)$ & 26.408 & 0.5046 & 187 & $-47.77 \%$ & 6.7446 & $0.226 \%$ \\
\hline & & (004) & 54.374 & 0.9966 & 95 & $-46.63 \%$ & 6.7436 & $0.280 \%$ \\
\hline & & $(006)$ & 86.594 & 2.7202 & 41 & $-56.84 \%$ & 6.7392 & $0.250 \%$ \\
\hline & & $(100)$ & 42.380 & 0.6387 & 148 & $-43.73 \%$ & 2.4608 & $-0.098 \%$ \\
\hline & & $(110)$ & 77.542 & 0.4113 & 310 & $-65.17 \%$ & 2.4602 & $-0.033 \%$ \\
\hline & & $(200)$ & 92.719 & 0.7350 & 174 & $-47.59 \%$ & 2.4581 & $-0.122 \%$ \\
\hline \multirow{6}{*}{1500} & \multirow{6}{*}{3.29} & (002) & 26.367 & 0.5032 & 188 & $-47.49 \%$ & 6.7548 & $0.377 \%$ \\
\hline & & (004) & 54.321 & 0.9758 & 97 & $-45.51 \%$ & 6.7496 & $0.369 \%$ \\
\hline & & $(006)$ & 86.518 & 2.2640 & 49 & $-48.42 \%$ & 6.7440 & $0.321 \%$ \\
\hline & & $(100)$ & 42.391 & 0.7925 & 116 & $-55.89 \%$ & 2.4601 & $-0.127 \%$ \\
\hline & & $(110)$ & 77.535 & 0.4624 & 266 & $-70.11 \%$ & 2.4604 & $-0.024 \%$ \\
\hline & & $(200)$ & 92.663 & 2.0127 & 59 & $-82.23 \%$ & 2.4593 & $-0.075 \%$ \\
\hline
\end{tabular}


Table 8. Summary of the peak information for irradiated NBG-18 specimens. Fitting was performed on the localized scans rather than the full-range scan.

\begin{tabular}{|c|c|c|c|c|c|c|c|c|}
\hline $\begin{array}{c}\text { Temp. } \\
\left({ }^{\circ} \mathrm{C}\right)\end{array}$ & $\begin{array}{l}\text { Dose } \\
\text { (dpa) }\end{array}$ & (hkl) & $2 \theta$ & $\begin{array}{c}\text { FWHM } \\
(2 \theta)\end{array}$ & $\begin{array}{c}\text { Crystallite } \\
\text { Size } \mathbf{L}_{c} \text { or } \mathbf{L}_{a} \\
(\AA)\end{array}$ & $\begin{array}{l}\text { Lc or La } \\
\text { Change }\end{array}$ & $\begin{array}{c}\text { Lattice } \\
\text { Parameter } \\
(\AA)\end{array}$ & $\begin{array}{l}\text { Lattice } \\
\text { Change }\end{array}$ \\
\hline \multirow{6}{*}{900} & \multirow{6}{*}{2.30} & (002) & 26.434 & 0.7048 & 127 & $-65.30 \%$ & 6.7382 & $0.119 \%$ \\
\hline & & (004) & 54.379 & 1.2233 & 76 & $-57.54 \%$ & 6.7432 & $0.238 \%$ \\
\hline & & $(006)$ & 86.243 & 3.7325 & 29 & $-71.57 \%$ & 6.7614 & $0.508 \%$ \\
\hline & & $(100)$ & 42.404 & 0.7816 & 118 & $-59.45 \%$ & 2.4594 & $-0.117 \%$ \\
\hline & & (110) & 77.572 & 0.3982 & 324 & $-64.67 \%$ & 2.4594 & $-0.065 \%$ \\
\hline & & (200) & 92.741 & 0.8180 & 154 & $-44.60 \%$ & 2.4577 & $-0.150 \%$ \\
\hline \multirow{6}{*}{900} & \multirow{6}{*}{3.27} & (002) & 26.407 & 0.7696 & 115 & $-68.58 \%$ & 6.7448 & $0.217 \%$ \\
\hline & & (004) & 54.345 & 1.3274 & 70 & $-60.89 \%$ & 6.7472 & $0.297 \%$ \\
\hline & & $(006)$ & 86.073 & 3.6468 & 30 & $-70.59 \%$ & 6.7722 & $0.669 \%$ \\
\hline & & $(100)$ & 42.430 & 0.9068 & 100 & $-65.64 \%$ & 2.4579 & $-0.178 \%$ \\
\hline & & $(110)$ & 77.581 & 0.4660 & 263 & $-71.32 \%$ & 2.4592 & $-0.073 \%$ \\
\hline & & $(200)$ & 92.763 & 1.9044 & 62 & $-77.70 \%$ & 2.4572 & $-0.169 \%$ \\
\hline \multirow{6}{*}{1500} & \multirow{6}{*}{1.55} & $(002)$ & 26.415 & 0.4963 & 191 & $-47.81 \%$ & 6.7428 & $0.187 \%$ \\
\hline & & (004) & 54.378 & 0.9812 & 97 & $-45.81 \%$ & 6.7432 & $0.238 \%$ \\
\hline & & (006) & 86.603 & 2.1002 & 53 & $-48.04 \%$ & 6.7386 & $0.169 \%$ \\
\hline & & $(100)$ & 42.389 & 0.5982 & 160 & $-45.02 \%$ & 2.4602 & $-0.084 \%$ \\
\hline & & $(110)$ & 77.536 & 0.3970 & 325 & $-64.56 \%$ & 2.4604 & $-0.024 \%$ \\
\hline & & $(200)$ & 92.683 & 1.4908 & 80 & $-71.22 \%$ & 2.4588 & $-0.103 \%$ \\
\hline \multirow{6}{*}{1500} & \multirow{6}{*}{3.29} & $(002)$ & 26.361 & 0.5076 & 186 & $-49.18 \%$ & 6.7564 & $0.389 \%$ \\
\hline & & (004) & 54.304 & 1.0141 & 93 & $-48.04 \%$ & 6.7516 & $0.363 \%$ \\
\hline & & $(006)$ & 86.406 & 2.2357 & 50 & $-50.98 \%$ & 6.7512 & $0.357 \%$ \\
\hline & & $(100)$ & 42.425 & 0.7033 & 133 & $-54.30 \%$ & 2.4582 & $-0.164 \%$ \\
\hline & & $(110)$ & 77.540 & 0.4706 & 260 & $-71.65 \%$ & 2.4602 & $-0.033 \%$ \\
\hline & & $(200)$ & 92.676 & 1.4534 & 83 & $-70.14 \%$ & 2.4591 & $-0.094 \%$ \\
\hline
\end{tabular}


Table 9. Summary of the peak information for irradiated PCEA specimens. Fitting was performed on the localized scans rather than the full-range scan.

\begin{tabular}{|c|c|c|c|c|c|c|c|c|}
\hline $\begin{array}{c}\text { Temp. } \\
\left({ }^{\circ} \mathrm{C}\right)\end{array}$ & $\begin{array}{l}\text { Dose } \\
\text { (dpa) }\end{array}$ & (hkl) & $2 \theta$ & $\begin{array}{c}\text { FWHM } \\
(2 \theta)\end{array}$ & $\begin{array}{c}\text { Crystallite } \\
\text { Size } L_{c} \text { or La } \\
(\AA)\end{array}$ & $\begin{array}{l}\text { Lc or La } \\
\text { Change }\end{array}$ & $\begin{array}{c}\text { Lattice } \\
\text { Parameter } \\
(\AA)\end{array}$ & $\begin{array}{l}\text { Lattice } \\
\text { Change }\end{array}$ \\
\hline \multirow{6}{*}{900} & \multirow{6}{*}{2.30} & $(002)$ & 26.457 & 0.5765 & 160 & $-69.64 \%$ & 6.7324 & $-0.006 \%$ \\
\hline & & (004) & 54.419 & 1.0699 & 88 & $-62.87 \%$ & 6.7388 & $0.113 \%$ \\
\hline & & (006) & 86.637 & 2.2132 & 50 & $-64.29 \%$ & 6.7368 & $0.098 \%$ \\
\hline & & $(100)$ & 42.402 & 0.4390 & 233 & $-42.61 \%$ & 2.4595 & $-0.108 \%$ \\
\hline & & (110) & 77.583 & 0.3212 & 441 & $-55.90 \%$ & 2.4590 & $-0.081 \%$ \\
\hline & & $(200)$ & 92.656 & 0.7056 & 182 & $-35.69 \%$ & 2.4595 & $-0.056 \%$ \\
\hline \multirow{6}{*}{900} & \multirow{6}{*}{3.27} & (002) & 26.440 & 0.6637 & 136 & $-74.19 \%$ & 6.7364 & $0.053 \%$ \\
\hline & & (004) & 54.358 & 1.1814 & 79 & $-66.67 \%$ & 6.7456 & $0.214 \%$ \\
\hline & & $(006)$ & 86.311 & 3.5766 & 31 & $-77.86 \%$ & 6.7572 & $0.401 \%$ \\
\hline & & $(100)$ & 42.415 & 0.5863 & 164 & $-59.61 \%$ & 2.4588 & $-0.136 \%$ \\
\hline & & $(110)$ & 77.596 & 0.4036 & 318 & $-68.20 \%$ & 2.4588 & $-0.089 \%$ \\
\hline & & (200) & 92.772 & 1.7712 & 67 & $-76.33 \%$ & 2.4570 & $-0.160 \%$ \\
\hline \multirow{6}{*}{1500} & \multirow{6}{*}{1.55} & $(002)$ & 26.439 & 0.4006 & 250 & $-52.56 \%$ & 6.7370 & $0.062 \%$ \\
\hline & & (004) & 54.426 & 0.7665 & 127 & $-46.41 \%$ & 6.7376 & $0.095 \%$ \\
\hline & & (006) & 86.716 & 1.5999 & 71 & $-49.29 \%$ & 6.7320 & $0.027 \%$ \\
\hline & & $(100)$ & 42.358 & 0.4815 & 207 & $-49.01 \%$ & 2.4619 & $-0.009 \%$ \\
\hline & & $(110)$ & 77.540 & 0.3381 & 408 & $-59.20 \%$ & 2.4602 & $-0.033 \%$ \\
\hline & & $(200)$ & 92.633 & 0.6334 & 206 & $-27.21 \%$ & 2.4600 & $-0.038 \%$ \\
\hline \multirow{6}{*}{1500} & \multirow{6}{*}{3.29} & $(002)$ & 26.389 & 0.4777 & 200 & $-62.05 \%$ & 6.7492 & $0.244 \%$ \\
\hline & & (004) & 54.315 & 0.9560 & 99 & $-58.23 \%$ & 6.7504 & $0.285 \%$ \\
\hline & & (006) & 86.386 & 2.2108 & 50 & $-64.29 \%$ & 6.7524 & $0.330 \%$ \\
\hline & & $(100)$ & 42.418 & 0.6678 & 141 & $-65.27 \%$ & 2.4586 & $-0.145 \%$ \\
\hline & & $(110)$ & 77.537 & 0.4335 & 289 & $-71.10 \%$ & 2.4604 & $-0.024 \%$ \\
\hline & & $(200)$ & 92.674 & 1.6574 & 72 & $-74.56 \%$ & 2.4591 & $-0.075 \%$ \\
\hline
\end{tabular}

\subsubsection{Structure Changes}

The irradiation-induced crystal structure changes of interest in graphite include changes to the lattice parameter in the $<\mathrm{a}>$ and $<\mathrm{c}>$ directions and the changes to the crystallite dimensions (coherent domain lengths). Traditionally, the changes in the lattice parameters have been calculated from the peak locations of the (002) and (110) XRD peaks, and the crystallite dimensions have been calculated from the widths of these two peaks, since neither peak has any overlap with a second peak that can cause issues with deconvolution. The calculated values for the post-irradiation lattice parameters and crystallite size, and the net change from the pre-irradiation values, are listed in Table 6 - Table 9. These same changes are plotted versus neutron damage for grade-to-grade and temperature effect comparison in lattice parameters in Figure 8 and Figure 9 and for crystallite size in Figure 10 and Figure 11. 

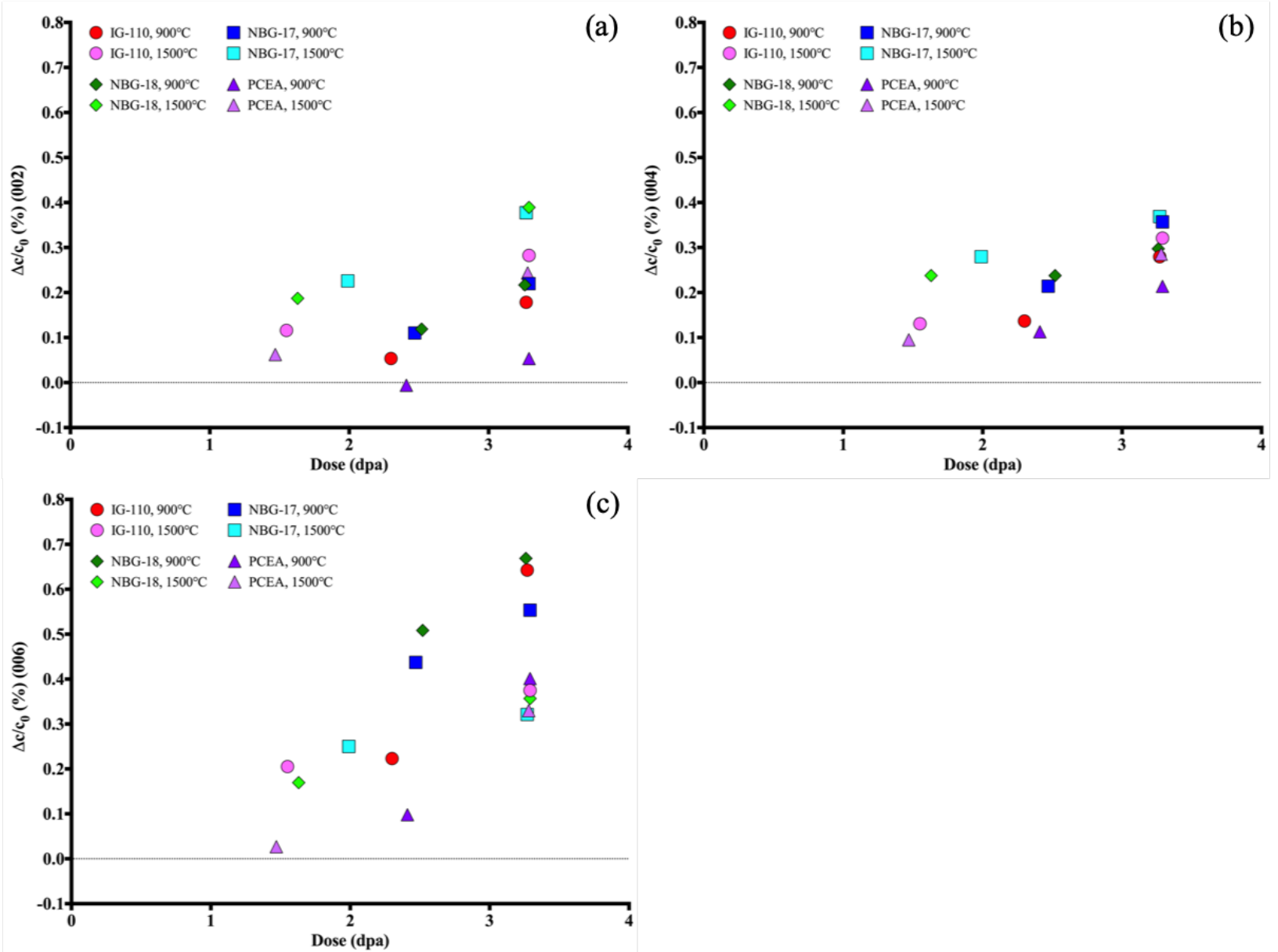

Figure 8. Change of c-direction spacing due to neutron irradiation, measured from the (a) (002), (b) (004), and (c) (006) diffraction peaks. 

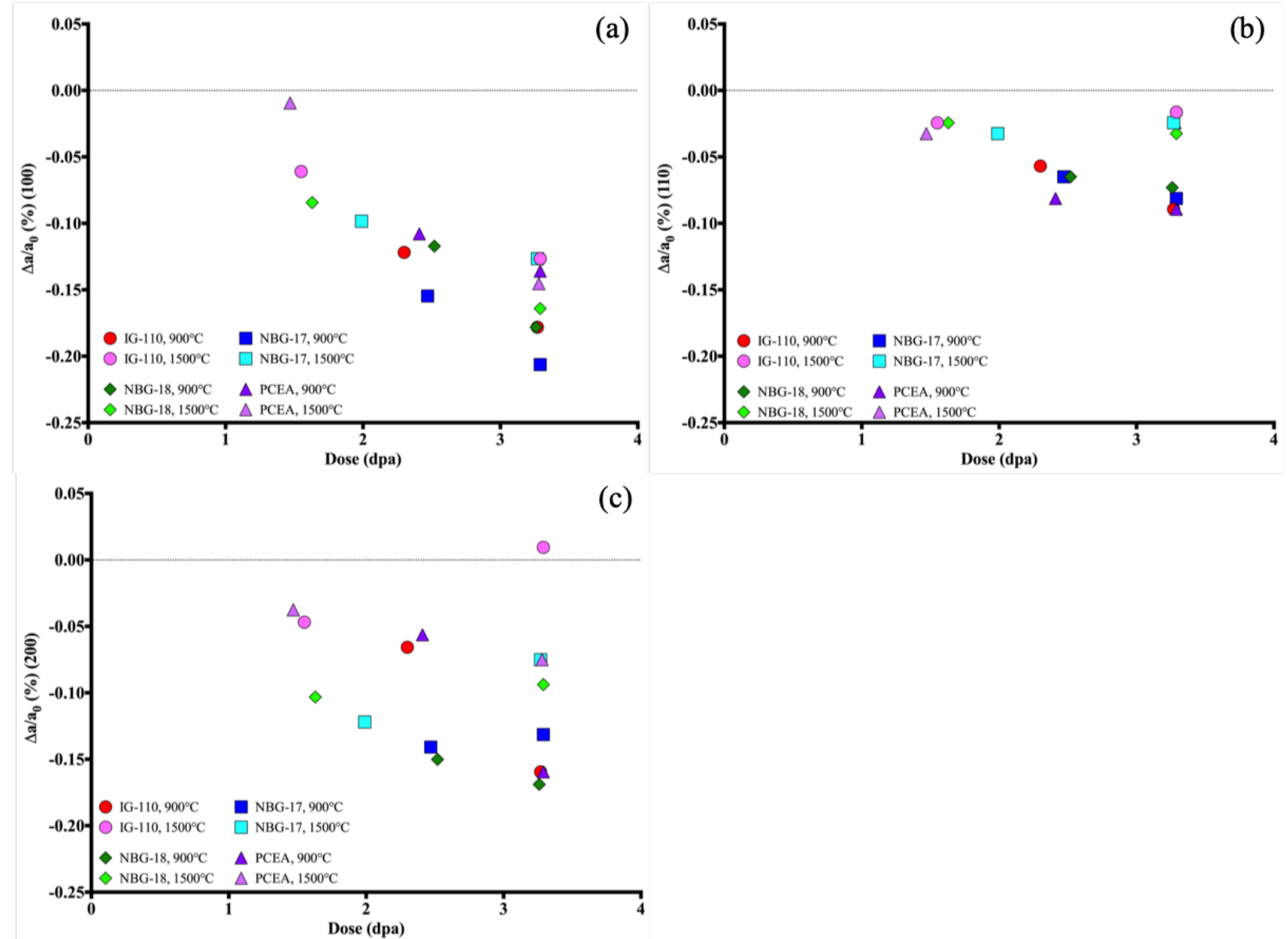

Figure 9. Change of a-direction spacing due to neutron irradiation, measured from the (a) (100), (b) (110), and (c) (200) diffraction peaks. 

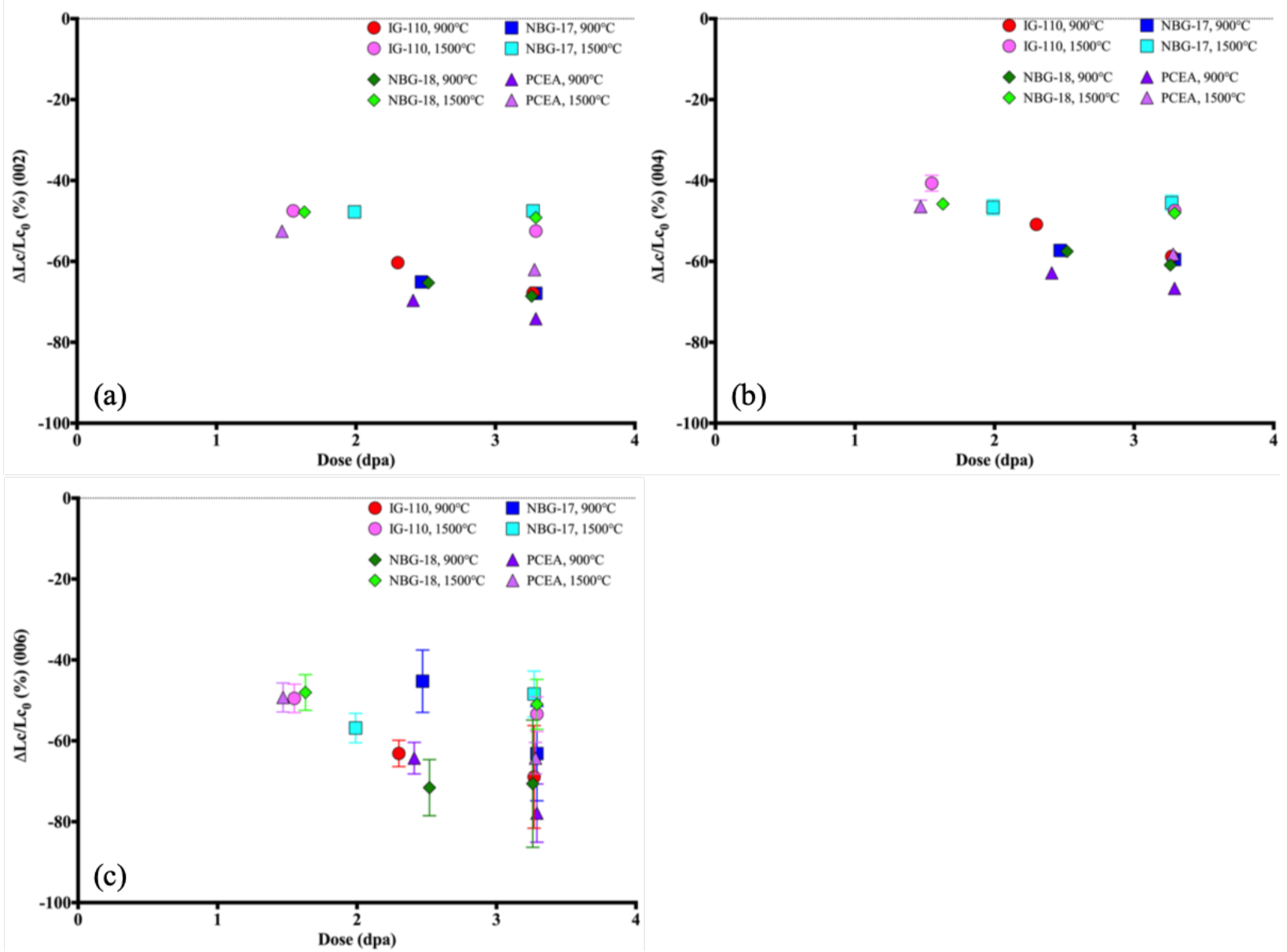

Figure 10. Net change of c-direction crystallite size due to neutron irradiation, measured from the (a) (002), (b) (004), and (c) (006) diffraction peaks. 

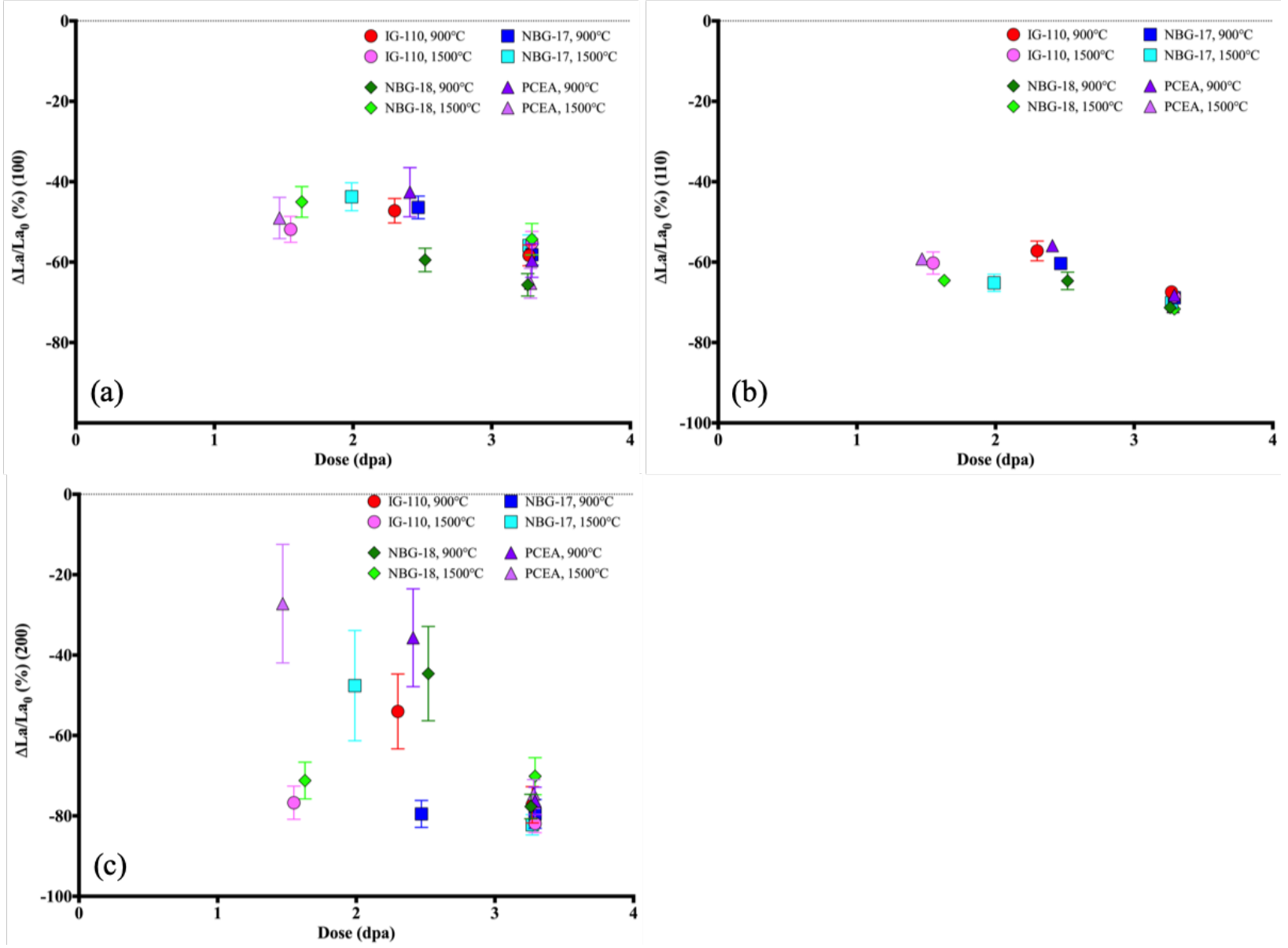

Figure 11. Net change of a-direction crystallite size due to neutron irradiation, measured from the (a) (100), (b) (110), and (c) (200) diffraction peaks.

The $<\mathrm{c}>$ direction spacing expanded, while the $<\mathrm{a}>$ direction contracted, with neutron irradiation for both temperatures. This phenomenon has been observed numerous times in the historical research. From Figure 8, it is interesting to observe that the $<\mathrm{c}>$ spacing growth from the (002) peak shows that the $1500^{\circ} \mathrm{C}$ expansion is greater than the $900^{\circ} \mathrm{C}$ expansion, and that the expansion in NBG-17 and NBG-18 is consistently larger than in IG-110 and PCEA. For the (004) peak, the $<\mathrm{c}>$ growth is more similar for all the grades at both temperatures. While for the (006) peak, the growth at $900^{\circ} \mathrm{C}$ is larger than at $1500^{\circ} \mathrm{C}$, there is a large grade-to-grade variation at $900^{\circ} \mathrm{C}$; but at the highest dose for $1500^{\circ} \mathrm{C}$, the net growth is nearly grade independent. It is interesting that the changes observed for these peaks were different- the changes would be assumed to be the same since they are all from the same reflection. The most likely cause of this difference was the effect of radiation defects on the long-range order. If the defects only slightly modified the c-spacing, then the changes to the (002) peak should be the most severe, while changes to the (006) peak suggested larger defects that modified the long-range structure. The change of the (002) peak is typically used for most analyses, because it is the most intense and easiest to capture. The net change from the (002) and (004) peaks was similar and was expected to be more accurate because these are both stand-alone peaks, whereas (006) must be deconvoluted from the (112) peak. For all the peaks, the net $<\mathrm{c}>$ spacing growth increased with increasing dose at both temperatures.

Figure 9 shows the changes to the $<\mathrm{a}>$ direction spacing for the (100), (110), and (200) peaks. For all three peaks, the net reduction of the $<\mathrm{a}>$ spacing was lower at $1500^{\circ} \mathrm{C}$ than at $900^{\circ} \mathrm{C}$. In the $(100)$ analysis, the net reduction increased with dose for both temperatures, whereas for (110), the reduction at 
$1500^{\circ} \mathrm{C}$ was constant with dose and the reduction at $900^{\circ} \mathrm{C}$ was slight. In the (200) analysis, the $900^{\circ} \mathrm{C}$ reduction increased with dose, while the $1500^{\circ} \mathrm{C}$ contraction was reduced at a higher dose. It is also interesting to note that the net change in the (100) and (200) directions was significantly larger than the change in the (110) direction.

The net change of the crystallite size in the $<\mathrm{c}>$ direction, calculated by the Scherrer equation for each peak, is plotted in Figure 10. Unlike the c-spacing change, the net change in crystallite size is fairly consistent from the three diffraction peaks. At $900^{\circ} \mathrm{C}$, the crystallite size shows a slight decrease with increasing dose, while at $1500^{\circ} \mathrm{C}$ the reduction appears to have reached a plateau value. Another trend is that the size reduction is nearly the same for IG-110, NBG-17, and NBG-18, while PCEA has a larger reduction. This was because the starting $<\mathrm{c}>$ direction crystallite size in PCEA was $\sim 50 \%$ larger than in the other three grades, whereas after irradiation, the crystallite size of all three grades was similar.

The change in the $<\mathrm{a}>$ direction crystallite size with increasing neutron damage is plotted in Figure 11. The net changes from the (100) peak show a slight reduction in size with increasing damage, and for (110), this reduction is almost negligible. The scatter from the (200) peak is much larger; most likely, the scatter is larger because the relatively low intensity of the (200) peak causes a higher uncertainty.

The changes in the crystallite sizes from the multiple peaks are plotted versus neutron damage in Figure 12 and Figure 13. The range of pre-irradiation crystallite sizes between grades is dramatic, from as large as a $54 \%$ difference from the (100) peak to as little as a $12 \%$ difference from the (110) peak. In the cdirection, the crystallite sizes at high fluences are nearly identical between grades, and the high-damage sizes are larger for the higher irradiation temperature. In the a-direction, the crystallite sizes are similar between grades at the high-damage sizes, and there does not appear to be a temperature effect like that in the c-direction. 

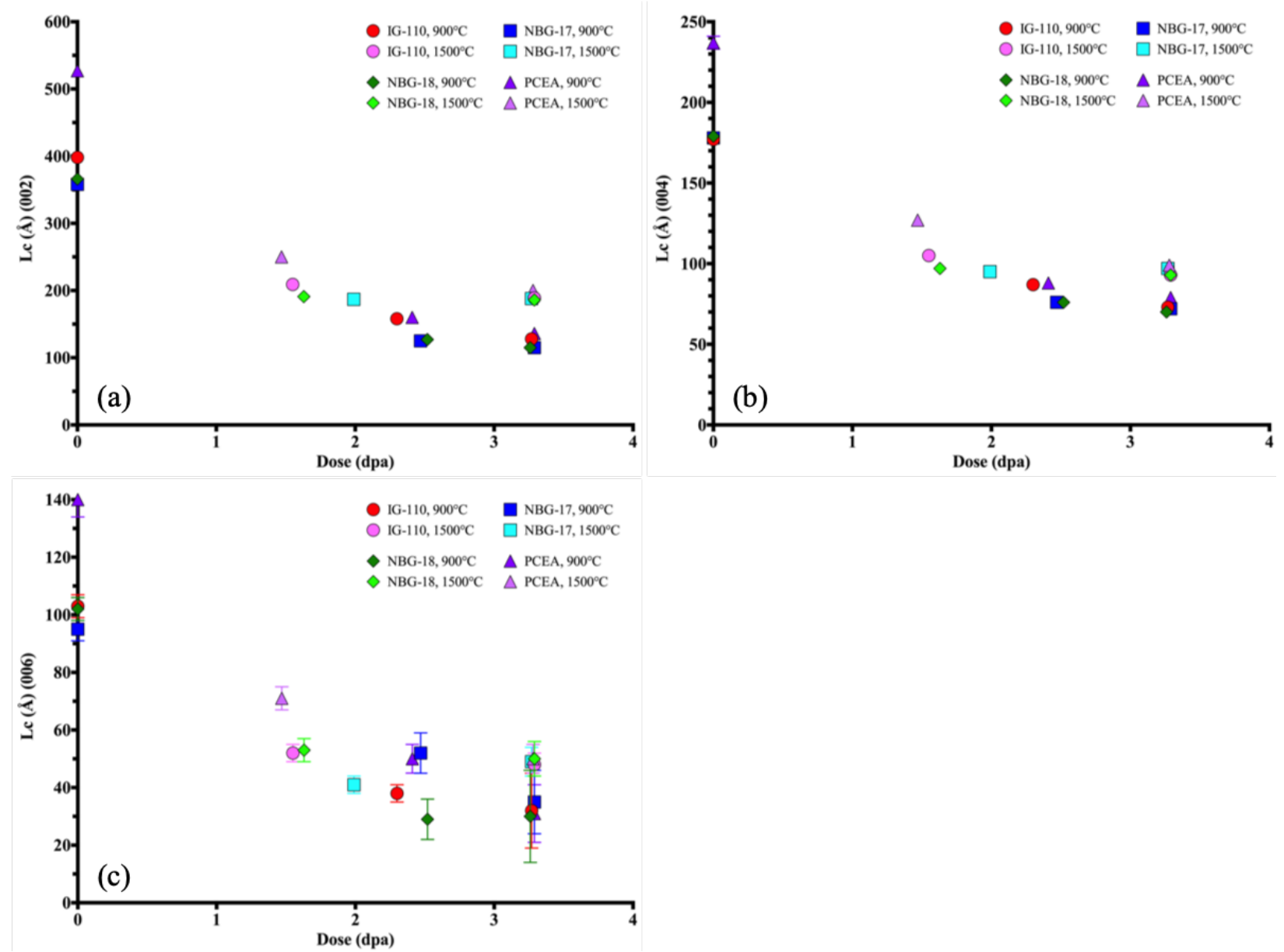

Figure 12. c-direction crystallite size due to neutron irradiation, measured from the (a) (002), (b) (004), and (c) (006) diffraction peaks. 

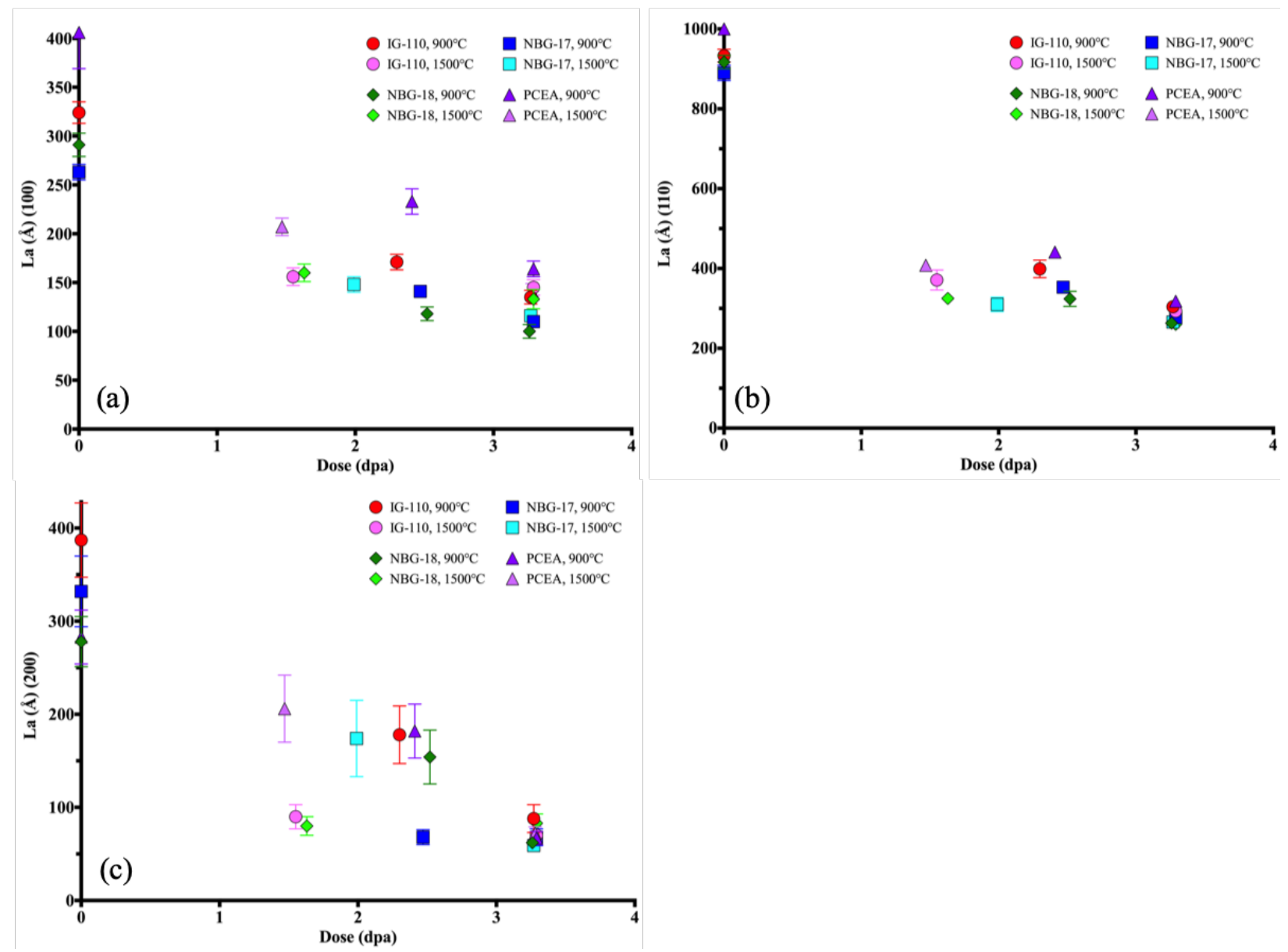

Figure 13. a-direction crystallite size due to neutron irradiation, measured from the (a) (100), (b) (110), and (c) (200) diffraction peaks.

\subsubsection{Williamson-Hall Analysis}

As mentioned previously, the Williamson-Hall analysis is easily applied for isotropic crystal structures; but in anisotropic systems like graphite, the analysis must be implemented by a slightly different method. In isotropic crystals, all the peaks are combined for a single analysis; but in anisotropic crystals, the analysis must be done for peaks with contributions from the $<\mathrm{a}>$ or $<\mathrm{c}>$ directions only. Figure 14 shows the Williamson-Hall plots for the four graphite grades, with points labeled with the diffraction peak indices. 

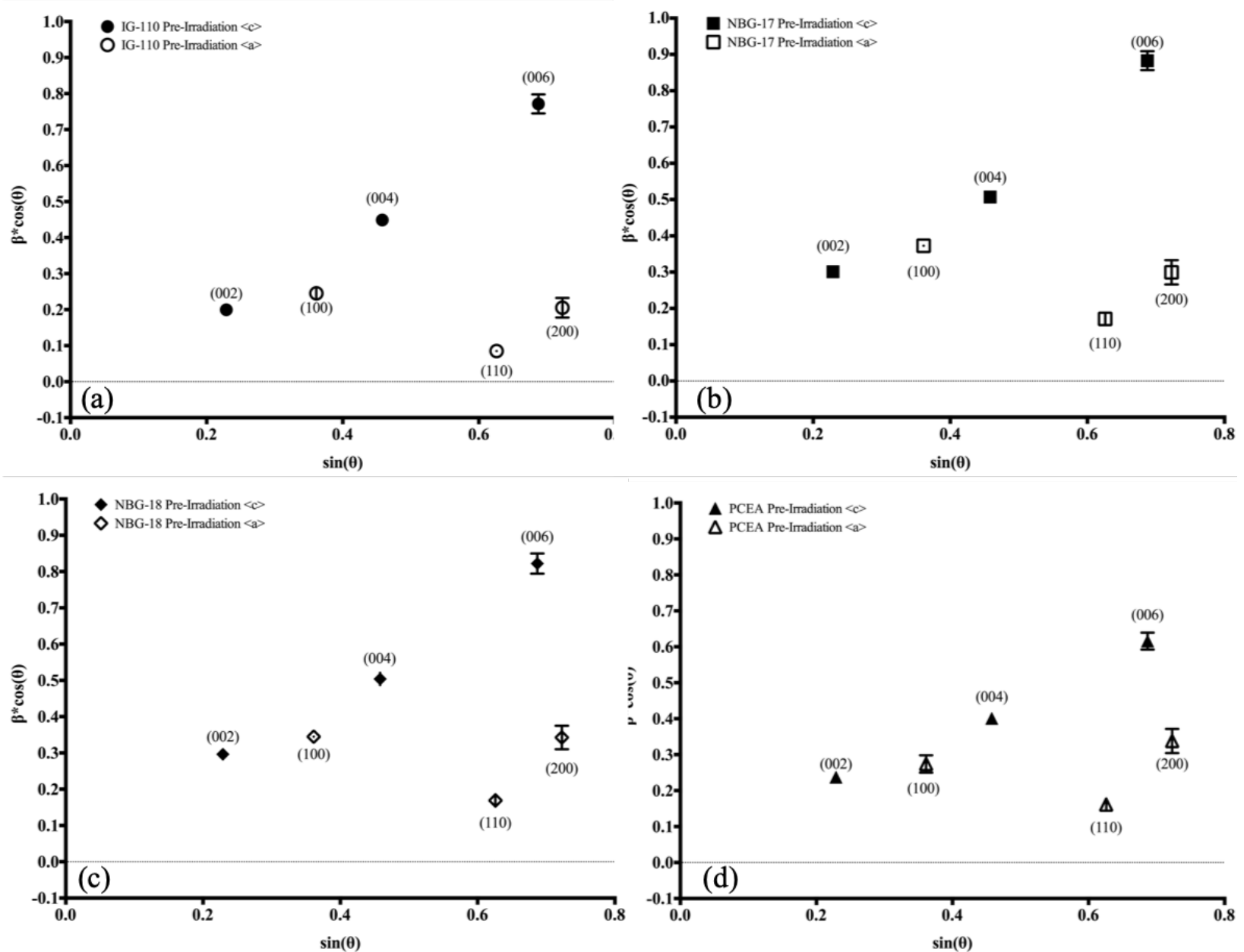

Figure 14. Williamson-Hall plots of (a) IG-110, (b) NBG-17, (c) NBG-18, and (d) PCEA.

The line fit of the Williamson-Hall points can be one of three options: (1) a line fit with the slope and intercept as variables, (2) a line fit with the intercept set to 0 , and (3) a line fit with a slope of 0 (constant). If either of the single-parameter fits has a similar or better fit to the two-parameter fit, then it is the better descriptor of the data. In all four grades, the points from the (002), (004), and (006) peaks fell on a line that is best described with a line fit through $y=0$. This indicated that all of the peak broadening of the preirradiation specimens was due to lattice strain and not crystallite size. Conversely, the two points from (100) and (200) are best described by a constant value, which indicates that the peak broadening is caused only by crystallite size reduction, but conclusions are difficult when there are only two data points available for analysis. The (110) peak was consistently lower than the (100) and (200) peaks, so it was not included in the analysis for the $<\mathrm{a}>$ direction. The three line fits for both the $<\mathrm{a}>$ and $<\mathrm{c}>$ direction data are plotted for each grade in Figure 15, where the lines best describing the data are shown in black. The summary of the linear fits of each set is given in Appendix A. 

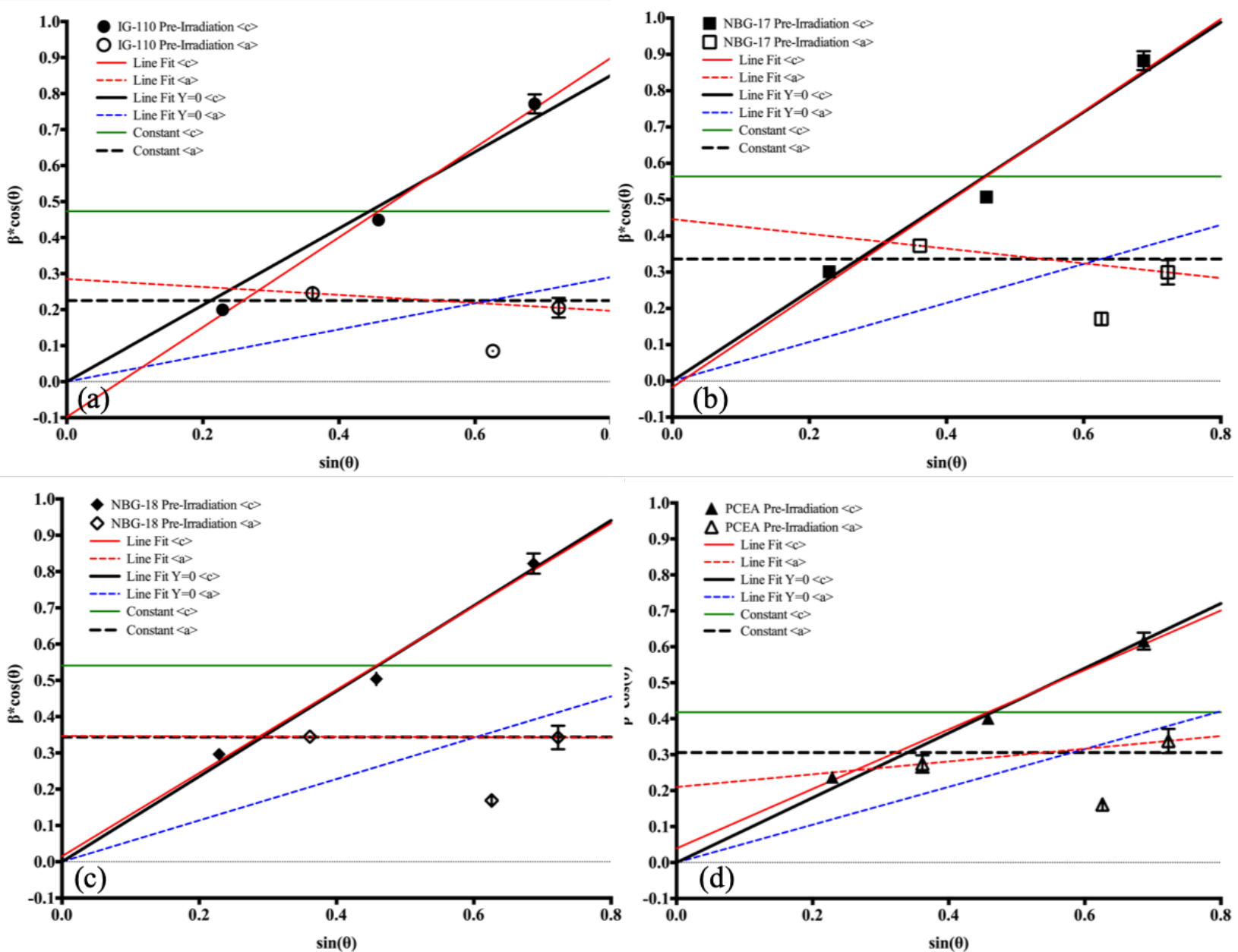

Figure 15. Williamson-Hall plots of (a) IG-110, (b) NBG-17, (c) NBG-18, and (d) PCEA with different conditional linear fits to the data.

The effects of irradiation on the Williamson-Hall plots for the four grades are shown in Figure 16 to Figure 19. For IG-110, NBG-18, and PCEA, the c-direction broadening due to crystal strain increased with irradiation, with the increase at $900^{\circ} \mathrm{C}$ being larger than that at $1500^{\circ} \mathrm{C}$. NBG-17 had more of a general scatter. For the a-direction broadening, some of the broadening in low-damage samples was due mainly to crystallite size; but in most cases, the broadening appears to have gained a strain-induced component. It was difficult to get a meaningful fit with only two data points for the $<a>$ direction, but they did suggest that strain becomes an issue after irradiation. The (110) peak also broadened as a result of irradiation. 

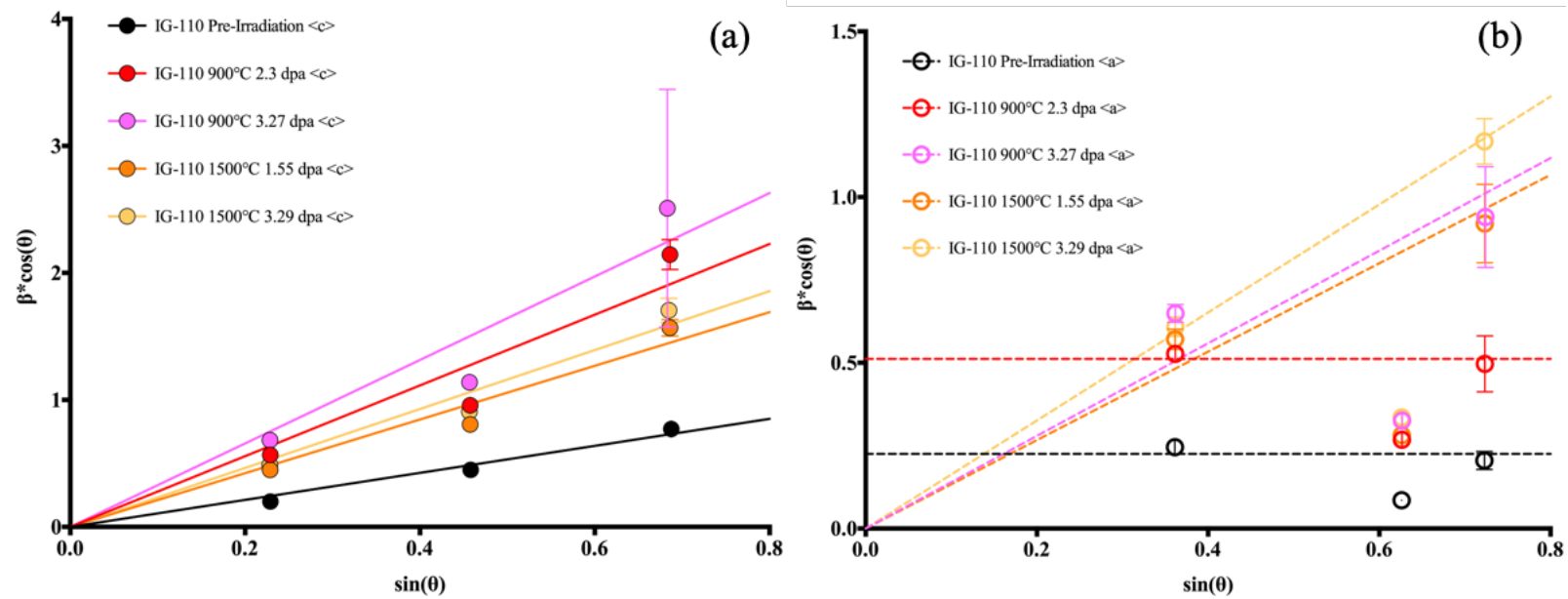

Figure 16. Williamson-Hall plots for IG-110 for the (a) (002), (004), and (006) peaks and the (b) (100), (110), and (200) peaks.
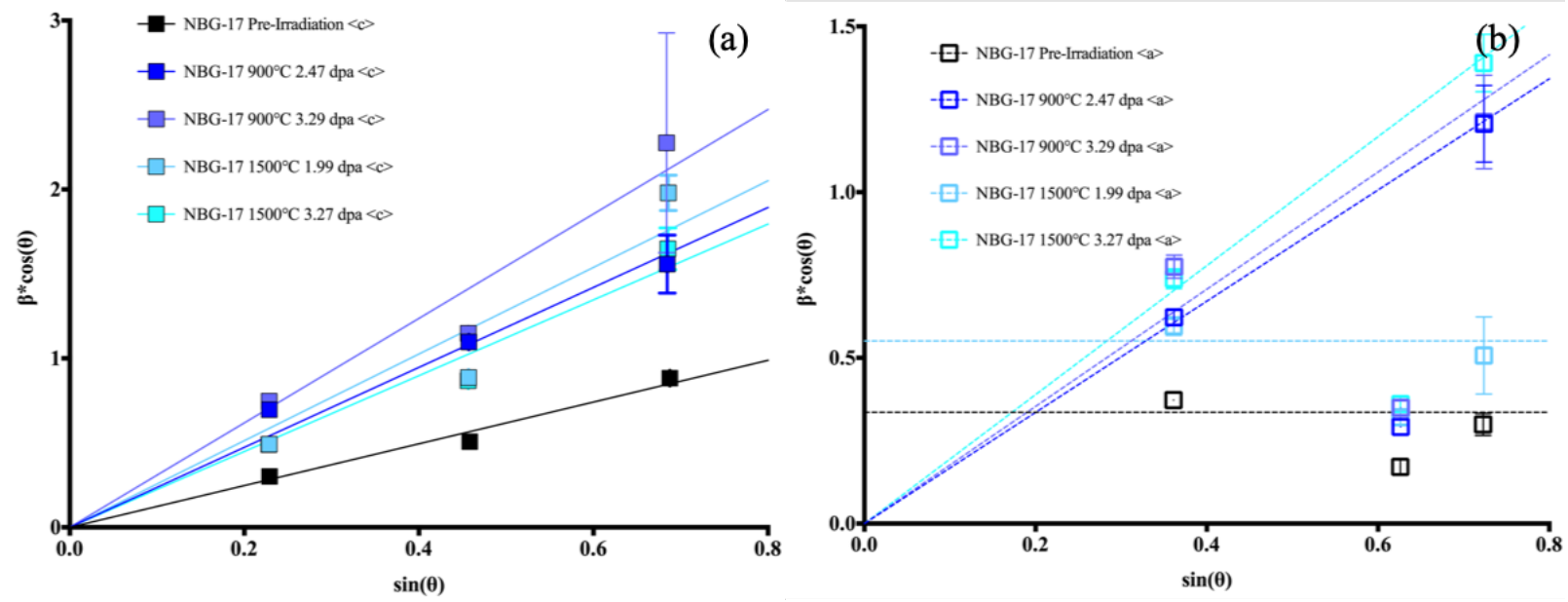

Figure 17. Williamson-Hall plots for NBG-17 for the (a) (002), (004), and (006) peaks and the (b) (100), (110), and (200) peaks. 

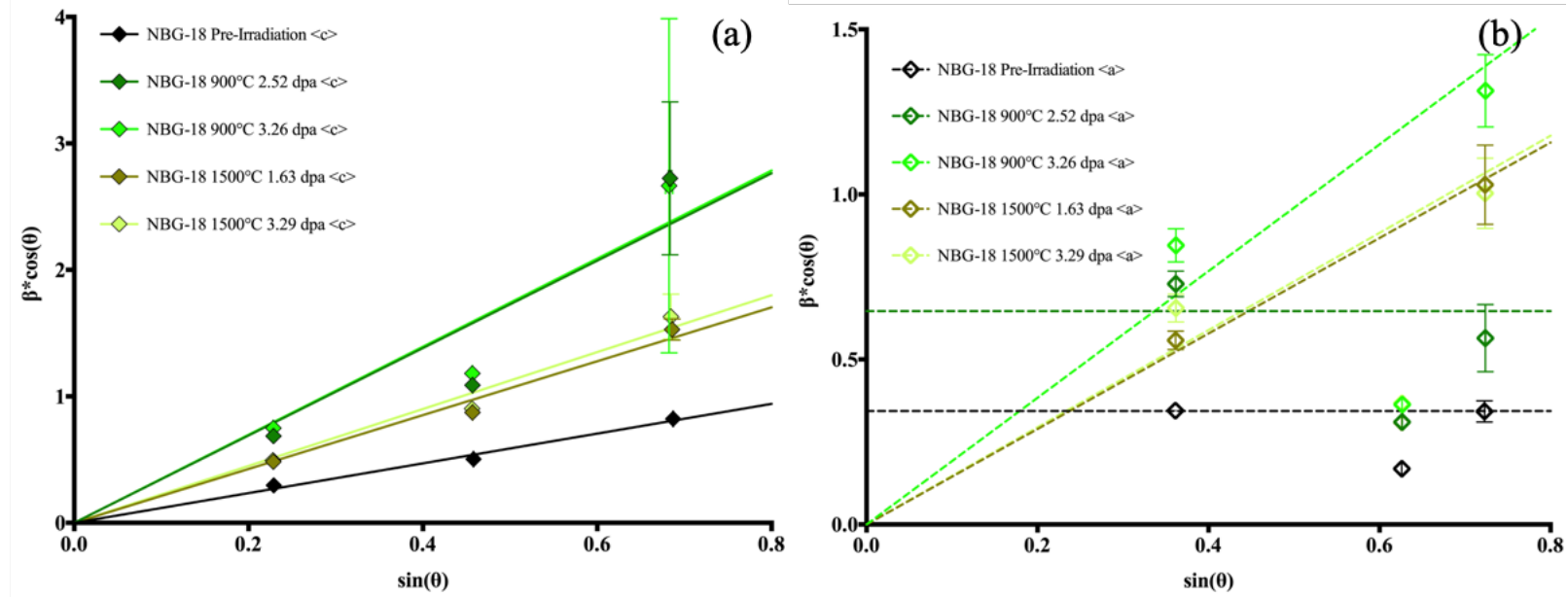

Figure 18. Williamson-Hall plots for NBG-18 for the (a) (002), (004), and (006) peaks and the (b) (100), (110), and $(200)$ peaks.
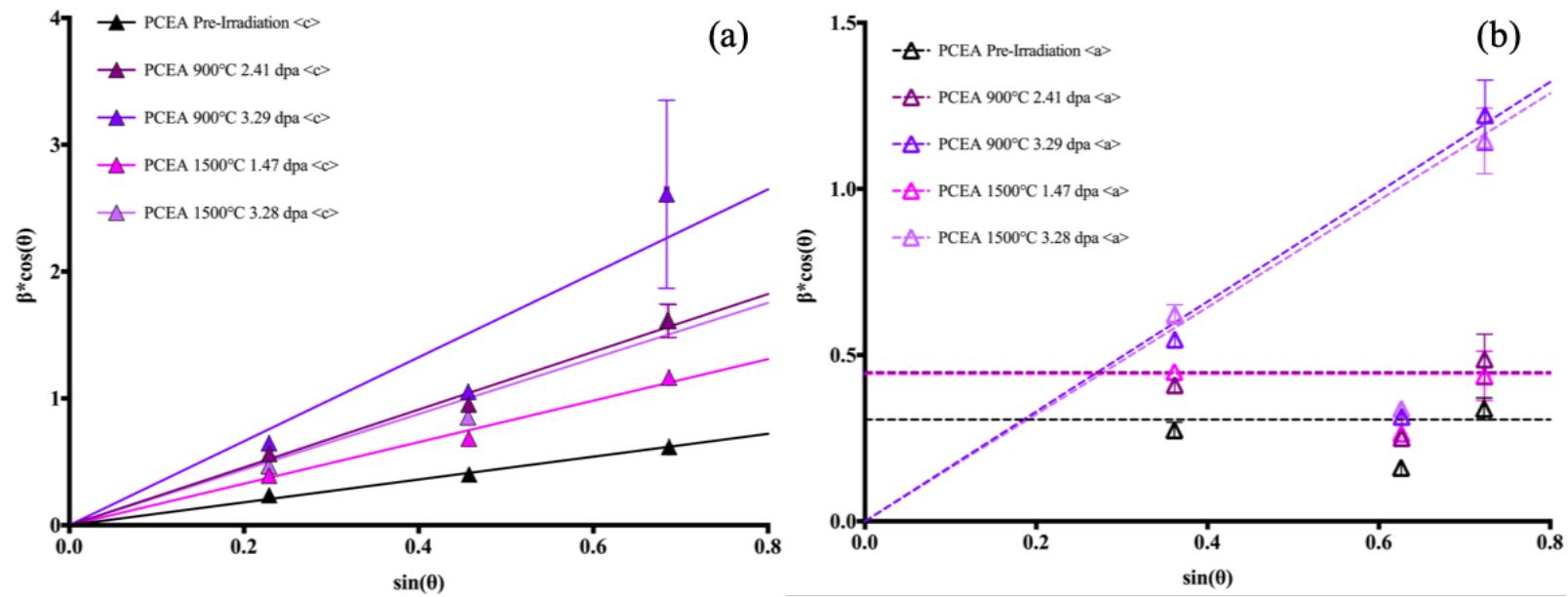

Figure 19. Williamson-Hall plots for PCEA for the (a) (002), (004), and (006) peaks and the (b) (100), (110), and (200) peaks.

These results suggest that a majority of the peak broadening was a result of lattice strain in the c-direction both before and after irradiation, and in the a-direction after irradiation. These observations require further discussions of the results, and possible analysis of the Williamson-Hall results is necessary prior to drawing any significant conclusions. The following are some of the questions that remain to be answered:

1. What is the analysis procedure when the line fit to the data has a negative intercept?

2. If the best-fit is a line through $\mathrm{y}=0$, then what is the crystallite size?

3. If, at higher dose, a strain component arises, should the y-intercept be larger than the pre-irradiation intercept? 


\subsection{NITROGEN ADSORPTION}

\subsubsection{Microstructural Information Available from Nitrogen Adsorption Measurements}

The nitrogen adsorption technique, also referred to improperly as "the BET method," provides much more microstructural information than the value of the surface area in open pores, routinely calculated by the procedure developed by Brunauer, Emmett and Teller in 1938 [9]. Nitrogen adsorption can also provide the total volume of open pores (up to $\sim 300 \mathrm{~nm}$ width), the distribution of open pore volumes by their width in the range of micropores $(<2 \mathrm{~nm})$ and mesopores $(2-50 \mathrm{~nm})$, information on the occurrence and shape of mesopores, total surface area and distribution by pore width of micropores and narrow mesopores $(<20 \mathrm{~nm})$, and information on the types of adsorption sites and their adsorption energies on gas-accessible surfaces inside the pores. All these properties are expected to change after irradiation in a manner that depends on the type of graphite, irradiation dose, and temperatures. A detailed summary of the results of the following analyses is provided in APPENDIX A.

\subsubsection{Total surface area}

The BET surface area is the total area in internal (and external) surfaces accessible to gas. It is calculated directly from the adsorbed amounts and their corresponding relative pressure values $\left(\mathrm{P} / \mathrm{P}_{0}\right)$ according to the BET equation:

$$
\text { Equation 14: } \frac{P / P_{0}}{W\left(1-P / P_{0}\right)}=\frac{1}{W_{m} C}+\frac{C-1}{W_{m} C}\left(\frac{P}{P_{0}}\right)
$$

where $W$ is the amount adsorbed per unit of mass at pressure $P, W_{m}$ is the monolayer capacity, $P_{0}$ is the saturation vapor pressure of adsorbate at the adsorption temperature and ambient barometric pressure, and $C$ is a constant that depends exponentially on the adsorption energy in the first monolayer. Plots of $1 /\left[W\left(\left(P_{0} / P\right)-1\right)\right]$ versus $P / P_{0}$ should be linear with slope $s$ and intercept $i$. The monolayer capacity is calculated from slope and intercept as $W_{m}=1 /(s+i)$, and the total surface area is calculated as

$$
\text { Equation 15: } \quad S_{B E T}=W_{m} A_{s} N / M,
$$

where $N$ is the Avogadro number, $M$ is the molecular weight of nitrogen, and $A_{s}$ is the cross-sectional area of nitrogen (normally taken as $16.2 \AA^{2}$ per molecule). The range of data points $\left(P / P_{0}\right.$ values) selected for linear regression is very important, and improper selections may lead to inaccurate results. The usual range is $0.05<P / P_{0}<0.35$, but not all data points in this range necessarily yield straight lines. We followed the four criteria recommended by Rouquerol et al. [10]: (1) selected data points must preferably be in the range $0.05-0.35$ of $P / P_{0}$; (2) they must be in the range of continuously increasing plots of $W(1$ $\left(P / P_{0}\right)$ ) versus $P / P_{0}$ but not beyond its maximum; (3) the intercept $i$ must be positive; and (4) the relative pressure corresponding to the monolayer $\left(P / P_{0}\right)_{m}=1 /(\sqrt{C}+1)$ must be within the range of selected data points. These criteria, when uniformly applied, reduce the uncertainty caused by any other arbitrary selection of data points. In the case of nuclear graphite, with a low $C$ constant (weak $\mathrm{N}_{2}$ adsorption) and low surface area, small variations in the range of data points selected cause large differences between the $S_{B E T}$ results. Based on discussions in the recent literature, in such situations, it is preferable to accept just a few data points (at least three) that obey these criteria even though the $R^{2}$ correlation coefficient may not be the highest (but should always be larger than 0.995). The other option, selecting many data points to maximize $R^{2}$ (because of the larger statistical base) may give incorrect $S_{B E T}$ information if not all of the above criteria have been met. 


\subsubsection{Total volume of open pores}

The amount of nitrogen condensed as liquid at the highest pressure $\left(\mathrm{P} / \mathrm{P}_{0}=1\right)$ of measurements is used to calculate the total pore volume $\left(V_{t o t}\right)$ in open pores. It includes all classes of pores with widths of less than about $350 \mathrm{~nm}$. Larger pores do not allow condensation of liquid nitrogen (because of liquid surface tension and low wettability of carbon); therefore, they behave as flat surfaces and cannot be detected. For that reason, $V_{\text {tot }}$ based on nitrogen condensation may be lower than the total pore volumes measured by helium pycnometry and mercury intrusion.

\subsubsection{Micropores and mesopores}

Classical methods for analysis of porosity are based on macroscopic models of condensation and evaporation and use fluid properties related to continuous models (e.g., surface tension, viscosity). Among them, the method of Barrett, Joyner and Halendra (BJH) was popular by the end of the previous century. Since then, new methods based on microscopic models of gases and fluids have quickly gained popularity and now are the standard for analysis of micropores and mesopores. Density functional theory (DFT) analysis calculates local gas-surface interaction potentials between numerous fluid-fluid and fluidsolid pairs in several pre-selected pore geometries and adsorbate-adsorbent combinations. A newer version of DFT analysis, the quenched solid state DFT method (QSDFT), can even account for the atomic roughness of internal pore walls in materials. However, the maximum pore size range calculated by DFT methods is only about $35 \mathrm{~nm}$, as it is limited by the range of fluid-solid molecular interaction. Pores widths larger than $35 \mathrm{~nm}$ are not analyzed. For that reason, the total surface area obtained from DFT analysis $\left(S_{D F T}\right)$ may be lower than that obtained by $S_{B E T}$, and the corresponding cumulative pore volume from DFT analysis $\left(V_{D F T}\right)$ is lower than $V_{t o t}$.

\subsubsection{Comparison between techniques}

One should always keep in mind that various analysis techniques return information only for open pores and within specific pore size ranges. Figure 20 emphasizes the commonalities and differences among various microstructural techniques for the characterization of porosity in graphite [11].

Microscopy techniques offer high resolution (up to nanometer and atomic scale) of materials and are extremely useful for identification of local features (see Figure 20). The "big picture" can be understood only by examining and comparing large numbers of high-magnification local images. In comparison with these techniques, gas adsorption methods offer structural data at the nanometer scale $(0.5-35 \mathrm{~nm})$ that were obtained from simultaneous analysis of much larger samples (in volume and weight) and therefore represent bulk-averaged properties. 


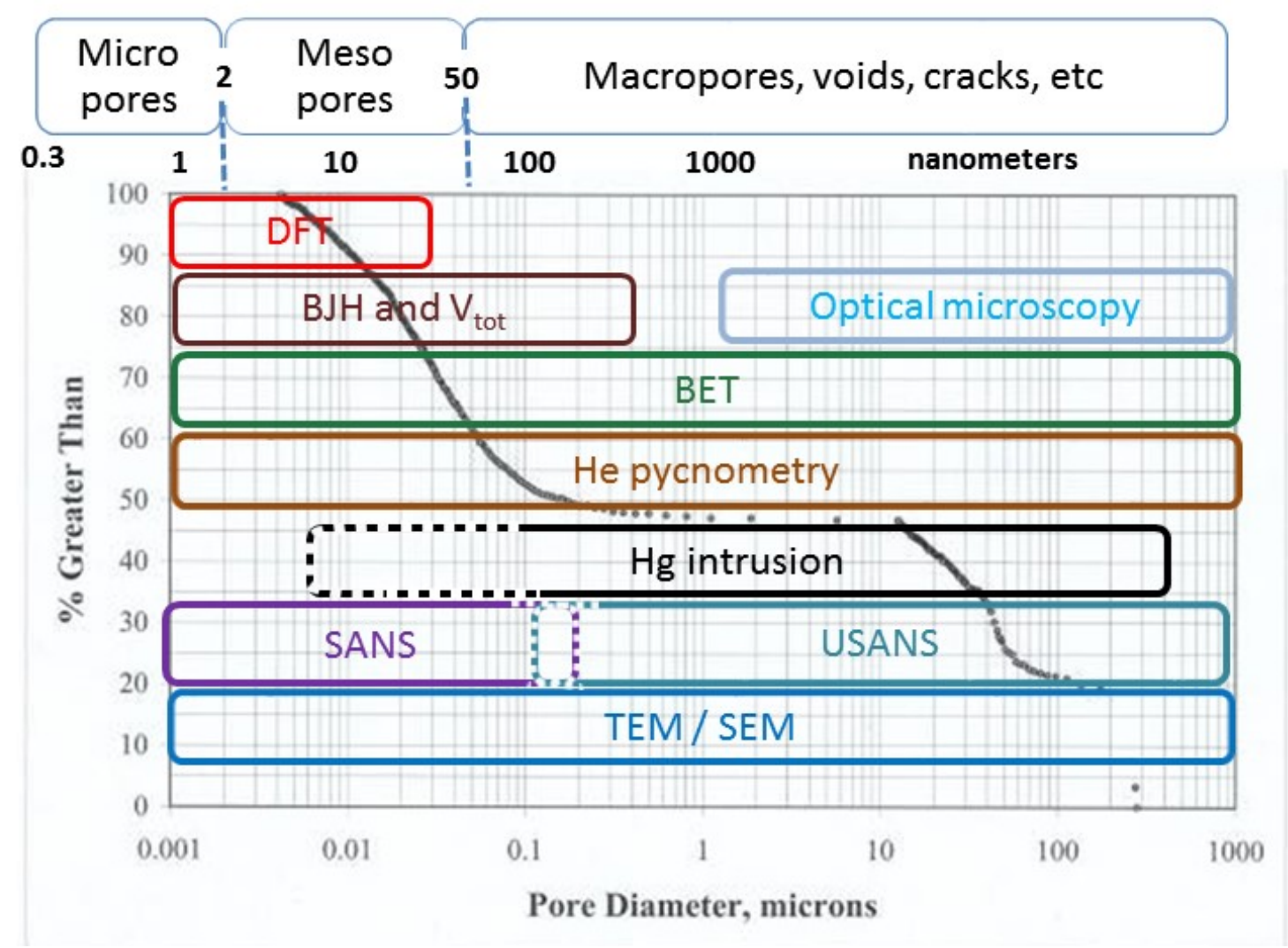

Figure 20. Comparison among pore size ranges analyzed by various microstructural techniques, showing the overlap between gas adsorption results and other techniques [12]. The background curve is the pore size distribution of a nuclear graphite with a bimodal pore structure, obtained from mercury intrusion porosimetry.

\subsubsection{Pore Size and Distribution of Unirradiated and Irradiated Nuclear Graphite}

Figure 21-Figure 24 show adsorption isotherms of nitrogen at $77 \mathrm{~K}$ on four graphite grades (see Table 3), along with the corresponding pore size distributions calculated by the QSDFT method. The same color codes indicate samples exposed to similar irradiation doses and temperatures. 

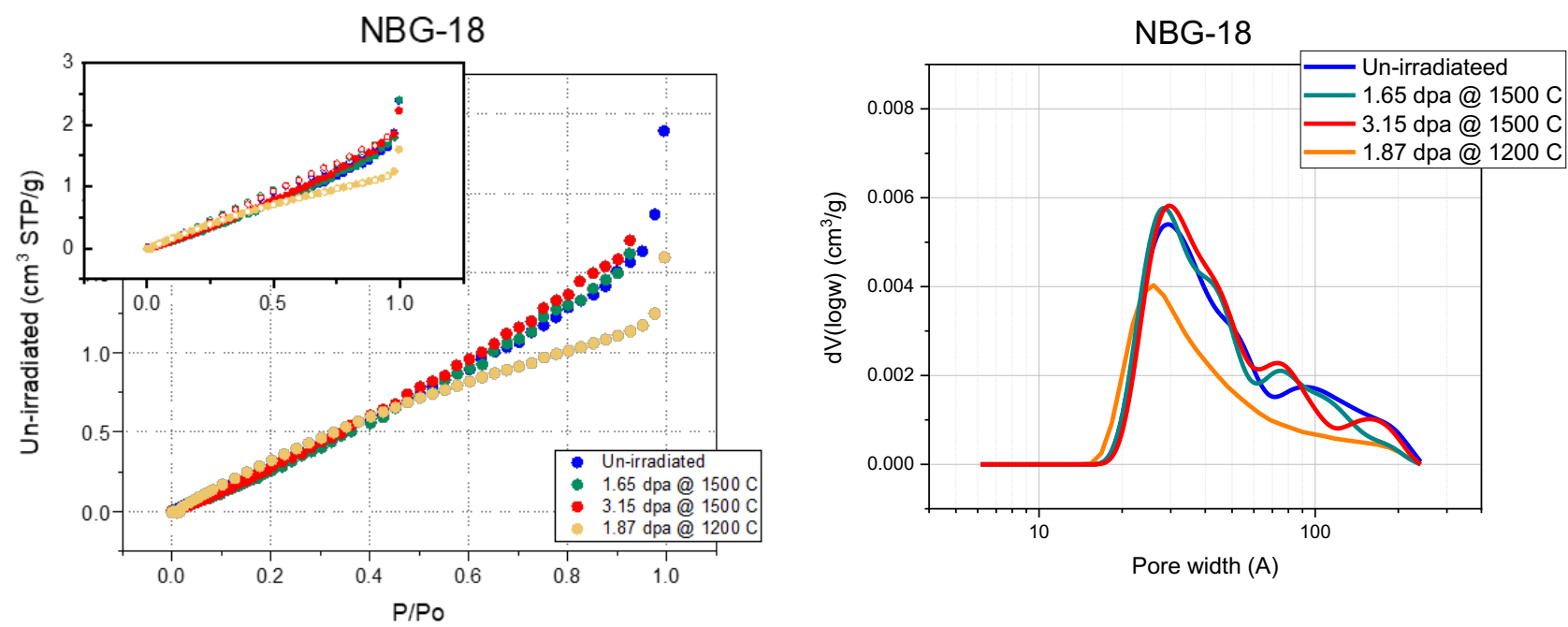

Figure 21. Adsorption-desorption isotherms of nitrogen on graphite NBG-18 and the corresponding pore size distributions (QSDFT method).
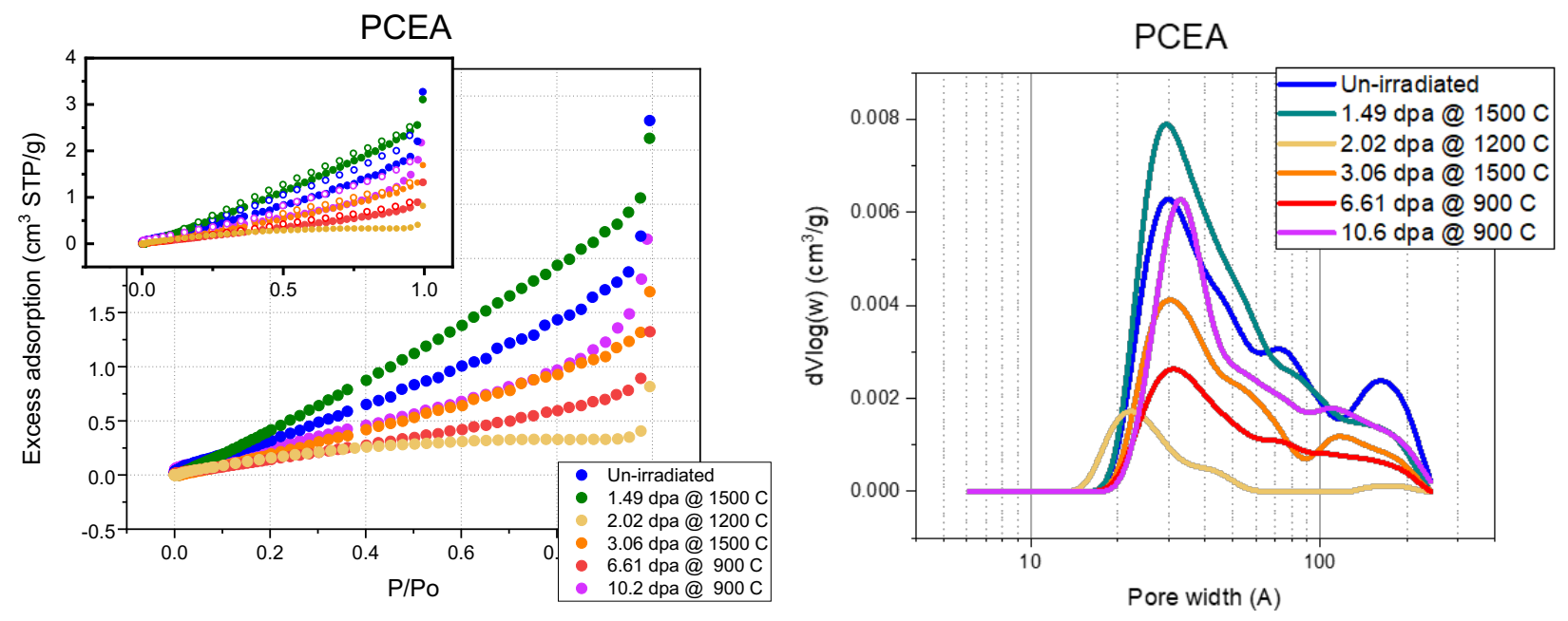

Figure 22. Adsorption-desorption isotherms of nitrogen on graphite PCEA and the corresponding pore size distributions (QSDFT method). 


\section{IG-110}

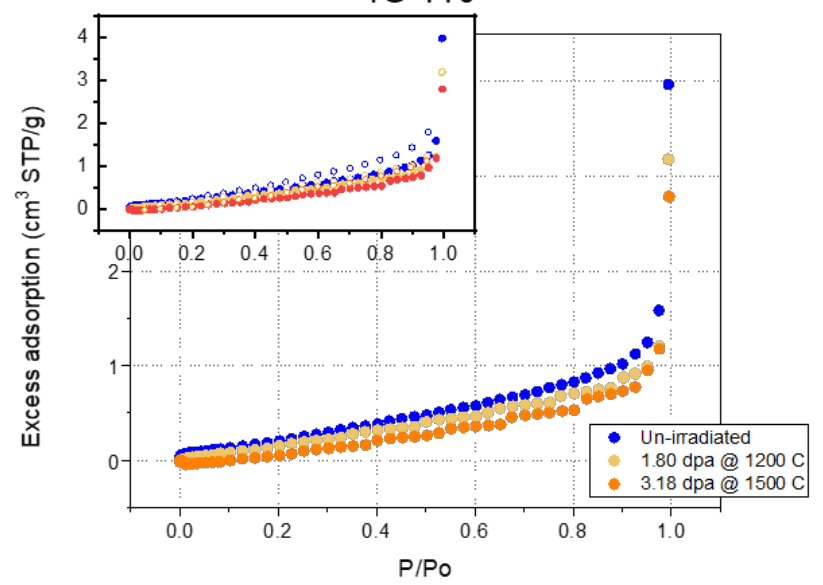

IG-110

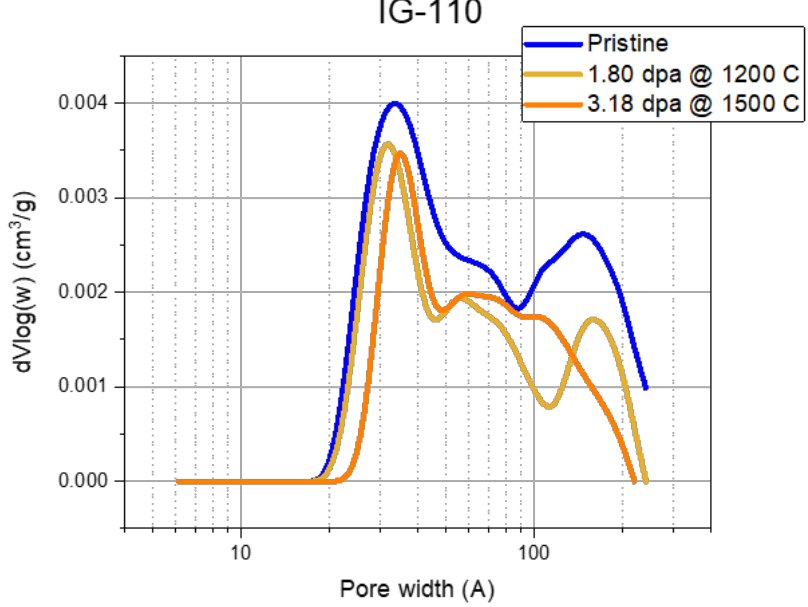

Figure 23. Adsorption-desorption isotherms of nitrogen on graphite IG-110 and the corresponding pore size distributions (QSDFT method).
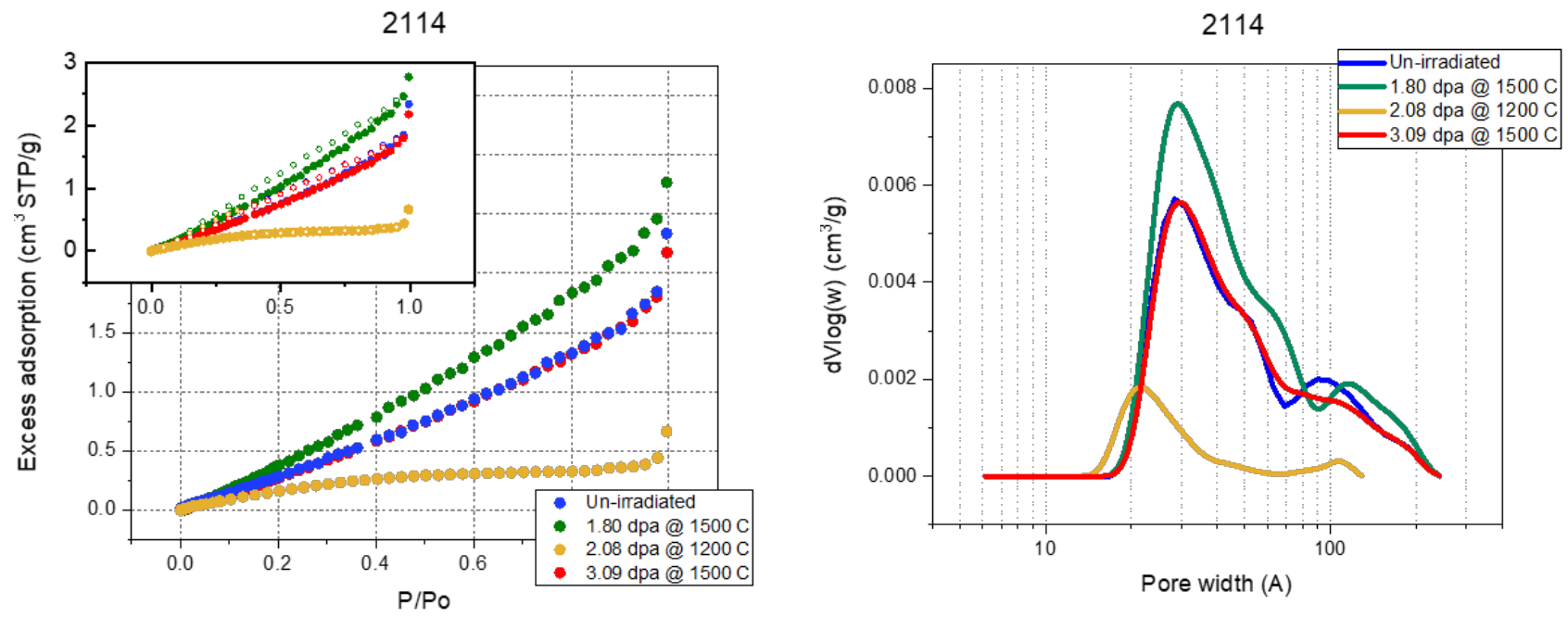

Figure 24. Adsorption-desorption isotherms of nitrogen on graphite 2114 and the corresponding pore size distributions (QSDFT method).

Upon closer examination, all the isotherms had a loose sigmoidal shape (classified as Type II according to International Union of Pure and Applied Chemistry [13]) which indicated an energetic and structural heterogeneity of the surface. They can be regarded as a collection of numerous patches of similar adsorption energies, which together generate the sigmoidal shape. Type II isotherms are typical for weakly adsorbing surfaces resulted from packing of random plate-like, but nonporous fragments, where unrestricted multilayer adsorption occurs at high relative pressures $\left(\mathrm{P} / \mathrm{P}_{0}\right)$.

There were visible differences between irradiated samples of the same graphite grade. There was little evidence of development of mesoporosity in any of these samples. However, it was interesting to see that irradiation at $1200^{\circ} \mathrm{C}$ at about $1.9 \mathrm{dpa}$ (golden lines in Figure 21-Figure 24) reduced the adsorption of all samples from both their initial level (unirradiated samples, blue lines) and from samples irradiated at $1500^{\circ} \mathrm{C}$ and 1.8 to $3 \mathrm{dpa}$ (green and red lines). 
Similar changes were visible in the pore size distributions. There were no micropores $(<2 \mathrm{~nm}$ or $<20 \AA)$ in any of these samples. However, all samples irradiated at $1200^{\circ} \mathrm{C}$ showed less mesoporosity than all the other samples, either unirradiated or irradiated at $1500^{\circ} \mathrm{C}$. Moreover, the maxima of pore size distributions for samples irradiated at $1200^{\circ} \mathrm{C}$ shifted to lower sizes $(2.0-2.5 \mathrm{~nm})$, whereas all the other samples showed maxima at higher mesopore sizes $(3 \mathrm{~nm})$.

These small differences were in perfect agreement with our previous nitrogen adsorption results on irradiated superfine grade graphite G347A from Tokay Carbon [12]. We have observed minor changes in isotherm shapes and pore size distributions for samples irradiated before the turnaround point at three temperatures. After turnaround, all G347A graphite showed intense development of mesoporosity and approximately a $5 \times$ increase in $S_{B E T}$. These observations were supported by different microscopy techniques. Since the samples in the present set of irradiated graphite have not reached yet the turnaround point, there has been little change in their structure, as monitored by nitrogen adsorption.

\subsubsection{Increase of Atomic Disorder on Irradiation-Damaged Graphite Basal Planes}

Interesting changes were observed, however, in the shapes of very early parts of the adsorption isotherms. At very low relative pressures $\left(10^{-3}-10^{-2} P / P_{0}\right)$, adsorption occurred on the surface sites with the largest adsorption energies. These sites were on the regularly ordered and energetically uniform basal plane fragments that might be exposed by graphite crystallites. There was a tendency to first complete a monolayer of adsorbed $\mathrm{N}_{2}$ on these basal planes before adsorption continued on the second layer or started on weaker adsorption sites; the latter, generally, were any types of edges sites, defects, dislocations, intercalates, and so on.

Figure 25 shows the initial parts of adsorption isotherms $\left(\mathrm{P} / \mathrm{P}_{0}<0.025\right)$ on unirradiated graphite and on materials irradiated at various damage levels. The completions of the first monolayers on basal plane fragments are visible either as plateaus or at least as inflection points close to $\mathrm{P} / \mathrm{P}_{0}=0.01$ on all unirradiated graphites (blue symbols). The defect buildup during irradiation may explain the lowering of adsorption in irradiated graphite. However, the short segment of negative adsorption at $0.005<\mathrm{P} / \mathrm{P}_{0}<$ 0.01 followed by recovery after $\mathrm{P} / \mathrm{P}_{0}>0.01$ does not have a convincing explanation at this time. To the best of our knowledge, this type of negative adsorption in bidimensional layers was theoretically predicted [14] but has never before been reported experimentally. Our efforts to understand this feature, and its relationship with the microstructural changes caused by graphite irradiation, continue. 

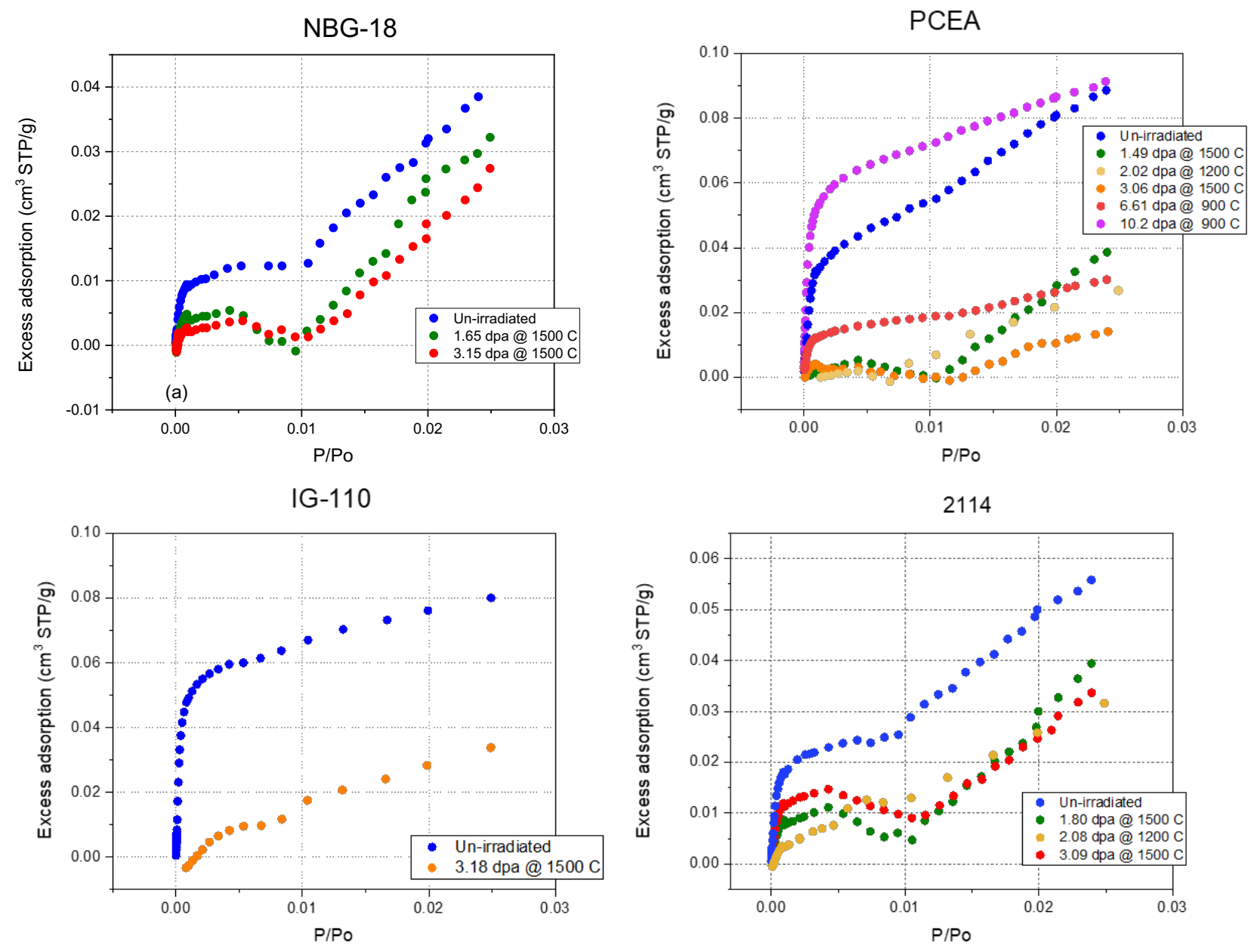

Figure 25. Initial parts of adsorption isotherms $\left(\mathrm{P} / \mathrm{P}_{\mathbf{0}}<0.025\right)$ on unirradiated graphite and on materials irradiated at various damage levels.

\section{SUMMARY}

The work reported here includes two nondestructive examinations of the microstructural changes that occur in graphite as results of high-temperature neutron irradiation. X-ray diffraction was used to measure and quantify the changes to the crystal structure, and nitrogen adsorption was employed to interrogate and quantify the size and distribution of the open porosity.

The XRD results show the same behaviors observed in other irradiated graphites, where the a-axis lattice spacing contracted while the c-axis spacing increased. This work analyzed multiple diffraction peaks, (002), (004), (006), (100), (110), and (200). The direct analysis of the peak locations showed that there were some differences in the calculated c-axis expansion and a-axis contraction, depending on the peak. The crystallite sizes of the different grades all started with different values, but it was shown that after irradiation, the sizes were similar for the same irradiation temperature.

The Williamson-Hall analysis was implemented with XRD to analyze the effects of crystallite size and lattice strain on the peak breadth. The pre-irradiation analysis for all grades showed that the peak 
broadening in the c-direction was primarily due to lattice strain, while the broadening in the a-direction was primarily due to crystallite size. After irradiation, the lattice strain in the c-direction planes increased, thereby increasing the peak widths, whereas the a-direction planes increased in breadth. The analysis suggested that the irradiation resulted in the introduction of a lattice strain. These results suggest that further investigations are necessary to fully quantify the effects of crystallite size and lattice strain on the peak broadening. It is possible that XRD measurements at a synchrotron (like the National Synchrotron Light Source at Brookhaven National Laboratory) would provide more insight into this topic, since capture and deconvolution of the higher order peaks would be achieved.

The nitrogen adsorption measurements provided insight into the change of the open porosity due to neutron irradiation at high temperatures. The specimens irradiated at $1200^{\circ} \mathrm{C}$ reduced the adsorption of all four grades, and the most-prevalent pores were found to be $2-2.5 \mathrm{~nm}$ in size. Conversely, at $1500^{\circ} \mathrm{C}$, irradiation had essentially no effect on the pores in NBG-18; PCEA and 2114 showed an initial increase in total adsorption, followed by a reduction for the higher dose; and IG-110 showed a reduction of total adsorption at the highest dose. The other interesting irradiation effect was found in the initial portions of the isotherms, where the unirradiated material displayed the typical carbon response where the first monolayer was visible. But when the material was irradiated, and the total adsorption was lower than before irradiation, there was negative adsorption before the first monolayer. That finding is still not physically explained.

The results from this work show that there is still a significant amount of work required to fully understand the changes to the crystal and pore structures of graphite exposed to high-temperature neutron irradiation.

\section{REFERENCES}

1. Burchell, T.D., J. Strizak, J. McDuffee, and K. Thoms, "Experimental Plan for HFIR High Temperature Graphite Irradiation Capsule (HTV)", ORNL/TM-2012/10, (2012).

2. Burchell, T.D., "HTV Post Irradiation Examination (PIE) Results and Analysis", ORNL/TM2017/292, (2017).

3. $\quad$ "Carbon Materials for Advanced Technologies", ed. T.D. Burchell, 1999.

4. Williamson, G.K. and W.H. Hall, "X-ray line broadening from filed aluminium and wolfram", Acta Metallurgica, 1, (1953) 22-31.

5. Gallego, N.C., C.I. Contescu, and T.D. Burchell, "XRD and SANS Evaluation of HOPG and Polycrystalline Graphite", ORNL/TM-2018/871, (2018).

6. Burchell, T.D. and J. Strizak, "Post-Irradiation Examination Data for PCEA Graphite Irradiated at $900^{\circ} \mathrm{C}$ in HFIR", ORNL/TM-2011/497, (2012).

7. Quantachrome Instruments, Optimizing Gas Sorption Parameters to Minimize B.E.T. Surface Area Analysis Time. Powder Tech Note \#58.

8. Ruland, W., "X-Ray Diffraction Studies on Carbon and Graphite", in Chemistry and Physics of Carbon, Vol.4, P.L. Walker, Jr., Editor, 1968, Marcel Dekker, New York, p. 1-84.

9. Brunauer, S., P.H. Emmett, and E. Teller, "Adsorption of Gases in Multimolecular Layers", Journal of the American Chemical Society, 60, (1938) 309-319.

10. Rouquerol, J., F. Rouquerol, P. Llewellyn, G. Maurin, and K. Sing, "Adsorption by powders and porous solids: principles, methodology and applications; 2nd ed.", 2013, New York, NY, Academic Press.

11. Contescu, C.I., A.A. Campbell, N.C. Gallego, K. Takizawa, and Y. Katoh, "Mesopores development in irradiated graphite", Presented at International Nuclear Graphite Specialist Meeting 2017, Baltimore, MD, September 17-21, 2017. 
12. Contescu, C.I., J.D. Arregui-Mena, A.A. Campbell, P.D. Edmondson, N.C. Gallego, K. Takizawa, and Y. Katoh, "Development of mesopores in superfine grain graphite neutronirradiated at high fluence", Carbon, 141, (2019) 663-675.

13. Thommes, M., K. Kaneko, A.V. Neimark, J.P. Olivier, F. Rodriguez-Reinoso, J. Rouquerol, and K.S.W. Sing, "Physisorption of gases, with special reference to the evaluation of surface area and pore size distribution (IUPAC Technical Report)", 87, (2015)

14. Vernov, A.V. and W.A. Steele, "Computer simulation study of the multilayer adsorption of fluid nitrogen on graphite", Langmuir, 2, (1986) 219-227. 


\section{APPENDIX A. DETAILED RESULTS}

\section{A.1 JADE PEAK FITTING RESULTS}

\section{A.1.1 IG-110}

\begin{tabular}{|c|c|c|c|c|c|c|c|c|c|c|}
\hline \multirow{2}{*}{$\begin{array}{c}\text { Irradiation } \\
\text { Temperature } \\
\left({ }^{\circ} \mathrm{C}\right)\end{array}$} & \multirow{2}{*}{$\begin{array}{l}\text { Dose } \\
\text { (dpa) }\end{array}$} & \multirow{2}{*}{ (hkl) } & \multicolumn{2}{|c|}{ (a) 2-Theta } & \multicolumn{2}{|c|}{$\mathbf{d}(\AA)$} & \multicolumn{2}{|c|}{ FWHM } & \multicolumn{2}{|c|}{$\begin{array}{c}\text { Jade crystal } \\
\text { size }(\AA)\end{array}$} \\
\hline & & & value & error & value & error & value & error & Size & Error \\
\hline \multirow{6}{*}{\multicolumn{2}{|c|}{ Pre-Irradiation }} & $(002)$ & 26.470 & 0.002 & 3.3646 & 0.0004 & 0.2885 & 0.0021 & 398 & 4 \\
\hline & & $(004)$ & 54.522 & 0.004 & 1.6817 & 0.0003 & 0.573 & 0.006 & 177 & 3 \\
\hline & & $(006)$ & 86.860 & 0.016 & 1.1205 & 0.0003 & 1.1224 & 0.0364 & 103 & 4 \\
\hline & & $(100)$ & 42.346 & 0.003 & 2.1327 & 0.0003 & 0.3424 & 0.0102 & 324 & 11 \\
\hline & & $(110)$ & 77.520 & 0.002 & 1.2304 & 0.0000 & 0.2151 & 0.0035 & 933 & 16 \\
\hline & & $(200)$ & 92.571 & 0.014 & 1.0657 & 0.0002 & 0.3876 & 0.0392 & 387 & 40 \\
\hline \multirow{6}{*}{900} & \multirow{6}{*}{2.30} & $(002)$ & 26.455 & 0.002 & 3.3664 & 0.0006 & 0.5825 & 0.0030 & 158 & 2 \\
\hline & & $(004)$ & 54.441 & 0.012 & 1.6840 & 0.0007 & 1.0771 & 0.0153 & 87 & 2 \\
\hline & & $(006)$ & 86.621 & 0.073 & 1.1230 & 0.0015 & 2.9472 & 0.1618 & 38 & 3 \\
\hline & & $(100)$ & 42.400 & 0.009 & 2.1301 & 0.0008 & 0.5650 & 0.0234 & 171 & 8 \\
\hline & & $(110)$ & 77.574 & 0.007 & 1.2297 & 0.0002 & 0.3436 & 0.0177 & 399 & 22 \\
\hline & & $(200)$ & 92.656 & 0.034 & 1.0650 & 0.0006 & 0.7192 & 0.1222 & 178 & 31 \\
\hline \multirow{6}{*}{900} & \multirow{6}{*}{3.27} & $(002)$ & 26.421 & 0.003 & 3.3706 & 0.0007 & 0.7015 & 0.0036 & 128 & 2 \\
\hline & & $(004)$ & 54.357 & 0.016 & 1.6864 & 0.0009 & 1.2806 & 0.0200 & 73 & 2 \\
\hline & & $(006)$ & 86.164 & 0.389 & 1.1277 & 0.0082 & 3.4355 & 1.2819 & 32 & 13 \\
\hline & & $(100)$ & 42.426 & 0.011 & 2.1289 & 0.0011 & 0.6961 & 0.0289 & 135 & 7 \\
\hline & & $(110)$ & 77.599 & 0.004 & 1.2293 & 0.0001 & 0.4176 & 0.0106 & 304 & 9 \\
\hline & & $(200)$ & 92.762 & 0.067 & 1.0640 & 0.0012 & 1.3625 & 0.2205 & 88 & 15 \\
\hline \multirow{6}{*}{1500} & \multirow{6}{*}{1.55} & $(002)$ & 26.438 & 0.002 & 3.3685 & 0.0005 & 0.4618 & 0.0026 & 209 & 2 \\
\hline & & $(004)$ & 54.445 & 0.010 & 1.6839 & 0.0006 & 0.9079 & 0.0131 & 105 & 3 \\
\hline & & $(006)$ & 86.634 & 0.062 & 1.1228 & 0.0013 & 2.1553 & 0.0899 & 52 & 3 \\
\hline & & $(100)$ & 42.373 & 0.012 & 2.1314 & 0.0012 & 0.6124 & 0.0329 & 156 & 9 \\
\hline & & $(110)$ & 77.545 & 0.009 & 1.2301 & 0.0002 & 0.3607 & 0.0235 & 371 & 25 \\
\hline & & $(200)$ & 92.634 & 0.049 & 1.0652 & 0.0009 & 1.3322 & 0.1715 & 90 & 13 \\
\hline \multirow{6}{*}{1500} & \multirow{6}{*}{3.29} & $(002)$ & 26.393 & 0.002 & 3.3741 & 0.0006 & 0.5010 & 0.0031 & 189 & 2 \\
\hline & & $(004)$ & 54.335 & 0.011 & 1.6871 & 0.0006 & 1.0204 & 0.0127 & 93 & 2 \\
\hline & & $(006)$ & 86.451 & 0.071 & 1.1247 & 0.0015 & 2.3394 & 0.1308 & 48 & 4 \\
\hline & & $(100)$ & 42.402 & 0.013 & 2.1300 & 0.0012 & 0.6530 & 0.0316 & 145 & 8 \\
\hline & & $(110)$ & 77.531 & 0.004 & 1.2302 & 0.0001 & 0.4295 & 0.0093 & 293 & 7 \\
\hline & & $(200)$ & 92.557 & 0.031 & 1.0658 & 0.0006 & 1.6897 & 0.0995 & 70 & 5 \\
\hline
\end{tabular}




\section{A.1.2 NBG-17}

\begin{tabular}{|c|c|c|c|c|c|c|c|c|c|c|}
\hline \multirow{2}{*}{$\begin{array}{l}\text { Irradiation } \\
\text { Temperature } \\
\left({ }^{\circ} \mathrm{C}\right)\end{array}$} & \multirow{2}{*}{$\begin{array}{l}\text { Dose } \\
\text { (dpa) }\end{array}$} & \multirow{2}{*}{ (hkl) } & \multicolumn{2}{|c|}{ (a) 2-Theta } & \multicolumn{2}{|c|}{ d $(\AA ̊)$} & \multicolumn{2}{|c|}{ FWHM } & \multicolumn{2}{|c|}{$\begin{array}{c}\text { Jade crystal } \\
\text { size }(\AA)\end{array}$} \\
\hline & & & value & error & value & error & value & error & Size & Error \\
\hline \multirow{6}{*}{\multicolumn{2}{|c|}{ Pre-Irradiation }} & $(002)$ & 26.469 & 0.001 & 3.3647 & 0.0003 & 0.3094 & 0.0015 & 358 & 3 \\
\hline & & (004) & 54.540 & 0.004 & 1.6812 & 0.0002 & 0.5703 & 0.0073 & 178 & 3 \\
\hline & & $(006)$ & 86.864 & 0.017 & 1.1204 & 0.0004 & 1.2157 & 0.0362 & 95 & 4 \\
\hline & & $(100)$ & 42.336 & 0.004 & 2.1332 & 0.0004 & 0.3996 & 0.0113 & 263 & 8 \\
\hline & & (110) & 77.510 & 0.002 & 1.2305 & 0.0001 & 0.2194 & 0.0043 & 890 & 19 \\
\hline & & $(200)$ & 92.570 & 0.017 & 1.0657 & 0.0003 & 0.4331 & 0.0485 & 332 & 38 \\
\hline \multirow{6}{*}{900} & \multirow{6}{*}{2.47} & $(002)$ & 26.439 & 0.002 & 3.3684 & 0.0006 & 0.7155 & 0.0034 & 125 & 2 \\
\hline & & (004) & 54.412 & 0.016 & 1.6848 & 0.0009 & 1.2331 & 0.0227 & 76 & 2 \\
\hline & & (006) & 86.396 & 0.117 & 1.1253 & 0.0025 & 2.1374 & 0.2356 & 52 & 7 \\
\hline & & $(100)$ & 42.403 & 0.009 & 2.1299 & 0.0009 & 0.6675 & 0.0242 & 141 & 6 \\
\hline & & (110) & 77.573 & 0.003 & 1.2297 & 0.0001 & 0.3741 & 0.0097 & 353 & 10 \\
\hline & & (200) & 92.738 & 0.062 & 1.0642 & 0.0011 & 1.7485 & 0.1676 & 68 & 8 \\
\hline \multirow{6}{*}{900} & \multirow{6}{*}{3.29} & $(002)$ & 26.409 & 0.003 & 3.3721 & 0.0006 & 0.7669 & 0.0034 & 115 & 2 \\
\hline & & (004) & 54.330 & 0.022 & 1.6872 & 0.0012 & 1.2903 & 0.0264 & 72 & 2 \\
\hline & & (006) & 86.270 & 0.255 & 1.1266 & 0.0053 & 3.1186 & 0.8909 & 35 & 11 \\
\hline & & (100) & 42.426 & 0.014 & 2.1288 & 0.0014 & 0.8313 & 0.0373 & 110 & 6 \\
\hline & & (110) & 77.585 & 0.005 & 1.2295 & 0.0001 & 0.4481 & 0.0147 & 277 & 10 \\
\hline & & (200) & 92.732 & 0.072 & 1.0643 & 0.0013 & 1.7561 & 0.2047 & 68 & 9 \\
\hline \multirow{6}{*}{1500} & \multirow{6}{*}{1.99} & (002) & 26.408 & 0.002 & 3.3723 & 0.0005 & 0.5046 & 0.0027 & 187 & 2 \\
\hline & & (004) & 54.374 & 0.013 & 1.6859 & 0.0007 & 0.9966 & 0.0161 & 95 & 3 \\
\hline & & (006) & 86.594 & 0.073 & 1.1232 & 0.0015 & 2.7202 & 0.1441 & 41 & 3 \\
\hline & & (100) & 42.380 & 0.012 & 2.1311 & 0.0011 & 0.6387 & 0.0301 & 148 & 8 \\
\hline & & (110) & 77.542 & 0.009 & 1.2301 & 0.0002 & 0.4113 & 0.0219 & 310 & 18 \\
\hline & & $(200)$ & 92.719 & 0.053 & 1.0644 & 0.0009 & 0.7350 & 0.1687 & 174 & 41 \\
\hline \multirow{6}{*}{1500} & \multirow{6}{*}{3.27} & $(002)$ & 26.367 & 0.003 & 3.3774 & 0.0006 & 0.5032 & 0.0035 & 188 & 2 \\
\hline & & (004) & 54.321 & 0.014 & 1.6874 & 0.0008 & 0.9758 & 0.0158 & 97 & 3 \\
\hline & & (006) & 86.518 & 0.074 & 1.1240 & 0.0015 & 2.2640 & 0.1700 & 49 & 5 \\
\hline & & $(100)$ & 42.391 & 0.012 & 2.1305 & 0.0012 & 0.7925 & 0.0325 & 116 & 6 \\
\hline & & (110) & 77.535 & 0.005 & 1.2302 & 0.0001 & 0.4624 & 0.0131 & 266 & 9 \\
\hline & & (200) & 92.663 & 0.050 & 1.0649 & 0.0009 & 2.0127 & 0.1257 & 59 & 5 \\
\hline
\end{tabular}




\section{A.1.3 NBG-18}

\begin{tabular}{|c|c|c|c|c|c|c|c|c|c|c|}
\hline \multirow{2}{*}{$\begin{array}{c}\text { Irradiation } \\
\text { Temperature } \\
\left({ }^{\circ} \mathrm{C}\right)\end{array}$} & \multirow{2}{*}{$\begin{array}{l}\text { Dose } \\
\text { (dpa) }\end{array}$} & \multirow[t]{2}{*}{ (hkl) } & \multicolumn{2}{|c|}{ (a) 2-Theta } & \multicolumn{2}{|c|}{ d $(\AA ̊)$} & \multicolumn{2}{|c|}{ FWHM } & \multicolumn{2}{|c|}{$\begin{array}{c}\text { Jade crystal } \\
\text { size }(\AA)\end{array}$} \\
\hline & & & value & error & value & error & value & error & Size & Error \\
\hline \multirow{6}{*}{\multicolumn{2}{|c|}{ Pre-Irradiation }} & $(002)$ & 26.465 & 0.001 & 3.3651 & 0.0003 & 0.3044 & 0.0014 & 366 & 3 \\
\hline & & $(004)$ & 54.518 & 0.004 & 1.6818 & 0.0002 & 0.5669 & 0.0075 & 179 & 3 \\
\hline & & $(006)$ & 86.792 & 0.020 & 1.1212 & 0.0004 & 1.1315 & 0.0384 & 102 & 4 \\
\hline & & $(100)$ & 42.352 & 0.004 & 2.1324 & 0.0004 & 0.3697 & 0.0134 & 291 & 12 \\
\hline & & $(110)$ & 77.512 & 0.002 & 1.2305 & 0.0000 & 0.2167 & 0.0038 & 917 & 17 \\
\hline & & $(200)$ & 92.567 & 0.016 & 1.0658 & 0.0003 & 0.4957 & 0.0469 & 278 & 27 \\
\hline \multirow{6}{*}{900} & \multirow{6}{*}{2.52} & $(002)$ & 26.434 & 0.002 & 3.3691 & 0.0006 & 0.7048 & 0.0032 & 127 & 2 \\
\hline & & $(004)$ & 54.379 & 0.016 & 1.6858 & 0.0009 & 1.2233 & 0.0217 & 76 & 2 \\
\hline & & $(006)$ & 86.243 & 0.304 & 1.1269 & 0.0064 & 3.7325 & 0.8280 & 29 & 7 \\
\hline & & $(100)$ & 42.404 & 0.016 & 2.1299 & 0.0015 & 0.7816 & 0.0414 & 118 & 7 \\
\hline & & $(110)$ & 77.572 & 0.008 & 1.2297 & 0.0002 & 0.3982 & 0.0217 & 324 & 19 \\
\hline & & $(200)$ & 92.741 & 0.048 & 1.0642 & 0.0008 & 0.8180 & 0.1477 & 154 & 29 \\
\hline \multirow{6}{*}{900} & \multirow{6}{*}{3.26} & $(002)$ & 26.407 & 0.002 & 3.3724 & 0.0006 & 0.7696 & 0.0031 & 115 & 1 \\
\hline & & $(004)$ & 54.345 & 0.018 & 1.6868 & 0.0010 & 1.3274 & 0.0235 & 70 & 2 \\
\hline & & $(006)$ & 86.073 & 0.642 & 1.1287 & 0.0135 & 3.6468 & 1.8076 & 30 & 16 \\
\hline & & $(100)$ & 42.430 & 0.022 & 2.1286 & 0.0021 & 0.9068 & 0.0543 & 100 & 7 \\
\hline & & $(110)$ & 77.581 & 0.005 & 1.2296 & 0.0001 & 0.4660 & 0.0133 & 263 & 8 \\
\hline & & $(200)$ & 92.763 & 0.065 & 1.0640 & 0.0011 & 1.9044 & 0.1588 & 62 & 6 \\
\hline \multirow{6}{*}{1500} & \multirow{6}{*}{1.63} & $(002)$ & 26.415 & 0.002 & 3.3714 & 0.0005 & 0.4963 & 0.0027 & 191 & 2 \\
\hline & & $(004)$ & 54.378 & 0.012 & 1.6858 & 0.0007 & 0.9812 & 0.0149 & 97 & 2 \\
\hline & & $(006)$ & 86.603 & 0.072 & 1.1231 & 0.0015 & 2.1002 & 0.1158 & 53 & 4 \\
\hline & & $(100)$ & 42.389 & 0.011 & 2.1306 & 0.0011 & 0.5982 & 0.0299 & 160 & 9 \\
\hline & & $(110)$ & 77.536 & 0.004 & 1.2302 & 0.0001 & 0.3970 & 0.0106 & 325 & 10 \\
\hline & & $(200)$ & 92.683 & 0.058 & 1.0647 & 0.0010 & 1.4908 & 0.1739 & 80 & 10 \\
\hline \multirow{6}{*}{1500} & \multirow{6}{*}{3.29} & $(002)$ & 26.361 & 0.002 & 3.3782 & 0.0006 & 0.5076 & 0.0033 & 186 & 2 \\
\hline & & $(004)$ & 54.304 & 0.014 & 1.6879 & 0.0008 & 1.0141 & 0.0155 & 93 & 2 \\
\hline & & $(006)$ & 86.406 & 0.080 & 1.1252 & 0.0017 & 2.2357 & 0.2454 & 50 & 6 \\
\hline & & $(100)$ & 42.425 & 0.019 & 2.1289 & 0.0018 & 0.7033 & 0.0453 & 133 & 10 \\
\hline & & (110) & 77.540 & 0.006 & 1.2301 & 0.0001 & 0.4706 & 0.0131 & 260 & 8 \\
\hline & & $(200)$ & 92.676 & 0.048 & 1.0648 & 0.0009 & 1.4534 & 0.1543 & 83 & 10 \\
\hline
\end{tabular}




\section{A.1.4 PCEA}

\begin{tabular}{|c|c|c|c|c|c|c|c|c|c|c|}
\hline \multirow{2}{*}{$\begin{array}{c}\text { Irradiation } \\
\text { Temperature } \\
\left({ }^{\circ} \mathrm{C}\right)\end{array}$} & \multirow{2}{*}{$\begin{array}{l}\text { Dose } \\
\text { (dpa) }\end{array}$} & \multirow[t]{2}{*}{ (hkl) } & \multicolumn{2}{|c|}{ (a) 2-Theta } & \multicolumn{2}{|c|}{ d $(\AA)$} & \multicolumn{2}{|c|}{ FWHM } & \multicolumn{2}{|c|}{$\begin{array}{c}\text { Jade crystal } \\
\text { size }(\AA)\end{array}$} \\
\hline & & & value & error & value & error & value & error & Size & Error \\
\hline \multirow{6}{*}{\multicolumn{2}{|c|}{ Pre-Irradiation }} & $(002)$ & 26.455 & 0.001 & 3.3664 & 0.0004 & 0.2436 & 0.0019 & 527 & 5 \\
\hline & & $(004)$ & 54.484 & 0.004 & 1.6828 & 0.0002 & 0.4505 & 0.0064 & 237 & 4 \\
\hline & & $(006)$ & 86.747 & 0.017 & 1.1217 & 0.0003 & 0.8472 & 0.0323 & 140 & 6 \\
\hline & & $(100)$ & 42.353 & 0.008 & 2.1323 & 0.0008 & 0.2939 & 0.0260 & 406 & 37 \\
\hline & & $(110)$ & 77.510 & 0.002 & 1.2305 & 0.0000 & 0.2064 & 0.0037 & 1000 & 0 \\
\hline & & $(200)$ & 92.581 & 0.016 & 1.0656 & 0.0003 & 0.4893 & 0.0484 & 283 & 29 \\
\hline \multirow{6}{*}{900} & \multirow{6}{*}{2.47} & $(002)$ & 26.457 & 0.002 & 3.3662 & 0.0006 & 0.5765 & 0.0032 & 160 & 2 \\
\hline & & $(004)$ & 54.419 & 0.015 & 1.6847 & 0.0008 & 1.0699 & 0.0184 & 88 & 3 \\
\hline & & $(006)$ & 86.637 & 0.082 & 1.1228 & 0.0017 & 2.2132 & 0.1786 & 50 & 5 \\
\hline & & $(100)$ & 42.402 & 0.008 & 2.1300 & 0.0007 & 0.4390 & 0.0219 & 233 & 13 \\
\hline & & $(110)$ & 77.583 & 0.003 & 1.2295 & 0.0001 & 0.3212 & 0.0072 & 441 & 11 \\
\hline & & $(200)$ & 92.656 & 0.033 & 1.0650 & 0.0006 & 0.7056 & 0.1100 & 182 & 29 \\
\hline \multirow{6}{*}{900} & \multirow{6}{*}{3.29} & $(002)$ & 26.440 & 0.003 & 3.3682 & 0.0007 & 0.6637 & 0.0038 & 136 & 2 \\
\hline & & $(004)$ & 54.358 & 0.016 & 1.6864 & 0.0009 & 1.1814 & 0.0189 & 79 & 2 \\
\hline & & $(006)$ & 86.311 & 0.361 & 1.1262 & 0.0076 & 3.5766 & 1.0165 & 31 & 10 \\
\hline & & $(100)$ & 42.415 & 0.009 & 2.1294 & 0.0009 & 0.5863 & 0.0245 & 164 & 8 \\
\hline & & $(110)$ & 77.596 & 0.004 & 1.2294 & 0.0001 & 0.4036 & 0.0103 & 318 & 9 \\
\hline & & $(200)$ & 92.772 & 0.055 & 1.0639 & 0.0010 & 1.7712 & 0.1533 & 67 & 7 \\
\hline \multirow{6}{*}{1500} & \multirow{6}{*}{1.99} & $(002)$ & 26.439 & 0.002 & 3.3685 & 0.0005 & 0.4006 & 0.0027 & 250 & 3 \\
\hline & & $(004)$ & 54.426 & 0.009 & 1.6844 & 0.0005 & 0.7665 & 0.0114 & 127 & 3 \\
\hline & & $(006)$ & 86.716 & 0.049 & 1.1220 & 0.0010 & 1.5999 & 0.0715 & 71 & 4 \\
\hline & & $(100)$ & 42.358 & 0.006 & 2.1321 & 0.0006 & 0.4815 & 0.0178 & 207 & 9 \\
\hline & & $(110)$ & 77.540 & 0.003 & 1.2301 & 0.0001 & 0.3381 & 0.0076 & 408 & 10 \\
\hline & & $(200)$ & 92.633 & 0.032 & 1.0652 & 0.0006 & 0.6334 & 0.1076 & 206 & 36 \\
\hline \multirow{6}{*}{1500} & \multirow{6}{*}{3.27} & $(002)$ & 26.389 & 0.002 & 3.3746 & 0.0006 & 0.4777 & 0.0029 & 200 & 2 \\
\hline & & $(004)$ & 54.315 & 0.012 & 1.6876 & 0.0007 & 0.9560 & 0.0136 & 99 & 2 \\
\hline & & $(006)$ & 86.386 & 0.088 & 1.1254 & 0.0018 & 2.2108 & 0.1849 & 50 & 5 \\
\hline & & $(100)$ & 42.418 & 0.013 & 2.1292 & 0.0012 & 0.6678 & 0.0315 & 141 & 8 \\
\hline & & $(110)$ & 77.537 & 0.004 & 1.2302 & 0.0001 & 0.4335 & 0.0106 & 289 & 8 \\
\hline & & $(200)$ & 92.674 & 0.047 & 1.0648 & 0.0008 & 1.6574 & 0.1433 & 72 & 7 \\
\hline
\end{tabular}


A.2 WILLIAMSON-HALL PRE-IRRADIATION FIT RESULTS

\begin{tabular}{|c|c|c|c|c|c|c|c|}
\hline \multirow[b]{2}{*}{ Specimen information } & \multicolumn{3}{|c|}{ Line fit } & \multicolumn{2}{|c|}{$Y=0$ fit } & \multicolumn{2}{|c|}{ Slope $=0$ fit } \\
\hline & $\begin{array}{c}\text { Y } \\
\text { Intercept }\end{array}$ & Slope & $\begin{array}{c}\text { Absolute } \\
\text { Sum of } \\
\text { Squares }\end{array}$ & Slope & $\begin{array}{c}\text { Absolute } \\
\text { Sum of } \\
\text { Squares }\end{array}$ & $\begin{array}{c}\mathbf{Y} \\
\text { Intercept }\end{array}$ & $\begin{array}{c}\text { Absolute } \\
\text { Sum of } \\
\text { Squares }\end{array}$ \\
\hline IG-110 Pre-Irradiation $<\mathrm{c}>$ & -0.098 & 1.247 & 0.001 & 1.064 & 0.005 & 0.473 & 0.164 \\
\hline IG-110 Pre-Irradiation $<\mathrm{a}>$ & 0.285 & -0.110 & 0.000 & 0.363 & 0.016 & 0.225 & 0.001 \\
\hline IG-110 $900^{\circ} \mathrm{C} 2.3 \mathrm{dpa}<\mathrm{c}>$ & -0.355 & 3.451 & 0.106 & 2.785 & 0.160 & 1.223 & 1.350 \\
\hline IG-110 $900^{\circ} \mathrm{C} 2.3 \mathrm{dpa}<\mathrm{a}>$ & 0.557 & -0.083 & 0.000 & 0.841 & 0.062 & 0.512 & 0.000 \\
\hline IG-110 $900^{\circ} \mathrm{C} 3.27 \mathrm{dpa}<\mathrm{c}>$ & -0.388 & 4.015 & 0.142 & 3.286 & 0.206 & 1.444 & 1.807 \\
\hline IG-110 $900^{\circ} \mathrm{C} 3.27 \mathrm{dpa}<\mathrm{a}>$ & 0.358 & 0.804 & 0.000 & 1.397 & 0.026 & 0.794 & 0.042 \\
\hline IG-110 $1500^{\circ} \mathrm{C} 1.55 \mathrm{dpa}<\mathrm{c}>$ & -0.177 & 2.446 & 0.027 & 2.114 & 0.041 & 0.942 & 0.653 \\
\hline IG-110 $1500^{\circ} \mathrm{C} 1.55 \mathrm{dpa}<\mathrm{a}>$ & 0.222 & 0.965 & 0.000 & 1.334 & 0.010 & 0.746 & 0.061 \\
\hline IG-110 $1500^{\circ} \mathrm{C} 3.29 \mathrm{dpa}<\mathrm{c}>$ & -0.184 & 2.665 & 0.024 & 2.321 & 0.038 & 1.033 & 0.764 \\
\hline IG-110 $1500^{\circ} \mathrm{C} 3.29 \mathrm{dpa}<\mathrm{a}>$ & 0.049 & 1.548 & 0.000 & 1.629 & 0.000 & 0.888 & 0.156 \\
\hline NBG-17 Pre-Irradiation $<\mathrm{c}>$ & -0.018 & 1.268 & 0.005 & 1.236 & 0.005 & 0.564 & 0.174 \\
\hline NBG-17 Pre-Irradiation $<\mathrm{a}>$ & 0.446 & -0.203 & 0.000 & 0.538 & 0.040 & 0.336 & 0.003 \\
\hline NBG-17 $900^{\circ} \mathrm{C} 2.47 \mathrm{dpa}<\mathrm{c}>$ & 0.254 & 1.890 & 0.001 & 2.366 & 0.028 & 1.117 & 0.372 \\
\hline NBG- $17900^{\circ} \mathrm{C} 2.47 \mathrm{dpa}<\mathrm{a}>$ & 0.039 & 1.613 & 0.000 & 1.678 & 0.000 & 0.914 & 0.171 \\
\hline NBG- $17900^{\circ} \mathrm{C} 3.29 \mathrm{dpa}<\mathrm{c}>$ & -0.142 & 3.358 & 0.089 & 3.091 & 0.097 & 1.390 & 1.257 \\
\hline NBG- $17900^{\circ} \mathrm{C} 3.29 \mathrm{dpa}<\mathrm{a}>$ & 0.338 & 1.207 & 0.000 & 1.768 & 0.023 & 0.993 & 0.095 \\
\hline NBG-17 $1500^{\circ} \mathrm{C} 1.99 \mathrm{dpa}<\mathrm{c}>$ & -0.369 & 3.255 & 0.081 & 2.564 & 0.139 & 1.119 & 1.189 \\
\hline NBG-17 $1500^{\circ} \mathrm{C} 1.99 \mathrm{dpa}<\mathrm{a}>$ & 0.684 & -0.244 & 0.000 & 0.890 & 0.094 & 0.551 & 0.004 \\
\hline NBG-17 $1500^{\circ} \mathrm{C} 3.27 \mathrm{dpa}<\mathrm{c}>$ & -0.155 & 2.535 & 0.027 & 2.244 & 0.037 & 1.002 & 0.698 \\
\hline NBG-17 $1500^{\circ} \mathrm{C} 3.27 \mathrm{dpa}<\mathrm{a}>$ & 0.088 & 1.799 & 0.000 & 1.946 & 0.002 & 1.064 & 0.212 \\
\hline NBG-18 Pre-Irradiation $<\mathrm{c}>$ & 0.015 & 1.148 & 0.002 & 1.176 & 0.002 & 0.541 & 0.140 \\
\hline NBG-18 Pre-Irradiation $<\mathrm{a}>$ & 0.347 & -0.006 & 0.000 & 0.570 & 0.024 & 0.344 & 0.000 \\
\hline NBG-18 $900^{\circ} \mathrm{C} 2.52 \mathrm{dpa}<\mathrm{c}>$ & -0.544 & 4.477 & 0.257 & 3.455 & 0.383 & 1.500 & 2.331 \\
\hline NBG-18 $900^{\circ} \mathrm{C} 2.52 \mathrm{dpa}<\mathrm{a}>$ & 0.893 & -0.454 & 0.000 & 1.027 & 0.160 & 0.647 & 0.013 \\
\hline NBG-18 $900^{\circ} \mathrm{C} 3.26 \mathrm{dpa}<\mathrm{c}>$ & -0.390 & 4.216 & 0.189 & 3.482 & 0.253 & 1.532 & 2.021 \\
\hline NBG-18 $900^{\circ} \mathrm{C} 3.26 \mathrm{dpa}<\mathrm{a}>$ & 0.377 & 1.294 & 0.000 & 1.919 & 0.028 & 1.080 & 0.110 \\
\hline NBG-18 $1500^{\circ} \mathrm{C} 1.63 \mathrm{dpa}<\mathrm{c}>$ & -0.083 & 2.286 & 0.012 & 2.130 & 0.015 & 0.962 & 0.558 \\
\hline NBG-18 $1500^{\circ} \mathrm{C} 1.63 \mathrm{dpa}<\mathrm{a}>$ & 0.087 & 1.303 & 0.000 & 1.447 & 0.002 & 0.794 & 0.111 \\
\hline NBG-18 $1500^{\circ} \mathrm{C} 3.29 \mathrm{dpa}<\mathrm{c}>$ & -0.126 & 2.487 & 0.017 & 2.250 & 0.024 & 1.009 & 0.662 \\
\hline NBG-18 $1500^{\circ} \mathrm{C} 3.29 \mathrm{dpa}<\mathrm{a}>$ & 0.308 & 0.962 & 0.000 & 1.472 & 0.019 & 0.830 & 0.060 \\
\hline PCEA Pre-Irradiation $<\mathrm{c}>$ & 0.039 & 0.827 & 0.000 & 0.901 & 0.001 & 0.418 & 0.072 \\
\hline PCEA Pre-Irradiation $<a>$ & 0.210 & 0.177 & 0.000 & 0.526 & 0.009 & 0.306 & 0.002 \\
\hline PCEA $900^{\circ} \mathrm{C} 2.41 \mathrm{dpa}<\mathrm{c}>$ & -0.008 & 2.295 & 0.012 & 2.279 & 0.012 & 1.041 & 0.562 \\
\hline PCEA $900^{\circ} \mathrm{C} 2.41 \mathrm{dpa}<\mathrm{a}>$ & 0.331 & 0.216 & 0.000 & 0.765 & 0.022 & 0.448 & 0.003 \\
\hline PCEA $900^{\circ} \mathrm{C} 3.29 \mathrm{dpa}<\mathrm{c}>$ & -0.532 & 4.310 & 0.223 & 3.310 & 0.344 & 1.435 & 2.148 \\
\hline PCEA $900^{\circ} \mathrm{C} 3.29 \mathrm{dpa}<\mathrm{a}>$ & -0.128 & 1.864 & 0.000 & 1.652 & 0.003 & 0.884 & 0.228 \\
\hline PCEA $1500^{\circ} \mathrm{C} 1.47 \mathrm{dpa}<\mathrm{c}>$ & -0.028 & 1.689 & 0.006 & 1.637 & 0.006 & 0.745 & 0.305 \\
\hline
\end{tabular}




\begin{tabular}{|c|c|c|c|c|c|c|c|}
\hline \multirow[b]{2}{*}{ Specimen information } & \multicolumn{3}{|c|}{ Line fit } & \multicolumn{2}{|c|}{$Y=0$ fit } & \multicolumn{2}{|c|}{ Slope $=0$ fit } \\
\hline & $\begin{array}{c}Y \\
\text { Intercept }\end{array}$ & Slope & $\begin{array}{c}\text { Absolute } \\
\text { Sum of } \\
\text { Squares }\end{array}$ & Slope & $\begin{array}{c}\text { Absolute } \\
\text { Sum of } \\
\text { Squares }\end{array}$ & $\begin{array}{c}\text { Y } \\
\text { Intercept }\end{array}$ & $\begin{array}{c}\text { Absolute } \\
\text { Sum of } \\
\text { Squares }\end{array}$ \\
\hline PCEA $1500^{\circ} \mathrm{C} 1.47 \mathrm{dpa}<\mathrm{a}>$ & 0.461 & -0.032 & 0.000 & 0.732 & 0.042 & 0.443 & 0.000 \\
\hline PCEA $1500^{\circ} \mathrm{C} 3.28 \mathrm{dpa}<\mathrm{c}>$ & -0.171 & 2.513 & 0.024 & 2.192 & 0.036 & 0.976 & 0.681 \\
\hline PCEA $1500^{\circ} \mathrm{C} 3.28 \mathrm{dpa}<\mathrm{a}>$ & 0.101 & 1.443 & 0.000 & 1.610 & 0.002 & 0.883 & 0.136 \\
\hline
\end{tabular}




\section{A.3 SUMMARY OF NITROGEN ADSORPTION RESULTS}

\begin{tabular}{|c|c|c|c|c|c|c|c|}
\hline Grade & $\begin{array}{c}\text { Irradiation } \\
\text { Temperature }\end{array}$ & $\begin{array}{l}\text { Dose } \\
\text { (dpa) }\end{array}$ & $\begin{array}{c}S_{\text {BET }} \\
\left(\mathrm{m}^{2} / \mathrm{g}\right)\end{array}$ & $\begin{array}{c}S_{\text {DFT }} \\
\left(\mathrm{m}^{2} / \mathrm{g}\right)\end{array}$ & $\begin{array}{c}\text { SLangmuir } \\
\left(\mathrm{m}^{2} / \mathrm{g}\right)\end{array}$ & $V_{\text {tot }}\left(\mathrm{cm}^{3} / \mathrm{g}\right)$ & $\begin{array}{c}V_{\text {DFT }} \\
\left(\mathrm{cm}^{3} / \mathrm{g}\right)\end{array}$ \\
\hline \multirow{4}{*}{2114} & \multicolumn{2}{|c|}{ Unirradiated } & 2.12 & 1.26 & 0.11 & $3.61 \times 10^{-3}$ & $2.66 \times 10^{-3}$ \\
\hline & 1200 & 2.06 & 0.86 & 0.39 & n/a & $1.03 \times 10^{-3}$ & $5.21 \times 10^{-4}$ \\
\hline & \multirow{2}{*}{1500} & 1.77 & 2.59 & 1.70 & 0.05 & $4.28 \times 10^{-3}$ & $3.54 \times 10^{-3}$ \\
\hline & & 3.05 & 2.32 & 1.24 & 0.07 & $4.28 \times 10^{-3}$ & $3.54 \times 10^{-3}$ \\
\hline \multirow{6}{*}{ PCEA } & \multicolumn{2}{|c|}{ Unirradiated } & 2.62 & 1.47 & 0.20 & $5.06 \times 10^{-3}$ & $3.43 \times 10^{-3}$ \\
\hline & \multirow{2}{*}{900} & 6.61 & 1.04 & 0.58 & 0.07 & $2.05 \times 10^{-3}$ & $1.31 \times 10^{-3}$ \\
\hline & & 10.16 & 1.39 & 1.29 & 0.31 & $2.86 \times 10^{-3}$ & $4.13 \times 10^{-3}$ \\
\hline & 1200 & 1.98 & 0.85 & 0.38 & n/a & $1.26 \times 10^{-3}$ & $5.08 \times 10^{-4}$ \\
\hline & \multirow{2}{*}{1500} & 1.47 & 3.33 & 1.76 & 0.03 & $4.81 \times 10^{-3}$ & $3.73 \times 10^{-3}$ \\
\hline & & 3.02 & 1.37 & 0.89 & 0.03 & $2.62 \times 10^{-3}$ & $1.94 \times 10^{-3}$ \\
\hline \multirow{4}{*}{ NBG-18 } & \multicolumn{2}{|c|}{ Unirradiated } & 2.09 & 1.24 & 0.05 & $3.70 \times 10^{-3}$ & $2.63 \times 10^{-3}$ \\
\hline & 1200 & 1.85 & 2.09 & 0.96 & $n / a$ & $2.47 \times 10^{-3}$ & $1.73 \times 10^{-3}$ \\
\hline & \multirow{2}{*}{1500} & 1.63 & 1.37 & 1.28 & 0.02 & $3.71 \times 10^{-3}$ & $2.61 \times 10^{-3}$ \\
\hline & & 3.10 & 2.49 & 1.26 & 0.02 & $3.44 \times 10^{-3}$ & $2.65 \times 10^{-3}$ \\
\hline \multirow{4}{*}{ IG-110 } & \multicolumn{2}{|c|}{ Unirradiated } & 1.38 & 0.95 & 0.27 & $6.14 \times 10^{-3}$ & $2.62 \times 10^{-3}$ \\
\hline & 1200 & 1.78 & 0.94 & 0.71 & 0.06 & $4.91 \times 10^{-3}$ & $1.80 \times 10^{-3}$ \\
\hline & \multirow{2}{*}{1500} & 1.55 & 7.53 & 3.61 & 0.42 & $1.04 \times 10^{-2}$ & $7.22 \times 10^{-3}$ \\
\hline & & 3.13 & 0.66 & 0.58 & $\mathrm{n} / \mathrm{a}$ & $4.31 \times 10^{-3}$ & $1.64 \times 10^{-3}$ \\
\hline
\end{tabular}

n/a: unable to calculate Langmuir surface area with the data points collected. 